\title{
PROPRIEDADES TECNOLÓGICAS RELACIONADAS COM AS TENSÕES DE CRESCIMENTO EM CLONES DE Eucalyptus grandis W. Hill EX MAIDEN E Eucalyptus urophylla S.T. BLAKE, UTILIZADAS COMO INDICADORES PARA O MELHORAMENTO DA MADEIRA SERRADA
}

\author{
MARIA DE FATIMA CHRISTE ADORNO \\ Engenheiro Florestal
}

Orientador: Prof. Dr. JOSÉ NIVALDO GARCIA

Dissertacão apresentada à Escola Superior de Agricultura "Luiz de Queiroz", Universidade de São Paulo, para a obtenção do título de Mestre em Ciências, Área de concentraçäa: Ciências Florestais.

PIRACICABA

Estado de São Paulo - Brasil

Fevereiro - 2002 


\section{ERRATA}

Na página 62 e 112

62 e 112

63

63,100 e 101 100 e 101

102 e 103

102 e 103
Onde se lê $\mathrm{e}_{\mathrm{ij}}$ é o erro experimental associado a tora $\mathbf{j}$ e $\mathrm{e}_{\mathrm{il}}$ é o erro experimental associado a parcela $\mathbf{I}$ do clone i, aleatório; Erro a $\left(\mathrm{e}_{\mathrm{ij}}\right) \mathrm{I}(\mathrm{J}-1)$

As herdabilidades no sentido amplo, a nível As herdabilidades no sentido amplo, a nível de de médias e totais foram calculadas... $\mathrm{h}_{\mathrm{t}}^{2}$

Herdabilidade a nível de totais

Ganhos de seleção a nível de totais $\left[\mathrm{Gs}_{\mathrm{t}}(\%)\right]$ $\mathrm{Gs}(\%)$ do clone i, aleatório; Erro a $\left(\mathrm{e}_{\mathrm{il}}\right) \mathrm{I}(\mathrm{L}-1)$ médias e parcelas foram calculadas...

$\mathrm{h}_{1}^{2}$

Herdabilidade a nível de parcelas

Ganhos de seleção a nível de parcelas [ $\left.\mathrm{Gs}_{\mathbf{r}}(\%)\right]$ $\mathrm{Gs}_{\mathrm{L}}(\%)$ 


\section{Dados Internacionais de Catalogação na Publicação (CIP) DIVISÃO DE BIBLIOTECA E DOCUMENTAÇÃO - ESALQ/USP}

\section{Adorno, Maria de Fatima Christe}

Propriedades tecnológicas relacionadas com as tensōes de crescimento em clones de Eucalyptus grandis W. Hill ex Maiden e Eucalyptus urophylla S.T. Blake, utilizando como indicadores para o melhoramento da madeira serrada / Maria de Fatima Christe Adorno. - - Piracicaba, 2002.

p.

Dissertação (mestrado) - - Escola Superior de Agricultura Luiz de Queiroz, 2002. Bibliografia.

1. Eucalipto 2. Madeira serrada 3. Melhoramento genético vegetal 4. Tecnologia da madeira I. Título

CDD 634.9734

"Permitida a copia total ou parcial deste documento, desde que citada a fonte - O autor" 
À Deus e a minha mãe

OFEREÇO.

A minha irmã e ao meu marido, DEDICO. 


\section{AGRADECIMENTOS}

Ao Prof. Dr. José Nivaldo Garcia, pela orientação, amizade e incentivos constantes que permitiram a realização deste trabalho.

Aos Professores dos Departamentos de Ciências Florestais e de Genética da ESALQ/USP, pelos ensinamentos recebidos.

Ao Prof. Dr. Antônio Augusto Franco Garcia pela corientação e auxílio nas análises genético quantitativas.

À todos os funcionários da Serraria da ESALQ/USP, em especial ao Wilson Zane Filho.

Aos funcionários do Departamento de Ciências Florestais da ESALQ/USP, especialmente à Luis Eduardo Facco, pela atenção, amizade e dedicação fundamental nos ensaios laboratoriais.

Ao colega de pós-graduação, Laerte Scanavaca Junior, pelo apoio incansável durante o curso.

À CAF Santa Barbara Ltda., empresa integrante do conglomerado Belgo - Mineiro, pelo fornecimento do material de estudo e o inestimável apoio logístico que propiciou o pleno desenvolvimento do presente trabalho.

À FAPESP (Fundação de amparo à pesquisa do Estado de São Paulo), pela bolsa de mestrado concedida, vital para um pleno trabalho científico em tempo integral . 


\section{SUMÁRIO}

LISTA DE FIGURAS ................................................................ viii

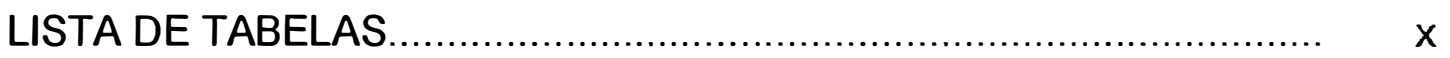

LISTA DE ABREVIATURAS E SÍMBOLOS ...................................... xiii

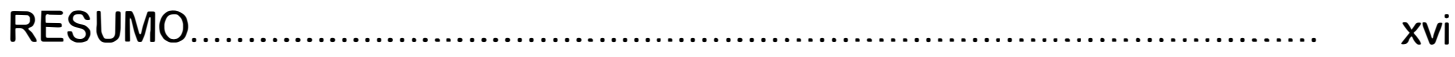

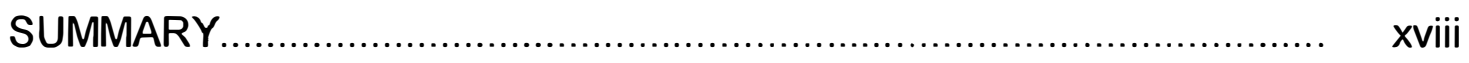

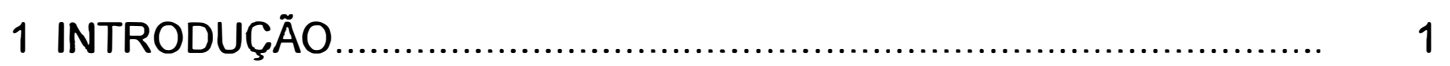

2 REVISÃO DE LITERATURA...................................................... 4

2.1 Consideração sobre o gênero Eucalyptus...................................... 4

2.1.1 O Eucalyptus grandis.............................................................. 6

2.1.2 O Eucalyptus urophylla.......................................................... 9

2.2 Algumas considerações sobre o uso atual e tendências futuras do emprego da madeira de Eucalyptus.

2.3 Aspectos do melhoramento florestal para o Eucalyptus.................. 16

2.4 Aspectos da silvicultura ligados ao melhoramento do $\begin{array}{ll}\text { Eucalyptus } & 21\end{array}$

2.5 Tensões de crescimento............................................................ 24

2.6 Conicidade....................................................................... 30

2.7 Processamento mecânico da madeira.............................................. 31

2.7.1 Rachadura de extremidade de tora (RT) ................................ 34

2.7.2 Rachadura de extremidade da prancha diametral (RPD)............ 37

2.7.3 Rendimento em madeira serrada (RMS).................................. 38

2.7.4 Flecha da costaneira (FC) e da peça serrada "vigota" (FV)......... 40 
2.8 Densidade básica (Db) da madeira de Eucalyptus......................... 40

2.9 Propriedades mecânicas da madeira de Eucalyptus...................... 48

2.9.1 Resistência ao cisalhamento radial $\left(f_{\mathrm{sr}}\right)$ e cisalhamento tangencial $\left(f_{s t}\right)$.

50

2.9.2 Resistência à compressão paralela às fibras $\left(f_{c}\right)$

2.9.3 Resistência à flexão estática $\left(f_{f}\right)$ e Módulo de elasticidade na flexão estática $\left(E_{f}\right)$

52

2.9.4 Resistência à tração paralela às fibras $\left(f_{t}\right)$.

3 ESTUDO DE CLONES DE Eucalyptus grandis E Eucalyptus urophylla, VISANDO O MELHORAMENTO GENÉTICO DAS CARACTERISTICAS TECNOLÓGICAS DA MADEIRA

55

Resumo.

Summary

56

3.1 Introdução.

57

3.2 Material e Métodos

59

3.2.1 Material genético selecionado.

3.2.2 Delineamento experimental..................................................... 61

3.2.3 Caracteres avaliados.......................................................... 65

3.2.4 Conicidade (Coni) ............................................................ 68

3.2.5 Rendimento em madeira serrada (RMS) e rachadura de extremidade de tora (RT).

69

3.2.6 Rachadura de extremidade da prancha diametral (RPD).

69

3.2.7 Flecha da costaneira (FC) e flecha da vigota (FV) obtida da costaneira

70

3.2.8 Densidade básica $(\mathrm{Db})$.

74

3.2.9 Resistência ao cisalhamento radial $\left(f_{\mathrm{sr}}\right)$ e tangencial $\left(\mathrm{f}_{\mathrm{st}}\right) \ldots \ldots \ldots \ldots . . . . .74$

3.2.10 Resistência à compressão paralela às fibras $\left(f_{c}\right) \ldots \ldots \ldots \ldots \ldots \ldots \ldots . . . . . . . . . . .76$

3.2.11 Resistência à flexão estática $\left(f_{f}\right)$ e módulo de elasticidade na flexão estática $\left(\mathrm{E}_{\mathrm{f}}\right)$.

3.2.12 Resistência à tração paralela às fibras $\left(f_{t}\right)$. 
3.3 Resultados e Discussão...................................................... 81

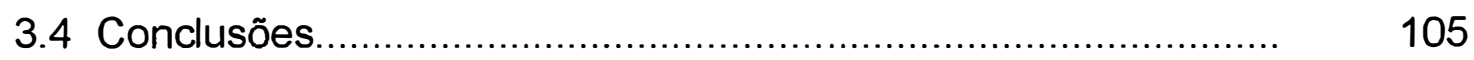

4 CORRELAÇÕES ENTRE AS PRINCIPAIS CARACTERÍSTICAS TECNOLÓGICAS DA MADEIRA DE CLONES DE Eucalyptus grandis E Eucalyptus urophylla.

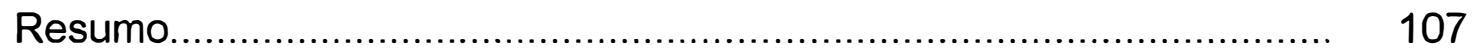

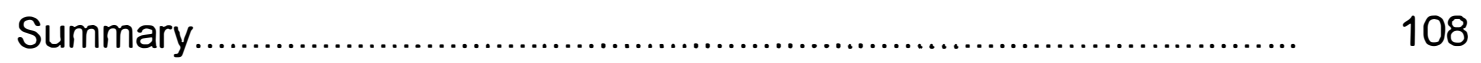

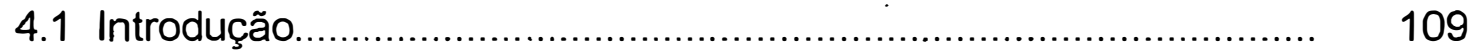

4.2 Material e Métodos.................................................................... 111

4.3 Resultados e Discussão............................................................. 116

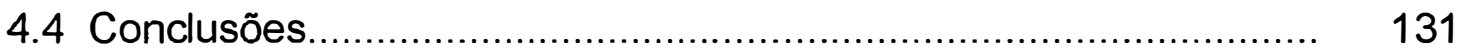

5 CONCLUSÕES GERAIS ......................................................... 133

REFERÊNCIAS BIBLIOGRÁFICAS.............................................. 135 


\section{LISTA DE FIGURAS}

1 Visão das orientações das microfibrilas nas várias camadas da parede celular (Wilkins, 1986)...................... 26

2 Esquema das forças de compressão do lado mais interno do caule de folhosas (Wilkins, 1986)................................. 27

3 Distribuição das tensões de crescimento contendo madeira de reação (Okuyama, 1997) ................................. 29

4 Início do desdobro da tora em serra de fita simples, para a retirada da primeira costaneira......................................... 67

5 Tora remanescente, no carro porta tora, após a retirada da primeira costaneira..................................................... 68

6 Medição da flecha da costaneira em relação a uma referência indeformável................................................ 71

7 Medição da flecha da vigota obtida da costaneira................ 73

8 Corpos de prova utilizados na determinação da resistência ao cisalhamento radial (a) e tangencial (b)........ 75

9 Esquema do ensaio de flexão estática para obtenção da resistência à flexão $\left(\mathrm{f}_{\mathrm{f}}\right)$ e do módulo de elasticidade na flexão $\left(E_{\mathrm{f}}\right)$

10 Corpo de prova adotado no ensaio de tração paralela às fibras, especificado pela norma Britânica "BSI" 
11 Rachaduras de extremidades das pranchas diametrais (RPD) com algumas toras ainda a serem desdobradas (ao fundo da Figura), do clone 37592 de E. grandis ............... 86

12 Pranchas diametrais não rachadas do clone 28228 de $E$.

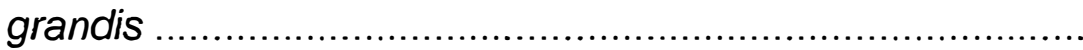




\section{LISTA DE TABELAS}

Página

1 Impacto da tecnologia na característica da madeira (Marques, 1998).

2 Variação da densidade média $\left(\mathrm{g} / \mathrm{cm}^{3}\right)$ de plantações aos 5 anos de idade nas regiões de Itupeva (SP) e Mogi-Guaçu (SP). Fonte: Ferreira e Kageyama (1978)

3 Variação da densidade da madeira $\left(\mathrm{g} / \mathrm{cm}^{3}\right)$ em função da espécie e idade na localidade de Itupeva (SP). Fonte: Ferreira e Kageyama (1978)

4 Características climáticas da região de coleta do material de $E$. grandis e $E$. urophylla.

5 Clones selecionados para o presente estudo e seus códigos de identificação

6 Componentes de variância para o delineamento inteiramente casualizado com parcelas subdivididas, com i clones, $\mathbf{k}$ árvores/clone e $\mathbf{j}$ toras/árvore.

7 Valores médios e amplitude de variação (valores máximos e mínimos) de todas as variáveis estudadas

8 Melhores médias e as médias estimadas, juntamente com o resultado do teste de Duncan (5\%)

9 Classificação dos clones do Eucalyptus grandis, de acordo com o número e a importância das características tecnológicas que Ihe são favoráveis 
10 Classificação dos clones do Eucalyptus urophylla, de acordo com o número e a importância das características tecnológicas que lhe são favoráveis

11 Comparação das flechas das costaneiras (FC1 e FC2) e das vigotas obtidas das costaneiras (FV1 e FV2)

12 Valores numéricos Graus de Liberdade (G.L) utilizados no modelo matemático de todas as variáveis do Eucalyptus grandis

13 Valores numéricos Graus de Liberdade (G.L) utilizados no modelo matemático de todas as variáveis do Eucalyptus urophylla.

14 Valores dos QM (Quadrados Médios) obtidos segundo o modelo matemático adotado para as características do Eucalyptus grandis

15 Valores dos QM (Quadrados Médios) obtidos segundo o modelo matemático adotado para as características do Eucalyptus urophylla.

16 Componentes de variância para as propriedades do $E$. grandis, com os coeficientes de variação.

17 Componentes de variância para as propriedades do $E$. urophylla, com os coeficientes de variação

18 Valores dos coeficientes "b" $\left(\mathrm{CV}_{\mathrm{g}} / \mathrm{CV}_{\mathrm{f}}\right)$ e das herdabilidades a nível de médias, com seus respectivos intervalos de confiança (IC) e a herdabilidade a nível de totais para o Eucalyptus grandis.

19 Valores dos coeficientes " $\mathrm{b}$ " $\left(\mathrm{CV}_{\mathrm{g}} / \mathrm{CV}_{\mathrm{f}}\right)$ e as herdabilidades a nível de médias, com seus respectivos intervalos de confiança (IC) e a herdabilidade a nivel de totais para o Eucalyptus urophylla 
20 Valores dos diferenciais de seleção "ds" e dos ganhos de seleção a nível de totais $\left(G s_{t} \%\right)$ e a nível de médias $\left(G s_{m} \%\right)$, com seus respectivos limites inferiores e superiores do intervalo de confiança (IC) para o 102 Eucalyptus grandis

21 Valores dos diferenciais de seleção "ds" e dos ganhos de seleção a nível de totais $\left(G s_{t} \%\right)$ e a nivel de médias $\left(G s_{m} \%\right)$, com seus limites inferiores e superiores do intervalo de confiança (IC) para o Eucalyptus urophylla ....

22 Componentes de variância dos Produtos Médios para as variáveis $\mathrm{X}$ e $\mathrm{Y}$, segundo o modelo matemático, com $\mathbf{i}$ clones, $\mathbf{k}$ árvores/clone e $\mathbf{j}$ toras/árvore.

23 Coeficientes de correlação de Pearson, obtidos nas correlações entre as variáveis estudadas do $E$. grandis

24 Coeficientes de correlação de Pearson, obtidas nas correlações entre as variáveis estudadas do $E$. urophylla.

25 Coeficientes de correlações genéticas (triângulo superior) e fenotípicas (triângulo inferior) entre as características avaliadas da madeira do $E$. grandis

26 Coeficientes de correlações genéticas (triângulo superior) e fenotípicas (triângulo inferior) entre as características avaliadas da madeira do $E$. urophylla. 


\section{LISTA DE ABREVIATURAS E SÍMBOLOS}

\begin{tabular}{|c|c|}
\hline ds & Diferencial de seleção \\
\hline$\Delta \mathrm{G}$ & Ganho genético \\
\hline$h^{2}$ & Herdabilidade no sentido amplo \\
\hline Coni & Conicidade \\
\hline RMS & Rendimento em madeira serrada \\
\hline RT & Rachadura da extremidade das toras \\
\hline RPD & Rachadura de extremidade da prancha diametral \\
\hline $\mathrm{FCm}$ & Flecha da costaneira, média da costaneira 1 e 2 \\
\hline FC1 & Flecha da costaneira 1 , primeira a ser retirada da tora \\
\hline FC2 & Flecha da costaneira 2, segunda a ser retirada da tora \\
\hline $\mathrm{FVm}$ & Flecha da vigota, média da vigota 1 e 2 \\
\hline FV1 & Flecha da vigota 1 , retirada a partir da costaneira1 \\
\hline FV2 & Flecha da vigota 2, retirada a partir da costaneira 2 \\
\hline $\mathrm{Db}$ & Densidade básica \\
\hline$f_{s r}$ & Cisalhamento radial \\
\hline$f_{s t}$ & Cisalhamento tangencial \\
\hline$f_{c}$ & Resistência à compressão paralela às fibras \\
\hline$f_{f}$ & Resistência à flexão estática \\
\hline$E_{f}$ & Módulo de elasticidade na flexão estática \\
\hline$f_{t}$ & Resistência a tração paralela ás fibras \\
\hline$C_{i}$ & Clone \\
\hline
\end{tabular}


$\mathrm{T}_{1} \quad$ Posição na árvore (tora 1 ou 2)

$\mathrm{CT}_{\mathrm{ij}} \quad$ Interação entre clone e posição

$\mathrm{e}_{\mathrm{ij}}^{2}$ ou $\mathrm{e}_{\mathrm{a}}^{2} \quad$ Estimativa da variância do erro devido a interação entre clones, ou chamado erro "a"

$e^{2}{ }_{i j k}$ ou $e^{2} \quad$ Estimativa da variância do erro devido a interação dos indivíduos $\mathbf{k}$, na tora $\mathbf{j}$, do clone $\mathbf{i}$ do experimento, ou simplesmente erro experimental "e"

$\sigma_{c}^{2} \quad$ Estimativa da variância entre clones

$\Phi^{2}{ }_{T} \quad$ Componente quadrático, variância das posições (tora) numa mesma árvore

$\sigma^{2}$ cr Estimativa da variância da interação entre clone e a posição dentro de clones

$\mathrm{E}(\mathrm{QM}) \quad$ Esperança do quadrado médio

$E(P M) \quad$ Esperança do produto médio

$\operatorname{Var}(X+Y) \quad$ Estimativa da variância das variáveis $X$ e $Y$

$\operatorname{Var}(X) \quad$ Estimativa da variância da variável $X$

$\operatorname{Var}(\mathrm{Y}) \quad$ Estimativa da variância da variável $\mathrm{Y}$

$\Phi(X+Y) \quad$ Componente quadrático de duas variáveis $X$ e $Y$

G.L Graus de liberdade

G.Lc Graus de liberdade devido ao clone

G. $L_{a} \quad$ Graus de liberdade do erro "a"

G.LT Graus de liberdade devido a posição

G.LCxT Graus de liberdade da interação clone $x$ tora

G.Le Graus de liberdade do erro 'e"

Q.Mc Quadrado médio devido ao clone

Q.M $\mathrm{M}_{\mathrm{a}} \quad$ Quadrado médio do erro "a"

Q.MT Quadrado médio devido a posição

Q.M CxT $_{\text {Q }} \quad$ Quadrado médio devido a interação clone x posição

Q.M $M_{e} \quad$ Quadrado médio do erro "e" . 
"b" Coeficiente do $\mathrm{CV}_{\mathrm{g}} / \mathrm{CV}_{\mathrm{f}}$

$\mathrm{CV}_{\text {exp }} \quad$ Coeficiente de variação experimental

$\mathrm{CV}_{\mathrm{g}} \quad$ Coeficiente de variação genotípica

$\mathrm{CV}_{\mathrm{f}} \quad$ Coeficiente de variação fenotípica

$\mathrm{h}_{\mathrm{t}}^{2} \quad$ Herdabilidade no sentido amplo a nivel de totais

$\mathrm{h}_{\mathrm{m}}{ }_{\mathrm{m}} \quad$ Herdabilidade no sentido amplo a nivel de médias

Gs(\%)t Ganho de seleção utilizando a herdabilidade à nível de totais

Gs(\%)m Ganho de seleção utilizando a herdabilidade à nivel de médias

IC Intervalo de confiança

$\operatorname{COV}_{G(x, y)} \quad$ Covariância genética das variáveis $X$ e $Y$

$\operatorname{COV}_{f(x, y)} \quad$ Covariância fenotípica das variáveis $X$ e $Y$

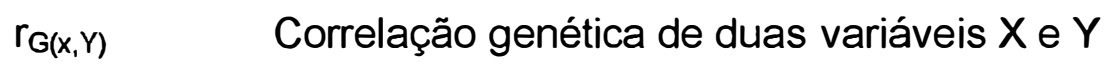

$r_{f(x, y)} \quad$ Correlação fenotípica entre duas variáveis $X$ e $Y$

daN $=$ Kgf Unidade em Newton, sendo 1/10 do "Newton" $(N)$, igual a Kgf (1daN=1Kgf e $1 \mathrm{~N}=10 \mathrm{Kgf}$ ) 


\title{
PROPRIEDADES TECNOLÓGICAS RELACIONADAS COM AS TENSÕES DE CRESCIMENTO EM CLONES DE Eucalyptus grandis W. HILL EX MAIDEN E Eucalyptus urophylla S.T. BLAKE, UTILIZADAS COMO INDICADORES PARA O MELHORAMENTO DA MADEIRA SERRADA
}

\author{
Autora: MARIA DE FÁTIMA CHRISTE ADORNO \\ Orientador: Prof. Dr. JOSÉ NIVALDO GARCIA
}

\section{RESUMO}

Os vários segmentos do comércio relacionados com a matéria prima madeira, baseiam-se em florestas de rápido crescimento. 0 gênero Eucalyptus é um dos mais promissores para a substituição da madeira nativa para diversos propósitos. Realizou-se o presente estudo objetivando a avaliação de característica tecnológicas com perspectivas de melhoramento genético. Foram utilizados 18 clones de Eucalyptus grandis e 15 clones de $E$. urophylla procedente de três bancos clonais situados em Bom Despacho-MG. Foram estudados os defeitos da madeira serrada relacionados as tensões de crescimento. As características estudadas foram a conicidade, rendimento em madeira serrada, rachaduras de topo de tora e da tábua diametral, flecha da costanieira e peça serrada (vigota), cisalhamento radial e tangencial, densidade 
básica, resistência à compressão paralela às fibras, resistência à flexão, módulo de elasticidade na flexão e resistência à tração paralela às fibras. As estimativas de variâncias foram obtidas pelo método dos momentos, da análise de variância. Todas as variáveis estudadas possibilitam bons ganhos genéticos com seleção, exceto conicidade e rendimento de madeira serrada. As herdabilidades apresentaram valores de alta magnitude, indicando que a escolha destas variáveis foram favoráveis ao melhoramento. As espécies apresentaram resultados distintos, comprovando que não se pode extrapolar os dados tecnológicos e nem os parâmetros genéticos. 


\title{
TECHNOLOGICAL PROPERTIES RELATED TO GROWTH STRESSES IN CLONES OF Eucalyptus grandis W. HILL EX MAIDEN AND Eucalyptus urophylla S. T. BLAKE, USED AS INDICATORS FOR THE IMPROVEMENT OF SAWED TIMBER
}

\author{
Author: MARIA DE FATIMA CHRISTE ADORNO \\ Adviser: Prof. Dr. JOSÉ NIVALDO GARCIA
}

\section{SUMMARY}

The several commercial segments dealing on wood as raw material rely on fast-growing forests. Eucalyptus is one of the most promising genera for replacing native wood for different purposes. The objective of this work was to evaluate technological characteristics aiming at genetic improvement. Eighteen clones of Eucalyptus grandis and 15 clones of $E$. urophylla from three clonal banks located in Bom Despacho-MG were used. The sawed wood defects related to growth stress were studied. The evaluated characteristics were taper, sawed timber yield, log-end splitting, diametrical board-end splitting, deflection of the first and second slabs, deflection of the beams obtained from these slabs, radial and tangential shear strength, basic density, compression strength parallel to grain, bending strength, elasticity modulus in the bending test and tensile strength parallel to fibers. The variance estimates were obtained by the Moments Method of the Variance Analysis. All the studied variables allow good genetic gains through selection, except for 
taper and sawed timber yield. Heritabilities presented high-magnitude figures, evidencing that choosing such variables favored improvement gains. The species showed distinct results, proving that technological data as well as genetic parameters cannot be extrapolated. 


\section{INTRODUÇÃO}

Indivíduos geneticamente superiores ou mais favoráveis terão uma maior capacidade produtiva e podem resultar em produtos de melhor qualidade, atendendo as exigências do mercado consumidor.

O melhoramento genético visa a obtenção de bons genótipos e também de novos genótipos, ambos, podendo estar juntos com genótipos inferiores. É necessário portanto, um árduo trabalho de seleção para isolarem-se os genótipos favoráveis .

O processo ainda corrente de identificação dos genótipos favoráveis é o que baseia-se no fenótipo. Isso significa que o fenótipo deve ser avaliado e quantificado com precisão e fidelidade para permitir reconheceremse as reais expressões dos genótipos.

Um dos caminhos para multiplicar-se um dado genótipo selecionado fenotipicamente é o uso da seleção e multiplicação clonal de indivíduos. Com a multiplicação vegetativa pode-se reproduzir qualquer genótipo (homozigoto ou heterozigoto), mas não é raro o aparecimento dos efeitos que resultam em indesejáveis variações intra clonais.

A variabilidade genética é também um ponto fundamental a ser considerado no desenvolvimento de programas de melhoramento genético. Existindo variabilidade e, principalmente, se a participação de componentes genéticos na manifestação das características for expressiva, pode-se prever as possibilidades de ocorrerem alterações desejadas nas características sob seleção. 
A existência de variabilidade fenotípica entre espécies, procedência, famílias e indivíduos para diversas características tecnológicas da madeira de interesse (Malan, 1998b) e o forte controle genético envolvidos na expressão da grande maioria dessas mesmas características, asseguram a possibilidade de obtenção de madeira de alta qualidade para suprir as necessidades industriais, a partir da implementação de programas de melhoramento genético.

Como as florestas nativas estão se tornando cada vez mais escassas e cada vez mais protegidas, o uso do gênero Eucalyptus vem se destacando consideravelmente. Certas espécies possuem altas taxas de crescimento, proporcionando enormes ganhos volumétricos em cada rotação. Entretanto, têm-se obtido altas perdas na linha de produção industrial madereira, como conseqüência dos defeitos oriundos da tensão de crescimento. Com isto, o melhoramento genético desse gênero, no que se refere às suas propriedades tecnológicas, é de extrema importância. Obtendose ganhos genéticos expressivos nas principais propriedades físico-mecânicas de interesse industrial, diminuir-se-ão as perdas de matéria prima nas indústrias e obter-se-á uma significante melhoria na qualidade final do produto.

A combinação da busca de uniformidade da matéria-prima, com a melhoria da qualidade do produto final e busca de novas fontes de abastecimento, uma vez que a madeira nativa passou a ser escassa em determinadas regiões, gerou uma reação econômica, com a busca de maiores valores agregados para a madeira produzida nas florestas plantadas (Ponce, 1995). Isso resultou na introdução da madeira de eucalipto na indústria moveleira, produzida especialmente para o uso industrial e de localização próximas aos centros de processamento e consumo. Algumas empresas optaram pelo desenvolvimento de clones provenientes de matrizes selecionadas e melhoradas para usos específicos, como aqueles destinados à produção de madeira para serraria. 
A floresta de eucalipto pode ser considerada de múltiplo uso e a sua madeira se presta aos mais diferentes usos, tanto na forma sólida, como para matéria prima na indústria de polpa e painéis reconstituídos.

As propriedades mecânicas são requisitos básicos para a utilização da madeira para fins estruturais e o gênero Eucalyptus atende às mais diferentes exigências quanto a estas propriedades.

Pela importância da perspectiva de obtenção de clones melhorados visando a melhoria da qualidade da madeira para serraria, o presente trabalho teve como primeiro objetivo realizar um estudo quantitativo das propriedades físico-mecânicas da madeira relacionadas com as tensões de crescimento, visando fornecer subsídios para programas de melhoramento genético. Assim, através de clones de Eucalyptus grandis e de Eucalyptus urophylla foi possivel obter as estimativas das herdabilidades e consequentemente, as estimativas dos ganhos genéticos.

Teve ainda como segundo objetivo um estudo das correlações genéticas e fenotípicas e das correlações lineares de Pearson existentes entre as características tecnológicas da madeira, fornecendo um maior embasamento para os programas de melhoramento genético.

Ao final, objetivou-se comparar as caracteristicas tecnológicas da madeira entre as duas espécies do gênero Eucalyptus, baseando-se nos diversos resultados obtidos das análises estatísticas quantitativas. 


\section{REVISÃO DE LITERATURA}

\subsection{Considerações sobre o gênero Eucalyptus}

O gênero Eucalyptus pertence à família Myrtaceae, que contém aproximadamente 70 gêneros e 3000 espécies. A maioria das espécies de Eucalyptus introduzidas no Brasil é proveniente da Austrália. As primeiras introduções ocorreram em 1868, no Rio Grande do Sul e Rio de Janeiro, mas o cultivo em larga escala foi iniciado no ano de 1903 no estado de São Paulo com a finalidade de produzir lenha.

O gênero Eucalyptus apresenta elevada plasticidade, isto é, grande capacidade de adaptação às condições ambientais e destaca-se pelo seu rápido crescimento. Face ao grande avanço das práticas silviculturais, manejo e do melhoramento genético, é possivel a obtenção de taxas de crescimento próximas de $100 \mathrm{~m}^{3} / \mathrm{ha} / \mathrm{ano}$, em plantios comerciais (Oliveira, 1999). Para as espécies mais densas (E. citriodora, E. paniculata, E. terenticornis e E. cloeziana ) a produtividade esta ao redor de $30 \mathrm{~m}^{3} / \mathrm{ha} / \mathrm{ano}$.

Segundo Ferreira (1990) os Eucalyptus são classificados pelo tipo de florestas que formam, sendo :

- Floresta fechada (árvores com 30 a $60 \mathrm{~m}$ de altura, que formam florestas sem a presença de sub-bosques) ( $E$. toreliana)

- Floresta aberta alta (árvores com 30 a $60 \mathrm{~m}$ de altura que formam florestas em que a penetração de luz permite a formação de sub bosque) : 
a) grupo casca fibrosa (E. urophylla)

b) grupo casca lisa ("gum") (E. grandis e E. urophylla)

c) grupo "ironbark" (E. paniculata)

d) grupo Monocalyptis (E. phaeotricha)

- Floresta aberta baixa (árvores que não ultrapassam $30 \mathrm{~m}$ de altura e que permitem a formação de sub-bosque e até a presença de gramíneas no solo) (E. camaldulensis)

As espécies de floresta aberta alta de casca lisa permitem a formação de sub-bosque, são tolerantes ao fogo, apresentam sistema radicular intermediário-superficial. É neste grupo que estão as principais espécies utilizadas para a fabricação de celulose e papel. As de casca fibrosa apresentam sistema radicular tipo intermediário-superficial e são espécies com alta capacidade de brotação. Sua madeira não muito adequada a fabricação de celulose e papel, por apresentar maior porcentagem de lignina, mas são mais indicados para usos múltiplos da madeira, sendo algumas conhecidas como mogno australiano. Os eucaliptos de floresta aberta alta, casca lisa, apresentam alta densidade e são mais indicados para fins energéticos (carvão) e serraria (Ferreira, 1992).

O Brasil, segundo Ferreira (1992), possui o maior acervo genético de Eucalyptus tropicais e subtropicais "ex. situ", um fato básico para a silvicultura clonal.

A madeira, além de ser muito usada para embalagens, em geral, também oferece potencial de uso para a confecção de móveis rústicos, onde muitas vezes é utilizada na forma semi desdobrada, associada a processos de envelhecimento e "design" específico, tendo garantia de mercado e preços atraentes (Oliveira, 1999).

Embora o gênero Eucalyptus represente um potencial alternativo no abastecimento de madeira serrada para o mercado, sua madeira apresenta restrições próprias e inerentes ao uso de florestas jovens, onde os niveis de tensões de crescimento se manifestam de forma mais proeminente do 
que em florestas maduras. A variabilidade entre e dentro de espécies aliada ao forte controle genético envolvido na expressão das características, asseguram a possibilidade de obtenção de madeira de alta qualidade para suprir as necessidades industriais, a partir da implementação de programas dessa natureza (Assis, 1999).

\subsubsection{O Eucalyptus grandis}

A primeira introdução de $E$. grandis foi efetuada antes de 1914 por Navarro de Andrade, com sementes supostamente originária de Newcastle, NSW $\left(33^{\circ}\right)$. A Segunda foi feita pelo IPEF (Instituto de Pesquisa e Estudos Florestais) em 1968 com sementes procedente de Coff's Harbour $\left(30^{\circ}\right)$. Em 1970, a Cia. Vale do Rio Doce importou da Austrália 5 novas procedências de $E$. grandis e 5 de $E$. saligna. Entre elas estava representado o $E$. grandis de Atherton (Golfari et al. 1978).

$\mathrm{Na}$ Austrália, conforme a região, o $E$. grandis tem os seguintes nomes populares: "Rose gum", "Flooded gum", "Gum", "Blue gum" e "Toohn" (Goes, 1960 e Brooker \& Kleinig, 1983).

Sua área de ocorrência natural é em forma descontínua e fragmentada por uma longa faixa costeira. As procedências mais temperadas vai desde Newcastle NSW $32^{\circ} 35^{\prime}$ S, para Golfari et al (1978) ou a $32^{\circ} 52^{\prime}$ S para Eldridge et al. (1994), até as procedências mais tropicais de Atherton, Queensland $17^{\circ} \mathrm{S}$ segundo Golfari et al. 1978 ou a $16^{\circ} \mathrm{S}$, em Windsor Tableland para Eldridge et al. (1994). Existem diferenças climáticas apreciáveis entre ambas, já que no setor meridional os povoamentos estão situados quase ao nivel do mar e no setentrional estão entre $600 \mathrm{~m}$ e $1250 \mathrm{~m}$ de altitude (Golfari et al. 1978) e para Eldridge et al. (1994) em Queensland entre 500 a $1100 \mathrm{~m}$. O clima de toda a área varia de temperado quente a subtropical moderado com 
invernos suaves e chuvas abundantes e bem distribuídas, menos no setor norte, onde são periódicas. Devido às condições de seu habitat, a espécie apresenta uma plasticidade limitada. Quando plantada em regiões tropicais úmidas torna-se sensível ao Cryphonectria cubensis ou ao Corticium salmonicolor (Golfari, 1977; Golfari et al. 1978; Eldridge et al. 1994), como foi observado em Cuba, Suriname, Costa Rica, Índia e Brasil, enquanto que em regiões tropicais com seca acentuada, seu crescimento torna-se mais lento quando comparado com outras espécies tais como $E$. tereticornis e $E$. camaldulensis (Golfari et al. 1978).

No Brasil, ao norte do paralelo 20 , em regiōes de baixa altitude, com vegetação de floresta, especialmente no norte do Espírito Santo e vale médio do Rio Doce, MG, onde a temperatura média anual é superior a $23^{\circ} \mathrm{C}$ e a umidade relativa é elevada, entre $78 \%$ e $85 \%$ anual, o E. grandis se torna susceptível ao Cryphonectria cubensis (Golfari et al. 1978).

Segundo Goes (1960), o clima da área de ocorrência é subtropical com uma pluviosidade anual de 1000 a $1800 \mathrm{~mm}$, chuvas estivais e uma elevada umidade relativa. $O$ verão quente, sendo a média das máximas temperaturas, do mês mais quente, de $30^{\circ}$ e a média das mínimas temperaturas, do mês mais frio, de $6^{\circ}$. Há evidência de que a espécie pode tolerar temperaturas baixas até $-5^{\circ} \mathrm{C}$, mas árvores fertilizadas podem ser mais sensiveis e toleraram somente $-3^{\circ} \mathrm{C}$ (Hillis, 1984).

Para Brooker \& Kleinig (1983), o E. grandis ocorre em clima subtropical com precipitação média anual de 700 a $2500 \mathrm{~mm}$, regime de verão úmido e uniforme e inverno seco, com temperatura média anual entre $14 \mathrm{e}$ $25^{\circ} \mathrm{C}$, temperatura média máxima nos meses mais quentes entre 25 e $34^{\circ} \mathrm{C} \mathrm{e}$ temperatura média mínima nos meses frios variando de 3 a $18^{\circ} \mathrm{C}$. $\mathrm{A}$ temperatura mínima absoluta pode chegar a $-8^{\circ} \mathrm{C}$.

É uma árvore de fuste muito reto, aparece geralmente ao longo dos rios e nos terrenos de aluvião, nos Estados da Nova Gales do Sul e. 
Queensland, constituindo povoamentos puros, as vezes parece consorciada com outras espécies principalmente com Tristania conferta (Goes, 1960).

Aparecem em solos profundos, bem drenados e de aluvião ou origem vulcânica. A espécie é intolerante a condições pantanosas mas resiste a periodos curtos de inundação (Hillis, 1984).

A madeira é de cor rosada e bastante dura, com densidade variando de 0,43 a $0,5 \mathrm{~g} / \mathrm{cm}^{3}$ (Ferreira, 1990), apresentando uma grã reta que facilita o trabalho e o acabamento das peças desdobrada (Goes, 1960).

Para Simula et al. (1998), a cor do E. grandis varia de cinza a amarela claro, até todas as nuâncias de rosa à avermelhado escuro. Quando em exposição, os tons mudam, variando de marrom avermelhado à marrom.

Em condições úmidas, algumas tábuas cortadas do híbrido E. grandis x E. urophylla, mostraram-se com tons de cor rosa escuro, comparado com o E. grandis, com pronunciada cor marrom escura no cerne (Malan, 2000).

É uma espécie que possui qualidades excelentes, superando qualquer outra em incremento, quando as condições ambientais são adequadas, sendo esta a causa de sua grande aceitação. Dentre as suas várias características, apresenta a capacidade de desramar-se espontaneamente, o que dá origem a fustes lisos com aspecto colunar. Sua madeira é boa para serraria e excelente para celulose. A brotação é ruim. (Golfari et al. 1978).

No Brasil, o E. grandis tem encontrado condições ideais para seu desenvolvimento desde o Rio Grande do Sul até o Sul de Minas Gerais. A única restrição existe no planalto Sul, onde há incidências de geadas. Mais ao norte, dentro da área do cerrado, esta espécie pode ser utilizada somente em lugares com altitude superior a $1000 \mathrm{~m}$. Tomando como base os limites de temperatura, tanto na Austrália como no Brasil, a região ótima para $E$. grandis está compreendida entre as isotermas anuais de $17^{\circ}$ e $21^{\circ} \mathrm{C}$ (Golfari et al. 1978). 
O Eucalyptus grandis é uma das espécies mais promissoras pelos seguintes motivos (SENAI/CETEMO, 1998):

- maior área plantada dentre as espécies comerciais;

- trata-se da espécie mais difundida no Brasil em plantios comerciais;

- maior disponibilidade imediata de florestas em idade de corte;

- madeira leve e de boa resistência mecânica;

\subsubsection{O Eucalyptus urophylla}

Esta espécie foi primeiramente introduzida no Brasil em 1919 erroneamente com o nome de $E$. alba. Na Austrália foi classificado como E. decaisneana, sendo somente em 1977 adotado a classificação de Blake como E. urophylla (Golfari, 1977; Hillis, 1984). No Brasil, as parcelas mais antigas desta espécie, com mais de 87 anos, estão em Rio Claro-SP, provenientes de sementes coletadas em uma ou duas árvores ainda presentes do Jardim Botânico de Bogor, Java, procedentes da ilha de Flores (Golfari et al. 1978).

No período entre 1936 e 1968 foi muito utilizada nos reflorestamentos brasileiros como semente do "alba híbrido de Rio Claro", derivada dos cruzamentos espontâneos ocorridos nas antigas parcelas de $E$. urophylla com outras espécies (Golfari et al. 1978).

OE. urophylla é reconhecido como uma espécie potencial a ser cultivada nas regiões tropicais. Entretanto a sua potencialidade vinha sendo comprometida com o uso de material proveniente de populações com base genética estreita ou com hibridação não controlada, gerando florestas heterogêneas e de baixa produtividade. Houve então a necessidade de reintroduzir a espécie para ampliar a base genética (Zani Filho et al. 1990). 
O E. urophylla é nativo de algumas ithas do arquipélago Sonda na Indonésia (parte oriental do arquipélago da Sonda), Timor, Flores, Adonara, Lomblem, Pantar, Alor e Wetar, situadas ao norte da Austrália (Golfari, 1977; Golfari et al. 1978). Para Martin \& Cossater (1976), a zona de ocorrência varia de $7^{\circ} 30^{\prime}$ a $10^{\circ} \mathrm{S}$ de latitude Sul e 122 a $127^{\circ} \mathrm{E}$ de longitude Leste. As altitudes variam do nivel do mar até $2960 \mathrm{~m}$, correspondendo a uma faixa de aproximadamente $500 \mathrm{Km}$, sendo que as populações mais produtivas estão entre 500 e 2200m (Martin \& Cossater, 1976). Em Timor, onde tem sua maior distribuição altitudinal, ocorre em colinas e montanhas entre 550 e 2940m e com clima que varia desde tropical sub-úmido a montano úmido e os melhores povoamentos ocorrem entre as altitudes de 800 a $1400 \mathrm{~m}$ (Golfari, 1977; Golfari et al. 1978).

Na sua área de ocorrência, segundo Martin e Cossater (1976), a temperatura varia de $24,2^{\circ} \mathrm{C}$ a $420 \mathrm{~m}$ de altitude até $20^{\circ} \mathrm{C}$ a $1449 \mathrm{~m}$ de altitude (com a variação de 1030' na latitude). A temperatura varia de 20 a $30^{\circ} \mathrm{C}$ e nos meses mais frios é de $15^{\circ} \mathrm{C}$. Nas regiões de ocorrência, a precipitação influenciada pelos ventos das monções e pela cadeia montanhosa de Timor, varia de 600 a $2500 \mathrm{~mm}$, sendo a média de $1300 \mathrm{~mm}$. Em Timor tem-se de 2 a 4 meses com menos de $50 \mathrm{~mm}$ de precipitação e no Sul de Wetar, região mais a leste da zona de ocorrência, a precipitação é de 700 a $800 \mathrm{~mm}$ com 7 a 8 meses com precipitação inferior a $60 \mathrm{~mm}$.

Não é encontrado naturalmente na Austrália. Ocorre em Timor e em outras ilhas da Indonésia na faixa altitudinal entre 300 até $3000 \mathrm{~m}$. Os índices pluviométricos são de 1000 a $2000 \mathrm{~mm}$. Foi introduzido na Austrália em 1966, mas a tentativa ao norte de Nova Gales do Sul e Queensland, não foram excelentes (Hillis, 1984).

O clima varia de subtropical seco a tropical úmido, tornando-se mais seco de oeste para leste, ao longo da área de ocorrência natural, na Indonésia (Vieira \& Bucsan, 1979). 
A altura das árvores na área de ocorrência natural não excede $50 \mathrm{~m}$ em locais favoráveis (Hillis, 1984). No Brasil é uma árvore de grande porte, sem tortuosidade, com forte dominância apical, casca do tipo rugosa e folhas afiladas. Na ilha de Timor, o E. urophylla ocorre em altitudes que variam de 800 a $2700 \mathrm{~m}$. Em Flores, aparece entre 450 a $1450 \mathrm{~m}$ de altitude. Nas outras ilhas, cresce em povoamentos puros a partir de 550 a $600 \mathrm{~m}$. (Brasil, 1983).

O E. urophylla apresenta também grandes variações morfológicas e fenológicas de acordo com sua distribuição altitudinal. Nas baixas altitudes, entre 800 e 1200m, é uma árvore de grande porte e tronco reto, atingindo até $50 \mathrm{~m}$ de altura e nas altitudes mais elevadas, acima de $1600 \mathrm{~m}$, apresenta a forma de arbusto "Malee" (Golfari et al. 1978).

Como espécie associada encontra-se o $E$. alba, que ocorre geralmente nas faixas costeiras de baixa a média altitude com clima tropical semi-árido (Golfari, 1977).

A madeira do $E$. urophylla é de cor parda, densidade mediana variando de 0,5 a $0,58 \mathrm{~g} / \mathrm{cm}^{3}$ (Ferreira,1990) e considerada muito boa para celulose como também para serraria (Hillis, 1984). Apresenta resistência ao cancro Cryphonectria cubensis (Hillis, 1984).

Darrow \& Roeder (1983), avaliaram progênies de $E$. urophylla e $E$. alba em relação ao $E$. grandis e $E$. saligna. $O$ volume produzido de $E$. urophylla foi menor do que o das outras progênies de $E$. grandis e $E$. saligna com a mesma idade, mas por causa da alta densidade da madeira a produção de massa de madeira por essa espécie foi melhor que o do $E$. saligna e igual a do E. grandis.

O E. urophylla apresenta bom potencial para a produção de madeira e polpa, com indicações de bom comportamento em serrarias (Darrow \& Roeder, 1983). 


\subsection{Algumas considerações sobre o uso atual e tendências futuras do emprego da madeira de Eucalyptus}

As empresas selecionam poucos clones para serem plantados em grandes áreas, visando maior produtividade possivel (Pires \& Paula, 1997). A silvicultura clonal segundo Ferreira \& Santos (1997) está mais para uma agricultura sofisticada, onde os riscos devem ser ponderados e as soluções encontradas dentro da própria silvicultura clonal cercada de toda as ciências, da prudência, da ética e dos recursos que ela necessita, e o melhoramento genético tradicional deverá ser parte integrante dessa nova silvicultura.

Devido à grande demanda de madeira e pressões econômicas para resultados imediatos em melhoramento florestal para curtas rotações, pode-se esperar cada vez mais o emprego de madeira juvenil como matéria-prima (Pires \& Paula, 1997). Com isto, a utilização crescente de toras de menor diâmetro e de madeira mais jovens é uma realidade. O mercado vem utilizando peças coladas e/ou reconstituídas em substituição à madeira maciça, tornando-se imperativo esse uso, tanto pela tecnologia desenvolvida quanto pela escassez de madeira sólida já identificada.

O mercado global de produtos sólidos de madeira, é classificado em três processos básicos: serraria, laminação e painéis/perfis. A gama de produtos possíveis é grande, com uma variação entre produtos de pouco valor agregado, até chegar a produtos de alto valor agregado. É possível segundo Marques (1998), com a tecnologia disponível e capacidade instalada, observar o impacto da tecnologia (Tabela 1) nas características da madeira e, consequentemente, a do produto. 
Tabela 1. Impacto da tecnologia na característica da madeira .

\begin{tabular}{lccc}
\hline Característica da matéria-prima & $\begin{array}{c}\text { Melhoramento } \\
\text { Florestal }\end{array}$ & $\begin{array}{c}\text { Manejo } \\
\text { Florestal }\end{array}$ & $\begin{array}{c}\text { Processo } \\
\text { industrial }\end{array}$ \\
\hline Diâmetro de toras & $\mathrm{XX}$ & $\mathrm{XX}$ & - \\
Circularidade de toras & $\mathrm{X}$ & $\mathrm{XX}$ & - \\
Conicidade de toras & $\mathrm{X}$ & $\mathrm{XX}$ & - \\
Ausência de nós & $\mathrm{X}$ & $\mathrm{XX}$ & - \\
Retidão de toras & $\mathrm{XX}$ & $\mathrm{XX}$ & - \\
Tensões internas de crescimento & $\mathrm{XX}$ & - & $\mathrm{XX}$ \\
Trabalhabilidade & - & - & $\mathrm{XX}$ \\
Resistência mecânica & $\mathrm{XX}$ & - & $\mathrm{X}$ \\
Massa específica aparente & $\mathrm{XX}$ & $\mathrm{X}$ & $\mathrm{X}$ \\
Estabilidade dimensional & $\mathrm{XX}$ & - & $\mathrm{XX}$ \\
Aparência (cor) & $\mathrm{XX}$ & - & $\mathrm{X}$ \\
Facilidade em serrar e laminar & - & - & $\mathrm{XX}$ \\
Facilidade em secar & $\mathrm{X}$ & - & $\mathrm{XX}$ \\
Facilidade em colar & $\mathrm{X}$ & - & $\mathrm{XX}$ \\
Acabamentos (tintas e vernizes) & - & - & $\mathrm{XX}$ \\
\hline XX: Grande influência & & & \\
X: Média influência & & & \\
(-): Pouca influência ou efeito desconhecido & & & \\
(Fonte: Marques, 1998). & & &
\end{tabular}

Há uma tendência crescente de converter a madeira roliça em produtos manufaturados, ocorrendo agregação de valores à madeira. onde supera o valor da própria madeira. $O$ crescimento do mercado de madeira serrada vem sendo lento em decorrência do desempenho de outros produtos mais próximos como, o compensado, chapas de fibra e aglomerados, bastante atraentes em alguns mercados (Villela Filho, 1996). Com os desenvolvimentos mais recentes de manufatura da madeira, surgiram os painéis reconstituídos 
como, o MDF (chapa de fibra de média densidade), OSB (chapa de "lacas" orientadas) e o LVL (vigas de madeira laminada) (Tomaselli, 1998).

Uma característica muito valorizada para a madeira utilizada na indústria moveleira é a uniformidade, porque permite a confecção de móveis com grande homogeneidade na cor, o que valoriza o produto final (Ponce, 1995; Malan, 2000).

Deve-se acreditar na industrialização do eucalipto como uma boa solução e uma alternativa à substituição de madeiras tradicionais. Com tecnologia produto de qualidade, os mercados serão certamente conquistados (Obino, 1996).

Nogueira \& Lahr (1993) analisaram e avaliaram os resultados dos ensaios para características físicas de resistência e de elasticidade de 16 espécies de eucalipto, classificando-os em 5 categorias: 1) construção civil pesada externa; 2) construção civil pesada interna; 3) construção civil leve externa; 4) construção civil leve interna; e 5) assoalhos. O E. urophylla foi recomendado para as categorias 4 e 5 , e o $E$. grandis somente para a 4.

A categoria 4 de "construção civil leve interna" compreende a aplicação decorativa (lambris, painéis, molduras, perfilados e guarnições) e a estrutural (vigas, caibros e ripas). A categoria 5 de "assoalhos" compreende o uso doméstico (tacos, tábuas e parquetes) e o industrial (tacos, tábuas e blocos).

O mercado interno a cada dia sente mais a influência do mercado internacional e globalizado. Existe uma demanda crescente por madeiras oriundas de florestas plantadas, sendo sentida com maior intensidade nos Estados de Santa Catarina e Rio Grande do Sul, com madeiras de melhor qualidade utilizadas na produção de móveis. A madeira de eucalipto deixou de ser usada apenas como estrutura interna de sofá, sendo bem aceita no mercado consumidor de móveis, porém falta disponibilidade de material relativamente homogêneo em grande quantidade (Santos, 1996). 
No setor da construção civil, a madeira do gênero Eucalyptus tornou-se expressiva nas cidades do interior, onde vem sendo empregada em construções populares, sob a forma de vigas, pontaletes, caibros, sarrafos, etc. (Santos, 1996).

O projeto de edifícios multiuso construídos com madeira de Eucalyptus grandis demonstra que a madeira adequada, além de facilitar a construção em função da leveza, apresenta baixo custo e pode constituir-se em uma solução para o setor da construção civil. Como material de engenharia, o eucalipto tem sido estudado de forma sistemática e avaliado por meio da norma técnica NBR 7190 - Ponte e estruturas de madeira - da ABNT (Associação Brasileira de Normas Técnicas) (Otto, 1986 e Nahuz et al., 1998).

A busca do uso múltiplo das florestas e de melhor remuneração para a madeira tem incentivado as empresas a ofertar madeira serrada de eucalipto. O consumo de madeira pela indústria moveleira é representado na sua maior parte por madeira de Pinus, sendo que o eucalipto não alcança grande expressão (SENAI/CETEMO, 1998).

Foram várias as razões para a busca do gênero Eucalyptus como alternativa as madeiras nativas, como: a alta produtividade das florestas plantadas, reduzida idade de corte ( 7 anos para celulose e papel e 15 a 20 anos para serraria), baixo custo da madeira (em torno de U $\$ 140,00 / \mathrm{m}^{3}$ da madeira verde) (SENAI/CETEMO, 1998), e a segurança do abastecimento, com fornecimento de florestas manejadas mais homogênea e próximas ao mercado consumidor (Obino, 1996).

A indústria brasileira de móveis é formada por 13.500 empresas sendo: micro (10.000), pequenas (3.000), e médias (500) empresas, de capital totalmente nacional, que localizam-se em sua maioria na região centro-sul, constituindo em alguns estados pólos moveleiros, como por exemplo, Bento Gonçalves no Rio Grande do Sul; São Bento do Sul em Santa Catarina; Arapongas no Paraná; Mirassol, Votuporanga e São Paulo em São Paulo; Ubá em Minas Gerais; e Linhares no Espírito Santo (Lima, 1998). 


\subsection{Aspectos do melhoramento florestal para o Eucalyptus}

O fator primordial capaz de alterar os padrões de formação, desenvolvimento e qualidade da madeira produzida pelas espécies florestais é a natureza genética. Porém, esta natureza quando associada a outros fatores, como a interação com o ambiente e/ou técnicas silviculturais, podem modificar os padrões a tal grau que as características físicas e anatômicas da madeira são significativamente alteradas (Shimoyama \& Barrichelo, 1989).

$\mathrm{Na}$ área florestal, as pesquisas e desenvolvimentos concentram-se em três áreas primordiais: o melhoramento genético, o manejo e por fim, as técnicas de desdobro, secagem e utilização da madeira. O melhoramento genético utiliza diversas técnicas da área de biotecnologia (técnicas de clonagem, organogênese, embriogênese, cultura de anteras) e da genética molecular, visando obter ganhos na seleção de indivíduos superiores como também no melhoramento da produtividade, com as mudanças de gerações (Couto, 1995).

O programa de melhoramento tradicional deve primeiro adaptar o material ao local de uso e posteriormente aumentar a produtividade das espécies florestais e não somente atuar na variabilidade natural ainda existente, visando produzir uma árvore superior em características tecnológicas. A propagação vegetativa, seja ela macro ou micropropagação, não é um método de melhoramento, mas é uma ferramenta utilizada para obter cópias de indivíduos superiores, isto é, adaptados à determinados locais (Ferreira, 1992).

A redução da variabilidade genética é diretamente proporcional ao grau de melhoramento de uma determinada espécie. A uniformidade genética, decorrente desse melhoramento, pode tornar o gernoplasma vulnerável do germoplasma a mudanças ambientais e ao aparecimento de novas pragas. Assim, esforços devem ser somados visando a manutenção do patrimônio genético das espécies, como forma de garantir a 
utilização futura das mesmas para usos diferentes dos atuais (Resende \& Vencovsky, 1990).

O estudo de estabilidade e adaptabilidade é de grande importância, por fornecer informações detalhadas do desempenho de cada genótipo frente às condições ambientais. Esbrisse et al. (1997) estudaram o comportamento de progênies de meio-irmãos de $E$. urophylla provenientes da ilha de Wetar, Alor e Pantar, em 5 ambientes e obtiveram uma significativa interação das progênies com os ambientes. A mesma linha de estudo foi realizado por López \& Fornés (1997), que encontraram para o E. grandis (progênie de polinização aberta) comportamentos diferenciados dos materiais nos diferentes sítios, sendo a interação entre genótipos e ambientes altamente significativa.

A variação genética de árvores de $E$. urophylla selecionadas em populações naturais da Indonésia, foram estudadas por Mori et al. (1988) em quatro locais, individualmente e em conjunto, visando subsídios para programas de melhoramento com a espécie. Os resultados mostraram que os coeficientes de herdabilidade a nivel de média de progênies para cada local e em conjunto para as três características estudadas foram maiores que os coeficientes a nivel de plantas, indicando que a seleção pode ser mais efetiva a nivel de média de progênies do que dentro de progênies e para cada local separadamente, do que uma seleção geral para todos os locais.

Nicholson et al. (1975) estudaram a forma do tronco de 10 progênies de $E$. regnans, onde concluíram que a variação dentro da árvore é uma resposta ao ambiente e a outros fatores genéticos.

Quando se utilizam clones, cujo histórico inclui a seleção convencional das populações reconhecidamente adaptadas às áreas ecológicas de plantio seguida de melhoramento, testes clonais, seleções e recombinações posteriores, a continuidade da silvicultura intensiva será assegurada e os ganhos nas gerações avançadas também o serão (Ferreira, 1992). 
Oliveira et al. (1997), estudaram as contrações da madeira de clones de $E$. grandis e $E$. saligna, aos 90 meses de idade e encontraram uma grande variabilidade dentro dos clones, indicando a possibilidade de manipulação genética das espécies para seleção com alta estabilidade dimensional, o que é interessante para o uso da madeira em serrarias e movelarias. $O E$. grandis apresentou maior estabilidade dimensional do que o $E$. saligna.

Malan \& Verryn (1996) estudaram o efeito do ambiente nas rachaduras provocada pelas tensões de crescimento, densidade, comprimento da fibra, retração e porcentagem de cerne, em E. grandis e hibridos deste com outras espécies. As análises mostraram uma interação entre genótipos e os ambientes em alguns clones. Alguns clones mostraram-se estáveis enquanto outros apresentaram interação genótipo $x$ ambiente.

A seleção individual intensa para um caráter de alta herdabilidade deve também ser vista com cautela, pois esta prática poderá provocar a eliminação ou perda precoce de alelos responsáveis por outros caracteres (Oda et al. 1989). Pode-se ter melhores resultados no melhoramento assexuado se:

- For utilizada espécie híbrida (adaptada ou não);

- Forem selecionadas matrizes em condições de estresse onde, eventualmente, uma heterose pode se manifestar;

- For utilizada alta intensidade de seleção.

No melhoramento florestal, é de grande importância conhecerem-se as correlações genéticas e fenotípicas entre a característica a ser melhorada e as demais características da árvore, como por exemplo densidade básica e características de crescimento (Shimoyama \& Barrichelo, 1989).

Com o objetivo de verificar a variabilidade genética, calcular as estimativas de herdabilidade e das correlações entre características do $E$. grandis, Fonseca et al. (1989), obtiveram para os três caracteres (altura, DAP e 
volume das árvores), valores razoáveis para as estimativas de herdabilidade, indicando um forte controle genético para estas características, possibilitando o melhoramento genético mediante seleção das melhores famílias. As estimativas dos coeficientes de correlações genotípicas e fenotipicas entre estas características foram altas, positivas e significativas e verificou-se maior influência dos componentes genéticos que ambientais.

O estudo de correlação entre caracteres é interessante por duas razões: em primeiro lugar é importante conhecer como o melhoramento de uma característica pode causar mudanças simultâneas em outras e em segundo lugar é a relação entre uma característica métrica e o poder adaptativo, importante na seleção natural. Por vezes, a seleção indireta é preferivel à seleção direta, quando a característica desejada é de difícil ou imprecisa medição e a característica correlacionada apresenta medição mais fácil ou maior herdabilidade que a característica de interesse (Falconer, 1981).

O principal problema na seleção indireta é a independência genética entre a maioria das características das árvores florestais (Zobel \& Talbert, 1984).

O conceito de herdabilidade é um dos mais importantes e mais usado na genética quantitativa. A herdabilidade expressa o valor da proporção da variação na população que é atribuida às diferenças genéticas entre indivíduos. A herdabilidade é a chave das estimativas dos ganhos que podem ser obtidos a partir de programas de seleção (Zobel \& Talbert, 1984).

A herdabilidade indica o grau de controle genético que é exercido sobre uma determinada característica. De maneira geral, as características da madeira apresentam de média a alta herdabilidade (Shimoyama \& Barrichelo, 1989). 


\subsection{Aspectos da silvicultura ligados ao melhoramento genético do Eucalyptus}

Para os Eucalyptus, a silvicultura clonal intensiva adquiriu uma alta importância, pois propicia: redução na idade de exploração; maior produção de madeira de melhor qualidade, no menor lapso de tempo por unidade de área; racionalização das atividades operacionais e redução nos custos de exploração e transporte (Ferreira, 1992).

A genética aplicada ao melhoramento das florestas tem conduzido cada vez mais o seu desempenho a melhores níveis. $A$ associação de manejo adequado e técnicas de melhoramento, com a visão de mercados $e$ suas tendências, é uma eficiente ferramenta para viabilizar as serrarias e garantir maior proporção de produtos sólidos com alto grau de valor agregado (Villela Filho, 1996).

O espaçamento é de grande importância para o desenvolvimento das árvores sob os aspectos tecnológico, silvicultural e econômico. Pode influenciar várias características quantitativas e qualitativas interferindo significativamente na morfologia das árvores e no seu crescimento, em particular, no diâmetro, independentemente das suas características genéticas (Shimoyama \& Barrichelo, 1989).

O potencial das florestas de eucalipto na produção de madeira para usos múltiplos foi explanado por Marsh \& Burgers (1967), Lückhoff (1967), Malan \& Hoon (1992) e Luz et al. (1993), através do método de desbastes sucessivos "CCT" (Correlated Curve Trend), onde o principal interesse foi a produção de madeira de alta qualidade, indicada para aplicações nas indústrias de móveis e construção civil, apresentando portanto maior valor de mercado. A aplicação desse método, segundo Luz et al. (1993) revelou que: 
- Os desbastes gradativos permitem a manutenção do ritmo de crescimento, resultando em madeira com menores tensões residuais, menos rachaduras e maior homogeneidade, refletindo em menores variações de densidade da madeira no sentido medula - casca.

- As árvores crescendo com mínima competição, atingem mais cedo níveis maiores de densidade, que são mantidos ao longo da vida.

Os desbastes aceleram o ritmo de crescimento e este, por sua vez, promove inevitavelmente a formação de anéis mais largos que apresentam-se menos densos, pois o lenho tardio, constituído por traqueídeos de paredes mais espessas, é menos afetado pela taxa de crescimento do que o lenho inicial (Malan, 1988c). Com a aceleração do ritmo de crescimento das árvores, há uma ligeira diminuição da densidade da madeira, que é recompensada pela maior produção de massa por unidade de área (Shimoyama \& Barrichelo, 1989).

Segundo Malan (1998a) existe uma pobre relação entre niveis de tensão de crescimento e taxa de crescimento, sendo correto assumir que os niveis de tensão podem ser manipulados geneticamente através da seleção e clonagem sem sacrificar a taxa de crescimento.

Malan \& Hoon (1992) estudaram o E. grandis, através do desbaste CCT, para observar o efeito da intensidade de desbaste sobre a densidade da madeira e algumas propriedades anatômicas, padrões de variação e a intensidade no desenvolvimento das rachaduras de toras e nas tábuas. As rachaduras foram significativas e afetadas pelo intensidade de desbaste e a madeira apresentou maior heterogeneidade nas propriedades físicas e anatômicas.

Lima (2000) concluiu que diferentes intensidades de desbastes, efetuadas segundo o método CCT não influenciaram as rachaduras de peça serrada úmida, mas influenciaram os índices de rachaduras de extremidade das toras e o encurvamento da peça serrada úmida (flecha), sendo estes altamente herdáveis. 
Em reflorestamento, onde o espaçamento entre árvores é uniforme, há uma tendência de redução dos níveis de tensão de crescimento nas árvores em relação às que crescem naturalmente (Hillis, 1978). Desta forma, ritmos de crescimento acelerados e constantes reduzem as variações internas das propriedades da madeira, devendo-se para isso realizar os desbastes e outras práticas silviculturais, para superar os problemas mais importantes no uso da madeira serrada de eucalipto (Luz et al. 1993).

Miranda \& Nahuz (1997) estudaram a influência do espaçamento de plantio de $E$. saligna no rendimento em madeira serrada verde, onde as médias dos tratamentos não diferiram entre si. Os espaçamentos não influenciaram na produtividade das florestas e sim no volume das toras e no volume de tábuas produzidas. A análise estatística acusou uma diferenciação no rendimento em madeira serrada, segundo a posição da tora (base e superior), sendo suportado por outros autores, onde alegam que o diâmetro é um fator que influencia no rendimento em madeira serrada (Stelle, 1984; Wade et al. 1992).

A prática do desbaste e desrama atuam, em parte, por mecanismos semelhantes sobre o crescimento das árvores e formação dos lenhos. Ambas as técnicas afetam a copa das árvores. A desrama, pela remoção direta da parte da copa viva, dependendo da intensidade, limita o crescimento. O desbaste diminui a competição entre copas estimulando o crescimento das mesmas. Dependendo da intensidade de desbaste há uma homogeneização do povoamento (desbaste executado por extratos), o que homogeneiza e valoriza a madeira (Shimoyama \& Barrichelo, 1989).

Um problema presente nas toras de eucalipto para desdobro, que influi na qualidade e no valor da madeira serrada, é a presença de nós. Considerando que o custo da mão de obra é relativamente baixo, e que o eucalipto pode produzir toras em ciclos curtos, os investimentos realizados nas podas das árvores destinadas à serraria são altamente compensadores (Freitas \& Brito Neto, 1993). Portanto, em madeira para serraria, a tendência é 
a valorização crescente de madeira "clear" (livre de defeitos) (Obino \& Menezes, 1995),

Bredenkamp et al. (1980) realizaram um experimento de $E$. grandis com 6 regimes de poda e uma testemunha. Observaram um efeito ínfimo das podas na taxa de crescimento. A recuperação depois da remoção de até $50 \%$ da parte viva da copa foi rápida. Os ganhos em madeira livre de nó não foram significativos, e a degradação devida as injúrias pela poda na parte viva da copa foi não significativa. As podas não influenciaram no ritmo de crescimento das árvores. As análises de covariância mostraram que a variação do DAP das árvores entre os tratamentos de poda foram pequenas o suficiente para não ter nenhum efeito significativo no rendimento em serrados.

A recuperação do crescimento do $E$. grandis depois da poda é extremamente rápido no DAP e no crescimento em altura. $O$ incremento em altura apresentou correlação significativa com o comprimento da copa viva, enquanto que para a altura total da árvore a correlação foi não significativa. As podas não influenciaram na conicidade da árvore dentro ou ao redor da zona podada (Bredenkamp et al. 1980).

O sistema adotado hoje de manejo para o eucalipto no Brasil, prioriza a produção de massa. A prática de manejo mais direcionada para a serraria é a de rotação de 21 anos, com desbaste e limpeza aos 7 anos, produzindo toras com diâmetros mais largos (Simula \& Tissari, 1998).

Simões \& Ferreira (1997) estudaram o comportamento, crescimento e produção de madeira grossa e fina de 14 espécies de eucalipto, entre elas o $E$. grandis e o E. urophylla, com qualidades apropriadas para serraria, laminação, postes, dormentes, moirões, lenha, etc. Os autores concluíram que para a produção de toras, devido ao grande crescimento em diâmetro e altura, destacou-se o E. grandis de Atherton (procedência mais tropical da espécie), portanto com maior probabilidade para cultivo em condições tropicais no Brasil. A produção extraída no $3^{\circ}$ desbaste foi de aproximadamente $60 \mathrm{~m}^{3}$ de toras/ha. Para a produção de postes, devido à 
rentidão dos seus fustes, destacou-se o $E$. urophylla de Timor, com a média no $3^{\circ}$ desbaste de 112 postes/ha.

Em relação ao manejo das toras em pátios de serraria, Silva et al. (1997), mostram que a secagem ao ar livre atende as expectativas de tempo de secagem e qualidade final da madeira. Como esta secagem permite alcançar valores de umidade da madeira até a de equilíbrio com as condições climáticas locais, recomendando que a secagem seja executada na região onde for utilizada definitivamente, ou que seja feita pelo menos, uma aclimatização desta madeira antes de ser utilizada.

Lelles \& Silva (1997) citam diversos métodos silviculturais e técnicas de manejo de toras para aliviar as tensões de crescimento e minimizar os efeitos provocados durante a liberação das forças, como o anelamento do alburno e a imediata execução do abate da árvore; anelamento, morte e secagem da árvore em pé; armazenamento da madeira totalmente imersa em água ou sob aspersão contínua ou intermitente, tratamento térmico através de vaporização e cozimento em água; diversas técnicas de desdobro como "cortes simultâneos; e uso de conectores metálicos tipo "gang nail" e ganchos na forma de "S" e "C".

\subsection{Tensões de crescimento}

As tensões de crescimento são geradas dentro do tecido da madeira, na formação de novas camadas de células a partir do câmbio, durante o desenvolvimento da árvore. São iniciadas durante o desenvolvimento da parede secundária das fibras e podem ser necessárias para o crescimento e desenvolvimento normal da árvore (Boyd, 1950c, 1973; Van Wyk, 1978).

As tensões de crescimento são desenvolvidas no xilema $e$ são distribuídas ortotropicamente no caule em direções longitudinais, radiais e 
transversais (tangenciais à circunferência do caule). Dependendo de sua localização dentro do caule, as tensões podem ser de tração ou de compressão (Chafe, 1977). As tensões transversais aparecem na periferia da árvore (câmbio) com o crescimento de novas camadas de células. As tensões radiais surgem como reação as tensões de crescimento transversais (Boyd, 1950 a,b).

As tensões de crescimento longitudinais surgem como madeira de reação em função da inclinação da árvore, e/ou esforços contra o vento ou neve e/ou para manter centralizada a copa (Jacob, 1938; Kubler, 1959; Nicholson, 1973a).

Segundo Boyd (1950c), as tensões de crescimento longitudinais acontecem devido ao encurtamento das células em direção a periferia da árvore e pelo alongamento das fibras em direção a medula.

As árvores com altos valores de tensão de crescimento apresentam dificuldades na sua utilização como madeira sólida, existindo meios tecnológicos para minimizar estes efeitos (Chafe, 1977). As árvores com elevadas tensões de crescimento desenvolvem fissuras radiais durante e após o abate. O problema é agravado se a tora for mantida diretamente sob a ação do sol, devido à interação da tensão de crescimento com as tensões de secagem (Oliveira, 1999). O alívio da tensão causa o relaxamento e consequentemente a deformação, envolvendo uma acomodação de células ou componentes da parede celular. Contudo, deve-se tentar aliviar as tensões de crescimento da árvore no campo, reduzindo a formação de trincas e rachaduras no momento da derrubada da árvore (Chafe, 1977).

As células que determinam as propriedades físicas da madeira são as fibras, e em geral compreendem 70 a $90 \%$ do volume da madeira. As fibras da estrutura da parede celular com sua forma alongada são responsáveis pela anisotropia natural da madeira. A madeira é, por exemplo, muitas vezes mais resistentes à tração paralela às fibras do que em ângulos retos (Wilkins, 1986). 
Na direção axial a tensão de tração da madeira é diversas vezes maior que a sua tensão de compressão. Isto é atribuído à alta tensão de tração da microfibrila combinada com o formato tubular das fibras e o padrão da lignina e distribuição celulósica na parede da fibra celular (Figura 1). Devido a sua grossa espessura e o ângulo das microfibrilas, a camada da parede mediana secundária (S2) é muito importante na determinação das propriedades de tensão das fibras da madeira (Wilkins, 1986).

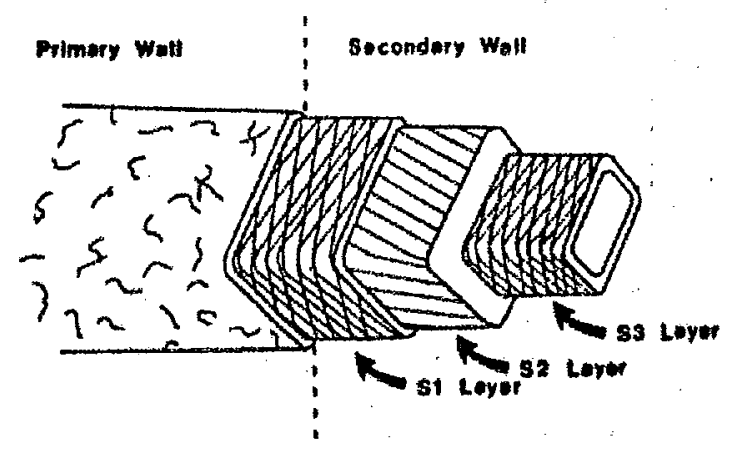

Figura 1 - Vista das orientações das microfibrilas nas várias camadas da parede celular da fibra.

Fonte: Wilkins (1986).

As árvores em pé normalmente estão sujeitas a atuação de forças que provocam arqueamento, devido a forças externas como o vento, e para uma melhor estabilidade no desenvolvimento assimétrico da copa. 0 padrão da tensão longitudinal encontrado em um arqueamento colunar (Figura 2), mostra como as forças de compressão na parte mais interna do caule das folhosas são minimizadas pelo pré-tensionamento do lado mais externo do tronco da árvore. Uma vez que o lado mais externo de um cilindro sólido é a região de maior tensão em arqueamento, este pré-tensionamento, devido a tensão de crescimento, fornecem à árvore uma maior efetividade no método de 
prevenção a falhas de compressão na sua periferia, durante o flexionamento (Wilkins, 1986).

Kubler (1959) fez analogia das matrizes lignina e celulose com um prédio, onde a celulose funcionaria como o aço que suporta as forças de tração e a lignina como o concreto que suporta as forças de compressão. Van Wyk (1978), fez uma analogia entre as tensões de crescimento com os cabos de aço ou tirantes de uma antena de televisão, onde estes correspondem ao alburno e estão sob tração, enquanto que o suporte da antena, corresponde a medula, que está sob compressão.

Uma outra hipótese, afirma que a origem da tensão de crescimento longitudinal seja devido ao encurtamento das células periféricas resultante da contração do cristal celulósico nas microfibrilas da camada S2 da parede secundária. $\mathrm{O}$ ângulo da microfibrila celulosica determina se a célula alongar-se-á ou encurtar-se-á, a um maior ângulo microfibrilar da camada S2 do que em certos valores resultantes da contração da célula. Similarmente, o englobamento da lignina à tensão celulósica em sua presente forma confirmase na relação do ângulo microfibrilar da camada S2, comprimento da célula e desenvolvimento da tensão (Kubler, 1959; Watanabe, 1965; Wilkins, 1986).
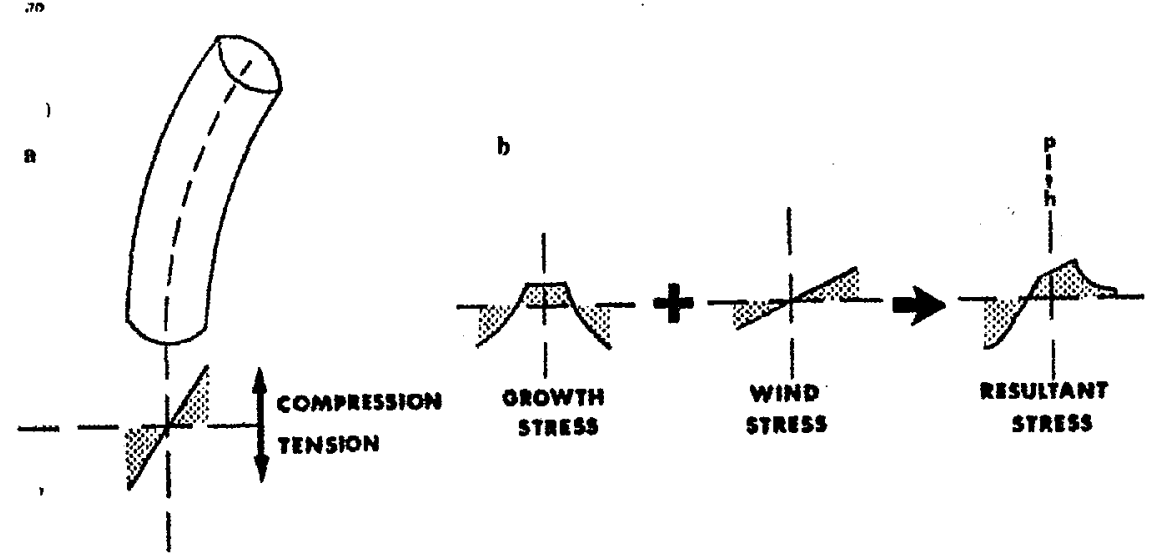

Figura 2 - Esquema das forças de compressão do lado mais interno do caule de folhosas.

Fonte : Wilkins (1986). 
Nicholson (1973a) e Dinwoodie (1966) estudaram árvores inclinadas e retas e concluíram que a influência genética é maior que a ambiental nas tensões de crescimento.

Nicholson (1979) mediu as tensões de crescimento na circunferência de árvores de $E$. regnans e $E$. obliqua. $O$ autor concluiu que as tensões surgem como reação das árvores na tentativa de manter a copa centralizada . O autor também afirmou que esta característica sofre influência genética.

Boyd (1977) cita que a teoria da tensão é compatível com a estimulação da diferenciação do tecido de reação em todas as localizações observadas no câmbio das árvores.

Segundo Boyd (1980) a única teoria válida para qualquer árvore, tanto de Angiospermas como de Gimnospermas que explica a tensão de crescimento é a teoria proposta por Boyd (1950a,b). Nicholson (1973a) acrescenta que a madeira de reação surge na tentativa da árvore manter a sua copa centralizada.

Na Figura 3, pode-se observar o mecanismo de distribuição da tensão de crescimento em uma tora contendo madeira de reação (Okuyama, 1997).

A madeira de reação é aquela formada na parte superior dos troncos inclinados, sendo então denominada de madeira de tração, e isto acontece quando o tronco é deslocado de sua posição de equilíbrio no plano vertical, seja pelo vento, ou mesmo por práticas de desbastes (Oliveira, 1999). 


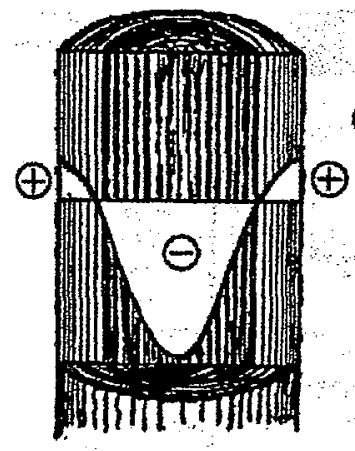

(a)

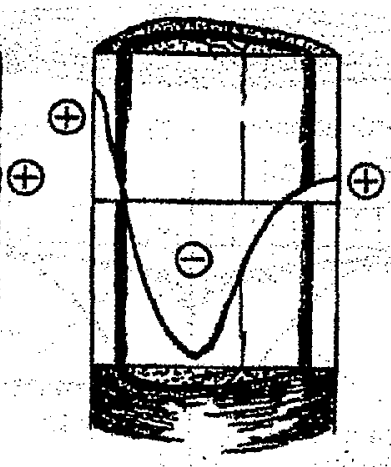

(b)

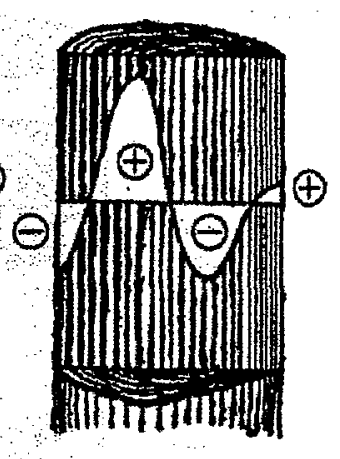

(c)

(a) não possui madeira de reação, tronco normal;

(b) madeira que sofreu influências externas, possui madeira de reação;

(c) madeira de coniferas, possuem madeira de compressão;

Figura 3 - Distribuição das tensões de crescimento contendo madeira de reação

Fonte: Okuyama (1997).

As tensões de crescimento e as tensões residuais são úteis para o crescimento da árvore, porém as tensões residuais no tronco tornam-se um obstáculo enquanto a madeira está sendo processada. Assim que as tensões residuais tridimensionais no tronco das árvores são liberadas pelo corte da árvore, durante a derrubada são desbalanceadas, uma vez que foi feito o rompimento das fibras no tronco da árvore. Segundo Okuyama (1997), a tensão tridimensional é formada em camadas mais externas do tronco, e no caso de uma árvore normal, existe uma força de tensão, compressão, e uma muito baixa tensão de crescimento diametral, que são geradas na direção longitudinal, tangencial e radial, respectivamente.

As microfibrilas, segundo Okuyama (1997), desenvolvem a tensão na direção axial, ocorrendo depois a deposição de lignina, observandose assim uma tensão de compressão. $O$ ângulo da microfibrila, o conteúdo de 
celulose, a celulose cristalizada e o conteúdo de lignina são formas efetiva que determinam o nível e a direção das tensões. Geralmente as tensões mensuráveis são: uma tensão de crescimento na direção longitudinal e uma tensão de compressão na direção tangencial.

A característica principal da tensão da madeira é a camada gelatinosa mais interna da parede celular. As camadas de gelatina são constituídas quase exclusivamente de celulose e o ângulo microfibrilar é próximo de zero com altas cristalizações. Tais fibras geram tensões muito altas na tensão de crescimento na direção axial e, às vezes, sofrem uma contração 10 vezes maior que da fibra normal quando a tensão é aliviada (Okuyama, 1997).

\subsection{Conicidade}

A conicidade possui grande importância econômica e varia muito de espécie para espécie de eucalipto e entre sítios. Segundo Balloni \& Simões (1980), a conicidade é uma característica que pode ser influenciada pelo espaçamento, tendo reflexos na produção de madeira serrada. Para Grosser (1980), árvores isoladas apresentam conicidade maior que árvores plantadas em espaçamentos regulares. Sanches Acosta (1995) afirma que as árvores de bordadura apresentam conicidades maiores e que isto implica numa queda de rendimento em madeira serrada. Miranda \& Nahuz (1997) trabalhando com E. saligna de 9 anos de idade, em três espaçamentos, concluíram que a conicidade não variou significativamente em função do espaçamento, e que não houve correlação entre a conicidade e o rendimento em madeira serrada. Del Menezzi (1999) também não encontrou correlação entre a conicidade e o rendimento em madeira serrada. 
Por outro lado, Zobel \& Jett (1995) afirmaram que existe um forte controle genético sobre a conicidade, o que possibilita para esta caracteristica, o seu emprego em programas de melhoramento genético.

Segundo Pederick (1970), as diferenças de conicidade entre famílias são pequenas, portanto, não está claramente evidenciado o controle genético para esta característica. Schacht (1998), trabalhando com clones de $E$. urophylla de 9 anos de idade, encontrou uma conicidade média de $1,61 \mathrm{~cm} / \mathrm{m}$ e herdabilidade no sentido amplo de 0,066 , indicando também que a variável sofre pouco controle genético.

Um estudo de conicidade realizado por Purnell (1988), em 5 procedências de $E$. nitens, com 11 anos de idade, na África do Sul, revelou que a característica não variou em função das procedências, mas variou com a altura da árvore, sendo muito maior na primeira tora do que nas demais, porém manteve-se crescente da segunda tora até a sexta tora. Mostrou também que a conicidade não está correlacionada com as tensões de crescimento e nem com a densidade básica. Del Menezzi (1999) trabalhando com E. grandis (21 anos) e E. cloeziana (17 anos), retirou 2 toras consecutivas de $3,5 \mathrm{~m}$ a partir da base de cada árvore e também encontrou maior conicidade na primeira tora para ambas as espécies. Malan (1984) trabalhando com E. grandis com 21 anos de idade, também não encontrou correlação entre a conicidade e as tensões de crescimento.

\subsection{Processamento mecânico da madeira}

A indústria florestal teve que aprender a processar toras de pequeno diâmetro, devido a fatores econômicos, usando novas tecnologias com alta taxa de rendimento e baixa geração de resíduos. As árvores com idade de 
10 anos, substituíram aquelas centenárias, facilitando a exploração e o transporte, tornando a sua mecanização mais viável (Villela Filho, 1996).

A espécie folhosa de reflorestamento com maior participação em produtos serrados é o $E$. grandis, devido a sua abundância $e$ facilidade de processamento. $O$ sistema de desdobro de toras para a obtenção de madeira serrada, segundo Sanches Acosta (1998) divide-se em: a) alta produtividade e b) produção de maior qualidade.

a) Para atenuar os efeitos da tensão, recomenda-se o corte inicial paralelo (liberação equilibrada de tensões), numa serra de fita dupla e logo após reserrar a peça central numa serra múltipla. A tendência atual é de serrar com alta velocidade, usando serra de fita dupla, ou circular dupla na entrada e logo após serras circulares múltiplas.

b) Buscar madeira de qualidade, por tipo de corte e especialmente o do tipo livre de defeitos "clear", que pode ser empregada em molduras, revestimentos, vigas laminadas, parquetes, pisos, etc. O sistema de corte que busca a melhor qualidade consiste em serrar a tora em "quartis" que são logo após, reserrados de maneira a obterem-se peças preferencialmente radiais. Este tipo de peça tem boa estabilidade dimensional porém, em peças largas podem ocorrer defeitos de arqueamento, sendo de dificílima correção. Para peças largas deve-se preferir tábuas com cortes tangenciais.

Os empenamentos ocorrem na madeira durante o desdobro e secagem. O desdobro provoca encurvamento das peças em virtude da liberação de tensões de crescimento, onde há uma tendência das peças curvarem-se de modo que as extremidades distanciem-se do centro da tora. Nesse momento é importante selecionar o tipo de encurvamento que é menos prejudicial à finalidade desejada para a madeira, uma vez que é inevitável. Assim na prática, prefere-se o encurvamento de tábuas no plano perpendicular ao das faces ("bow'), evitando-se o empenamento na direção das bordas ("crook"). Geralmente, os cortes tangenciais produzem mais tábuas curvadas no plano perpendicular ao das faces (mais fáceis de serem contornados) do que 
os cortes radiais que produzem mais peças curvadas no plano perpendicular as bordas (dificeis de serem utilizadas) (Shield, 1995).

Segundo Lelles \& Silva (1997) e Nahuz et al. (1999) o desdobro de toras de eucalipto mais utilizado, baseando-se na facilidade da operação em serrarias, é o de cortes paralelos, onde as peças obtidas estão em plano tangencial aos anéis de crescimento. O grande problema que surge nesse caso é o da obtenção de peças com a face tangencial, muito susceptível ao encanoamento. Segundo Lelles \& Silva (1997) recomendam para amenizar os efeitos de instabilidade dimensional da madeira, a obtenção de peças com faces radiais e para isto, utiliza-se 2 cortes cruzados que passam pela medula, permitindo a obtenção de 4 peças de formato de 1/4 de disco. Após essa etapa, realizam-se cortes paralelos às faces, sempre girando a peça remanescente $e$ procurando obterem-se peças radiais.

López (1998) propõe um esquema de corte em toras a partir de $32 \mathrm{~cm}$ de diâmetro, resultando em um número máximo de peças radiais sem alburno. $O$ esquema consiste numa serra de fita simples e carro porta tora, onde os cortes são feitos em lados alternados da medula.

Segundo Freitas \& Brito Neto (1993), com o equipamento básico de serra de fita germinada, com volante de $1.10 \mathrm{~m}$ de diâmetro, um bitolador automático, duas reserras também de $1.10 \mathrm{~m}$ de diâmetro, duas refiladeiras múltiplas pneumáticas de um só eixo, uma serra circular múltipla de dois eixos para cortes de toras com até $20 \mathrm{~cm}$ de espessura, e quatro destopadeiras, utilizados no processamento de toras de $E$. grandis e $E$. saligna de 15 a $30 \mathrm{~cm}$ de diâmetro, obtiveram os rendimentos variando entre $42 \%$ e $50 \%$, dependendo da classe de diâmetro das toras.

Para Freitas \& Brito Neto (1993), os efeitos das tensões de crescimento podem ser controlados através de cortes simultâneos de duas costaneiras através de serras de fita dupla, circulares, alternativas ou picadores canteadores. Em seguida, o bloco restante é desdobrado em uma serra múltipla onde sofre cortes simultâneos. Deste modo, são obtidos bons resultados e 
rendimentos em madeira serrada próximos a $50 \%$ para toras de 15 a $30 \mathrm{~cm}$ de diâmetro. Outra caracteristica deste sistema é a alta produtividade. É possivel com equipamentos Brasileiros o processamento de até cinco toras por minuto (Shield, 1995).

Sendo o custo da matéria-prima significativo, Hochhein \& Martin (1993) realizaram diversas simulações em serraria para estudar a influência do diâmetro da tora sobre o custo final dos produtos desdobrados. A qualidade das toras serradas foram classificadas em três categorias (boa, regular e ruim), em função dos produtos que delas foram obtidos. Observou-se que o custo diminui com o aumento do diâmetro, mas que esta relação não foi linear e tende a se estabilizar após o diâmetro de $45 \mathrm{~cm}$, onde através do gráfico observou-se uma curva de " $\mathrm{J}$ invertido". Os bons resultados observados a partir dos custos dos produtos obtidos das toras de maior diâmetro ( $>45 \mathrm{~cm}$ ) foi explicado pelo seu melhor rendimento em porcentagem.

\subsubsection{Rachadura de extremidade de tora (RT)}

A severidade da tensão de crescimento associada com problemas encontrados na conversão de árvores em produtos florestais pode variar consideravelmente de um indivíduo para outro, entre e dentro de espécies. Assim, uma árvore pode não desenvolver trincas depois da queda, enquanto outras podem rachar explosivamente em inúmeros segmentos, ou ainda, uma tora pode ser serrada com relativa facilidade e obter um alto rendimento, enquanto outra pode mover sobre a bancada de uma serra, contraindo-se e travando a serra e/ou produzindo uma alta proporção de material arqueado ou rachado (Chafe, 1977).

As madeiras das espécies do gênero Eucalyptus geram efeitos desfavoráveis para alguns usos, dependendo da procedência, 
dimensões, idade, tratos silviculturais e variabilidade de propriedades físicas e mecânicas da espécie. Tais efeitos são causados pela liberação de tensões de crescimento, anisotropia dimensional, e secagem da madeira. As tensões de crescimento que ocorrem transversalmente em um tronco são menores que as que ocorrem longitudinalmente (cerca de 10 vezes maior). Como a madeira é menos resistente no sentido transversal, as tensöes neste sentido, mesmo sendo menores, causam rachaduras (Lelles \& Silva, 1997).

As rachaduras estão relacionadas negativamente com 0 diâmetro da árvore, isto é, quanto maior o diâmetro, menor a rachadura das toras. Por ouro lado, em árvores com diâmetro de $46 \mathrm{~cm}$ (por volta de 18 anos de idade), observou-se maior quantidade de "trincas de derrubada", contudo tais trincas foram observadas em face expostas ao sol (Chafe, 1977).

Ao se abater a árvore, o corte transversal do tronco libera tensões que provocam fendas radiais e diametrais ("star checks") no topo das toras. Dependendo do grau de severidade dessas tensões e do tempo em que as toras permaneceram no campo ou no pátio da serraria, essas rachaduras podem progredir ao ponto de inutilizá-las para a produção de madeira serrada, causando algumas vezes a divisão da tora em duas ou três partes (Freitas \& Brito Neto, 1993).

A rachadura de topo pode começar imediatamente após a derrubada da tora (Wilkins, 1986) e segundo Malan (2000), até 72 horas. As rachaduras desenvolvidas podem ser medidas sem prejuízo após esse período. As rachaduras podem ser minimizadas pelo rápido desdobro depois da queda da árvore usando o método de desdobro balanceado, o qual libera as tensões em lados opostos das toras simultaneamente (Simula \& Tissari, 1998).

Quanto maior for o tempo em que a tora permanecer no pátio sem ser desdobrada, piores serão as conseqüências das tensões de crescimento . O ideal segundo Freitas \& Brito Neto (1993), seria abater a árvore, transportá-la até a serraria e desdobrá-la dentro de poucas horas (o chamado "hot logging"), para que realmente não haja tempo para a tora rachar. 
Se as toras tiverem que ser armazenadas, o melhor é fazê-lo nos comprimentos maiores possiveis e efetuar um corte circular parcial nas extremidades, até um terço do raio (o chamado anelamento).

Segundo Assis (1999) estudos realizados em clones de $E$. grandis, E. saligna e hibrido de $E$. grandis $\times E$. urophylla, revelaram diferenças significativas entre eles para as rachaduras de toras e de tábuas. As variações entre locais também foram significativas, sugerindo que além da seleção clonal, - zoneamento ambiental deva ser implementado como estratégica para a produção de madeira com menores tensões de crescimento.

O efeito do periodo do ano na rachadura de tora é maior onde as temperaturas são elevadas, e as chuvas escassas com déficit hídrico no solo, sendo o período de maior incidência de rachadura entre os meses de abril a maio (no hemisfério Sul) (Malan, 1984).

A madeira é um material elástico onde, toda a porção tracionada (a chamada tensão de crescimento periférica $\left(\sigma_{p}\right)$ ) na árvore, alonga-se proporcionalmente à distribuição de tensões existente e tenderá a encurtar-se no desdobro, e quando esta distribuição de tensões for aliviada, a porção comprimida (parte central da tora) tender-se-á a alongar-se. Esta diferença de tensão (tração $x$ compressão) explica o porque de uma árvore recém cortada ter o seu diâmetro aumentado adquirindo a forma de calota, sendo quase sempre acompanhada por rachaduras de extremidade, as quais, Villiers (1973), Malan (1984) e Garcia (1995), citam que têm sido tomadas como indicador de seleção de árvores para serraria.

As toras de $E$. urophylla, apresentaram grandes variações na intensidade das rachaduras nas extremidades das toras durante o desdobro, sendo que as variações dentro de progênies são maiores que entre progênies (Fernandes, 1982). 


\subsubsection{Rachadura de extremidade da prancha diametral (RPD)}

Em relação à posição radial das tábuas na tora, as da periferia praticamente não racham, enquanto que as tábuas próximas à medula e a prancha diametral que contem a medula, são as que mais racham. Isto está de acordo com todos os trabalhos sobre a variação radial das tensões de crescimento postulados por Boyd (1950b), Kubler (1959), Hillis et al. (1973), Nicholson (1973) e Van Wyk (1978).

Se não forem cuidadosamente controlados os fatores que atuam sobre as tensões de crescimento, o melhoramento para as rachaduras de topo de tora, pode resultar em ganhos reduzidos ou muito abaixo do esperado para as rachaduras e empenamentos da madeira serrada (Schacht \& Garcia, 1997a,b).

Lopes (2000), trabalhando com E. saligna com 22 anos de idade, não encontrou correlação entre a rachadura da extremidade da tora com a rachadura de extremidade da peça serrada (tábua). Segundo Malan (2000), as correlações entre rachadura de tora e a rachadura da prancha diametral foram geralmente pequenas e não significativas, independente da altura ao longo do fuste da árvore e para onde conduziram-nas. As toras que apresentam baixos níveis de rachaduras não necessariamente produzem tábuas serradas com baixos niveis de rachaduras. Outros pesquisadores encontraram resultados semelhantes (Crespo, 2000; Lopes, 2000 e Lima, 2000).

$\mathrm{Na}$ secagem natural de tábuas, ocorre perda de água livre (acima do ponto de saturação das fibras) num periodo de 15 a 30 dias e o restante é eliminado num período de 3 a 5 vezes maior, considerando que as tábuas estejam sob as mesmas condições iniciais de exposição. Silva et al. (1997), estudaram o comportamento da madeira de $E$. grandis durante o processo de secagem ao ar livre, visando suprir as necessidades do setor moveleiro, e concluiram que os maiores indices de rachaduras foram 
observados nas tábuas que continham as porções provenientes da medula. Estas tábuas devem ser, quando possivel, reprocessadas ou ignoradas no processo produtivo do setor moveleiro, ou ainda, ser utilizadas para outros fins, como em caldeiras para geração de energia.

\subsubsection{Rendimento em madeira serrada (RMS)}

O rendimento em madeira serrada é afetado pela interação de diversos fatores, sendo os mais importantes, o diâmetro, o comprimento, a conicidade, a qualidade das toras, a espessura do corte, o número alternativo de produtos, os tipos e as condições de funcionamento e de manutenção dos equipamentos, além dos métodos de processamento mecânico (Steele, 1984).

O rendimento em madeira serrada varia de uma espécie para outra, em função das inerentes distinções das características físicas da madeira, como densidade básica, disposição dos elementos estruturais, componentes químicos, teor de umidade etc. (Steele, 1984). Outros autores citam também que as variações no rendimento em função das espécies podem estar relacionadas a diferentes tipos de corte e de serras (Berengut et al., 1973; Villiers, 1973; Lhuele \& Waugh, 1980; Steele, 1984; Freitas \& Brito Neto, 1993; Garcia, 1995; Combes et al., 1997; Jara et al., 1997 e Del Menezzi, 1999). Segundo Simula \& Tissari (1998), somente 30 a $35 \%$ de rendimento são usualmente obtidos em serrarias.

O rendimento em madeira serrada aumenta com o aumento do diâmetro das toras, devido à menor proporção de madeira perdida em aparas em relação ao volume total da tora (Wade et al. 1992). Mas segundo Freitas \& Brito Neto (1993) esse aumento é devido à menor proporção de madeira juvenil nas toras de diâmetros maiores. 
Quando se trata de madeira do gênero Eucalyptus, a manifestação das tensões internas de crescimento prejudicam sobremaneira o rendimento, com a rachadura das toras antes, durante e depois do desdobro. Estudos revelam que a intensidade destas tensões estão relacionadas com o crescimento em diâmetro da árvore (Boyd, 1950b; Garcia, 1992 e Vignote et al., 1996).

A excessiva espiralidade da grã, é uma causa natural ou evidenciada no desdobro, onde pode ocasionar empenamentos e torcimentos, bem como dificuldades no processo de secagem, acarretando perdas no material serrado e consequentemente diminuição no rendimento final (Grosser, 1980; Harris, 1989 e Bindzi \& Samson, 1995).

O comprimento da tora, não tem efeito significativo no rendimento, entretanto segundo Grosser (1980), Steele (1984) e Vianna Neto (1984), se for considerado de forma conjunta com o efeito da conicidade e do diâmetro da tora, principalmente com o aumento em diâmetro, dificultar-se-á o desdobro, o qual redunda em maiores perdas de material no primeiro corte da tora e no posterior canteamento da tábua.

De acordo com Malan (1979), quanto mais rápido a madeira for trabalhada, melhor será sua qualidade e menores serão as injúrias nelas produzidas. A otimização está dentro de 24 horas da derrubada e preparação das toras, onde observaram-se os melhores resultados de rendimento em madeira serrada.

Os resultados do aquecimento de toras de $E$. grandis obtidos por Jara et al. (1997), por um período de 67 horas com temperatura média de $64,5^{\circ} \mathrm{C}$, reduziram as tensões de crescimento, maximizando o rendimento em madeira serrada e minimizando o rachamento de tábuas quando as toras foram desdobradas pelo método de quadro cheio. 


\title{
2.7.4 Flecha da costaneira (FC) e da peça serrada "vigota" (FV)
}

\begin{abstract}
A flecha constitui-se num importante indicador de seleção de árvores para serraria por ser uma variável de avaliação fácil e segura, portanto, pode ser utilizada como critério de seleção (Garcia, 1992 e Schacht et al., 1998).
\end{abstract}

Quando uma árvore é abatida, o equilibrio das forças são quebradas, liberando as tensões de crescimento, que podem ser expressas pela equação $\sigma_{(r)}=\sigma_{p}(-2+3 r / R)$ (Kluber, 1959), onde $\sigma_{(r)}$ é a tensão num ponto " $r$ " entre a medula e a periferia da árvore, $\sigma_{p}$ é a tensão de crescimento estimada na periferia da árvore, e $\mathrm{R}$ é o raio as seção transversal.

A equação $f=\left[\left(3 L^{2} / 4\right) \times\left(\xi_{p} / D\right)\right]$ (onde: $f=$ flecha da peça serrada; $L=$ comprimento da tora; $D=$ diâmetro da árvore; $e \xi_{p}=$ deformação de crescimento medido na periferia da árvore) demonstra que para a seleção de árvores para serraria é importante à relação $\xi_{\mathrm{p}} / \mathrm{D}$ e não somente $\xi_{\mathrm{p}}$ medido na periferia da árvore. Isto explica o porque das rachaduras de extremidade da tora e os empenamentos na madeira serrada se agravarem com o aumento da altura da tora na árvore. A deformação $\xi_{p}$ é difícil, imprecisa e demorada obtenção, portanto, a medição da flecha da peça serrada constitui-se num importante indicador de seleção de árvores para serraria (Garcia, 1995).

\subsection{Densidade básica (Db) da madeira de Eucalyptus}

A densidade é uma das propriedades físicas mais importantes na caracterização tecnológica da madeira para os mais diversos fins, já que sua variação afeta em grande parte a resistência mecânica da 
madeira e está associada às tensões de crescimento (Ferreirinha, 1961; Nicholson et al., 1972; Barret et al., 1975 e Bortolleto Jr., 1993).

A densidade da madeira é uma característica importante para vários segmentos da produção industrial. É uma propriedade tecnológica bastante estudada por ser de fácil melhoramento, pela grande variabilidade fenotípica, baixa presença de interação entre genótipo e ambiente e apresentar uma alta herdabilidade (Brasil, 1983; Zobel \& Talbert, 1984).

A densidade de clones de $E$. grandis, com sete anos de idade, variam de $0,37 \mathrm{~g} / \mathrm{cm}^{3}$ a $0,55 \mathrm{~g} / \mathrm{cm}^{3}$. Uma amplitude de variação desta ordem, permite direcionar as propriedades da matéria prima para os mais diversos fins (Assis, 1999).

A correlação encontrada entre densidade e a tensão de crescimento, sugere que a manipulação genética de uma pode ter efeito na outra. A seleção para a redução dos níveis de tensão de crescimento, por exemplo, tem um efeito benéfico, dentro da uniformidade da árvore, na qualidade da madeira, mas pode também reduzir a densidade, ao mesmo tempo (Malan, 1984). A redução dos níveis de tensão nas árvores resultará em densidades da madeira mais baixas e mais homogêneas em partes mais exteriores do caule (Malan, 1984).

Combes et al. (1997) trabalhando com híbridos de $E$. urophylla com 4,83 anos de idade no Congo, não encontrou correlação entre as tensões de crescimento e a densidade básica.

Malan (1990) trabalhando com E. grandis, encontrou correlação genética negativa entre a taxa de crescimento e a densidade básica. Porém, árvores com altos niveis de tensões de crescimento, geralmente apresentam densidade básica mais elevada que as árvores com tensões de crescimento com menores níveis.

A amplitude de variação da densidade básica encontrada por Brasil (1983) para procedência de E. urophylla, nas ilhas Timor e Flores e em dois locais de plantio (Belo Oriente-MG e Linhares-ES) foi de 0,402 a 0,491 
$\mathrm{g} / \mathrm{cm}^{3}$. As maiores diferenças foram entre as procedência, indicando que isto deveria ser seguida numa primeira fase, para um programa de melhoramento da espécie.

O estudo da variabilidade da densidade é altamente importante para a determinação e adequação da madeira à finalidade desejada. Apesar da densidade apresentar baixa interação com o ambiente, Ferreira \& Kageyama (1978), observaram a variação da densidade em função da localidade e encontraram os resultados expressos na Tabela 2.

Segundo Ferreira (1968), Ferreira \& Kageyama (1978), Mendes et al. (1983) e Rockwood et al. (1995) ocorre um aumento da densidade com a idade da árvore. Considerando o período de 5 a 7 anos de idade, que são mais adequadas à exploração e utilização da madeira, o $E$. grandis apresenta densidade média variando de 0,43 a $0,5 \mathrm{~g} / \mathrm{cm}^{3}$ e $\circ E$. urophylla de 0,5 a $0,58 \mathrm{~g} / \mathrm{cm}^{3}$ (Ferreira \& Kageyama, 1978). Na Tabela 3 observa-se alguns exemplos da variação da densidade básica de cada ano analisado.

Tabela 2. Variação da densidade média $\left(\mathrm{g} / \mathrm{cm}^{3}\right)$ de plantações aos 5 anos de idade nas regiões de Itupeva (SP) e Mogi-Guaçu (SP).

\begin{tabular}{lll}
\hline Espécie & Itupeva & Mogi-Guaçu \\
\hline E. urophylla & $0,528 \mathrm{~g} / \mathrm{cm}^{3}$ & $0,546 \mathrm{~g} / \mathrm{cm}^{3}$ \\
E. saligna & $0,454 \mathrm{~g} / \mathrm{cm}^{3}$ & $0,545 \mathrm{~g} / \mathrm{cm}^{3}$ \\
E. grandis & $0,409 \mathrm{~g} / \mathrm{cm}^{3}$ & $0,527 \mathrm{~g} / \mathrm{cm}^{3}$ \\
E. propinqua & $0,538 \mathrm{~g} / \mathrm{cm}^{3}$ & $0,628 \mathrm{~g} / \mathrm{cm}^{3}$ \\
\hline
\end{tabular}

Fonte: Ferreira \& Kageyama (1978). 
Tabela 3. Variação da densidade da madeira $\left(\mathrm{g} / \mathrm{cm}^{3}\right)$ em função da espécie e da idade na localidade de Itupeva (SP).

\begin{tabular}{lllll}
\hline Idade (anos) & E. urophylla & E. grandis & E. propinqua & E. saligna \\
\hline 5 & $0,528 \mathrm{~g} / \mathrm{cm}^{3}$ & $0,409 \mathrm{~g} / \mathrm{cm}^{3}$ & $0,538 \mathrm{~g} / \mathrm{cm}^{3}$ & $0,454 \mathrm{~g} / \mathrm{cm}^{3}$ \\
7 & $0,572 \mathrm{~g} / \mathrm{cm}^{3}$ & $0,462 \mathrm{~g} / \mathrm{cm}^{3}$ & $0,580 \mathrm{~g} / \mathrm{cm}^{3}$ & $0,482 \mathrm{~g} / \mathrm{cm}^{3}$ \\
9 & $0,574 \mathrm{~g} / \mathrm{cm}^{3}$ & $0,460 \mathrm{~g} / \mathrm{cm}^{3}$ & $0,604 \mathrm{~g} / \mathrm{cm}^{3}$ & $0,488 \mathrm{~g} / \mathrm{cm}^{3}$ \\
11 & $0,603 \mathrm{~g} / \mathrm{cm}^{3}$ & $0,474 \mathrm{~g} / \mathrm{cm}^{3}$ & $0,623 \mathrm{~g} / \mathrm{cm}^{3}$ & $0,586 \mathrm{~g} / \mathrm{cm}^{3}$ \\
\hline
\end{tabular}

Fonte: Ferreira \& Kageyama (1978).

Segundo Mendes et al. (1983) e Vital et al. (1984) a densidade tende a aumentar com a idade devido ao aumento da espessura da parede celular, diminuição da largura das células e diminuição do teor de lignina. Portanto, madeira com maior proporção de madeira juvenil é mais rica em lignina do que a madeira madura.

Alguns autores acharam correlação positiva entre a densidade básica e a taxa de crescimento, isto é, aumentando-se a densidade básica, aumenta a taxa de crescimento das árvores (Ferreira, 1968; Foelkel et al., 1978; Souza et al., 1979, 1986; Ferreira et al., 1978, 1979, 1997; Camargo et al. 1988; Nogueira, 1991 e Malan, 1993). Outros autores acharam correlação negativa (Taylor, 1973; Schönau, 1974; Mello et al., 1976; Ferreira et al., 1978, 1979; Albino, 1983; Migliorini, 1986; Moura, 1986; Souza et al., 1986; Migliorini et al., 1988 e Rezende et al., 1998).

Outros autores não acharam nenhuma correlação entre a densidade da madeira e a taxa de crescimento (Brasil \& Ferreira, 1971; Brasil, 1972, 1976; Ferreira et al., 1978; Brasil et al., 1979; Albino et al., 1985; Souza et al., 1986; Malan \& Hoon, 1992 ; Vale et al., 1995 e Combes et al., 1997).

Em progênies de $E$. grandis provenientes de 3 locais diferentes, Moraes (1987) também não encontrou correlação genética entre a densidade básica da madeira com as características de crescimento.

Brasil (1983), trabalhando com E. urophylla com 5 anos em dois espaçamentos e dois locais, não encontrou influência do éspaçamento e 
nem da taxa de crescimento na densidade básica em nenhum local. Para Tome et al. (1995) trabalhando com E. globulus com 17,17 anos de idade em Portugal, em diversos espaçamentos $(3 \times 2 \mathrm{~m}$ a $5 \times 4 \mathrm{~m})$, não encontraram diferenças na densidade básica em função do espaçamento de plantio.

A densidade cresce da base para a copa da árvore para o E. urophylla. Para o E. grandis de 15 a 20 anos, na África do Sul, há uma tendência da densidade decrescer do nível do DAP até 4,5m de altura. Acima deste nível, a densidade tende a crescer novamente. No estado de São Paulo, não foi verificada essa tendência de decréscimo até a altura de o 4,5m (Ferreira \& Kageyama, 1978).

Segundo Souza et al. (1986), não existe um modelo definido de variação da densidade básica da madeira no sentido base - topo. Para o gênero Eucalyptus observa-se com maior freqüência a tendência de decréscimo até $50 \%$ da altura da árvore e crescente deste ponto até o topo, ou ainda podendo diminuir próximo ao topo. O E. grandis possui um valor de densidade por volta de $0,44 \mathrm{~g} / \mathrm{cm}^{3}$, e as posições de maiores densidades foram a base, $75 \%$ e $100 \%$ da altura comercial. O intervalo de variação da densidade no sentido base - topo é maior para o $E$. grandis do que para o $E$. saligna .

Para o E. urophylla, há autores que verificaram que a densidade básica diminui da base até o DAP ou $25 \%$ da altura, para depois crescer até o topo (Barrichelo et al., 1984 e Shimoyama, 1990).

Para a variação longitudinal da densidade básica dos eucaliptos, os dados são bastante controversos, autores como Fernandes (1982) e Gouvêa et al. (1997) encontraram uma variação crescente da base até o topo. Outros autores como Busnardo et al. (1978), Barrichelo \& Brito (1982), Sturion et al., (1987), Vital \& Della Lucia (1987) e Oliveira (1998), acharam que a densidade básica diminui da base para o topo, e Oliveira (1998) também achou que a densidade básica cresce até o DAP, para depois diminuir até o topo. 
Dependendo do local a densidade básica é maior a uma determinada altura, Ferreira (1968) afirma que isso acontece devido a reação da árvore a ações do vento.

Albino \& Tomazello Filho (1985) verificaram uma fraca correlação da altura com a densidade básica para 12 espécies de eucalipto, em três localidades de Minas Gerais. $O$ diâmetro também apresentou baixa correlação com a densidade, e as espécies apresentaram maiores taxas de crescimento e menores densidades básicas ao nível do DAP. Observam também que, na maioria das espécies, não houve correlação significativa entre densidade básica da madeira e espessura de casca. Para o volume cilíndrico, também não foi verificada uma correlação com a densidade básica, porém foi detectado um efeito significativo do local sobre a densidade básica e produção volumétrica, em todas as espécies.

Garcia \& Lima (1990) estudaram a densidade do E. grandis em diversos diâmetros e não encontraram variação entre as classes de diâmetro [pequeno (15 a $21 \mathrm{~cm})$, médio (23 a $26 \mathrm{~cm})$ e grande $(27$ a $33 \mathrm{~cm})$ ] e também não encontraram correlação.

Em E. grandis, a densidade básica aumenta rapidamente com o distanciamento da medula, mas este gradiente tende a se tornar menos pronunciado com o aumento da altura em relação ao nível do solo (Malan, 1990).

Segundo Malan (1995), a variação no sentido radial é mais importante, sendo que a sua extensão é determinada pela proporção da madeira juvenil e suas características físico-químicas e anatômicas ao longo do raio. A madeira juvenil pode constituir uma grande proporção do tronco em áreas de rápido crescimento, originando desta forma, elementos de importância considerável, e de uma maneira geral, a madeira apresenta uma rápida elevação dos valores de densidade, componentes químicos, comprimento de fibra etc., da fase juvenil para a adulta, onde os valores permanecem mais ou menos constantes. 
Variações na densidade da madeira estão associadas a variações na morfologia da fibra. O volume de parede das fibras pode responder por até $70 \%$ da variação da densidade. A densidade correlaciona-se significativamente com porcentagem de vasos, tamanho e freqüência dos vasos, mas estas características explicam uma pequena porcentagem da variação total da densidade, sugerindo assim que a densidade pode ter pouca influência na permeabilidade da madeira (Malan, 1990).

A variação da densidade no sentido medula - casca do $E$. grandis de 15 a 20 anos de idade, demonstrou que a densidade da madeira próxima à medula foi de $0,39 \mathrm{~g} / \mathrm{cm}^{3}$, aumentando na direção da casca $(0,5$ $\mathrm{g} / \mathrm{cm}^{3}$ ). Ocorreram variações entre a medula e a casca da ordem de $0,25 \mathrm{~g} / \mathrm{cm}^{3}$ e em árvores classificadas como uniformes, a variação foi da ordem de 0,16 $\mathrm{g} / \mathrm{cm}^{3}$ (Ferreira \& Kageyama, 1978).

Para o E. grandis, nas idades de 11 a 16 anos, foram estudadas variações radiais dentro em função das classes diametrais. Para as classes diametrais de 14 a $38 \mathrm{~cm}$, as diferenças entre a densidade da madeira próxima à casca e da madeira próxima à medula foram da ordem de 0,084 a $0,242 \mathrm{~g} / \mathrm{cm}^{3}$, respectivamente (Ferreira \& Kageyama, 1978).

A densidade aumenta rapidamente com o distanciamento da medula. Os efeitos da distância a partir da medula e da altura da árvore foram altamente significativos num estudo de Malan (1988c), que avaliou 11 posições radiais de $E$. grandis. Os efeitos da altura e da posição radial apresentaram um acréscimo de $60 \%$ e $8 \%$, respectivamente, na variabilidade.

A madeira juvenil apresenta geralmente fibras mais curtas e com menor densidade que a madeira normal (cerne), por isto, possui propriedades mecânicas inferiores, sendo frágil e quebradiço (Ponce, 1995).

Para o E. grandis, com 15 anos de idade, foram determinados os valores de densidade aparente a $12 \%$ de umidade. Para o diâmetro de aproximadamente $28 \mathrm{~cm}$, a porção de madeira juvenil corresponde 
aproximadamente a $18 \mathrm{~cm}$ e observa-se um acréscimo na densidade de $50 \%$ na madeira adulta, em relação à madeira juvenil (Oliveira, 1998).

Malan (1988c), que estudou a variação da densidade básica dentro e entre árvores, encontrou herdabilidades para a densidade básica de 0,30 e 0,54, respectivamente, ressaltando que a maior variabilidade dentro de árvores ocorre no sentido radial, do centro para a casca e nos níveis de altura, porém, as diferenças entre árvores são muito mais importantes. Uma maior eficiência na amostragem pode ser conseguida pela tomada de um maior número de árvores do que de posições dentro da árvore. Segundo Ferreira \& Kageyama (1978), a variação da densidade entre árvores para o $E$. urophylla nas idades de 5 a 7 anos, encontraram-se entre 0,443 a $0,667 \mathrm{~g} / \mathrm{cm}^{3}$ e para o E. grandis de 11 a 16 anos, entre 0,433 a $0,73 \mathrm{~g} / \mathrm{cm}^{3}$.

Em um estudo feito por Malan (2000) com o E. grandis e o híbrido $E$. grandis $\times E$. urophylla, com o objetivo de comparar a qualidade das tábuas, avaliando-se as rachaduras $e$ as trincas do cerne, não encontrou nenhuma diferença estatística significativa entre os materiais. Os resultados em relação a densidade básica indicaram que a madeira do híbrido foi de 0,70 $\mathrm{g} / \mathrm{cm}^{3}$ e maior que a média do $E$. grandis. A densidade do híbrido foi consideravelmente mais variável entre, bem como dentro das árvores, devido os hibridos agregarem heranças de 2 espécies.

Trugilho et al. (1997) estudaram a variação nas características físicas, químicas e anatômicas da madeira de $E$. grandis em quatro idades, com o objetivo de obter uma matéria prima mais homogênea. Os resultados demonstraram que a densidade está intimamente relacionada à composição química da madeira e que os carboidratos são os maiores responsáveis pelo seu aumento. O teor de lignina apresentou correlação negativa com a densidade básica e com o teor de holocelulose.

Há uma tendência da madeira ser mais estável e melhor, quanto mais baixos e próximos forem os valores de contração nos sentidos tangencial e radial. Segundo Calori \& Kikuti (1997) o E. grandis apresenta 
contração tangencial, radial, axial e volumétrica, em média igual a $9,77 \% ; 5,6 \%$; $0,16 \%$ e $15 \%$, respectivamente. Para o E. urophylla, em média os valores são superiores, sendo de $12,45 \% ; 7,18 \% ; 0,11 \%$ e $19,77 \%$, respectivamente (Watai, 1990; Oliveira, 1997; e Vital \& Trugilho, 1997).

\subsection{Propriedades mecânicas da madeira de Eucalyptus}

As características mecânicas estão relacionadas com a resistência que se opõem a aplicação de forças externas, importantes para usos em estruturas. Em relação à flexão estática e compressão axial, Sanches Acosta (1995) cita que o comportamento dos Eucalyptus é comparável ao de madeiras nativas da Argentina, sendo semi-pesada à leve e como estes valores estão relacionados com a densidade básica, é possivel prever as propriedades mecânicas através da densidade básica.

A madeira de eucalipto atende às mais diferentes exigências quanto às propriedades mecânicas. A grande variabilidade destas propriedades ao longo do raio ou na direção da medula-casca em um tronco de madeira, está relacionado à formação de madeira juvenil que caracteriza-se por apresentar empenamentos, resistência muito inferior àquelas da madeira adulta e excessiva contração longitudinal. Em alguns casos, ocorre a formação de "brittle heart" na medula com menor densidade básica, fibras mais curtas e maior ângulo microfibrilar (Oliveira, 1999). Segundo Malan et al. (1996) o "brittle heart" é assumido como sendo o resultado da acumulação da tensão de compressão na parte central do caule em crescimento, conjuntamente com uma baixa densidade básica da madeira naquela parte do caule (medula). Surgem então, fraturas na parede celular do tecido, porque as tensões solicitantes ultrapassam a resistência da madeira à compressão. 
Os parâmetros relacionados à resistência e elasticidade das peças fletidas de madeira, são os mais importantes para a avaliação do material visando a sua utilização em construção. As propriedades mecânicas, de maneira geral, não variam significativamente. A tração paralela cresce até $50 \%$ da altura comercial e depois decresce até o topo e o cisalhamento, decresce até $50 \%$ da altura comercial e a partir deste ponto, cresce até o topo, podendo-se observar diferenças significativas entre as resistências avaliadas em determinadas posições do tronco (Calori \& Kikuti, 1997).

O método mais utilizado para a obtenção dos valores, baseia-se em resultados obtidos a partir de pequenos corpos de prova, isentos de defeitos, ajustados por coeficientes de ponderação que levam em conta as influências relativas à variabilidade do material, umidade, densidade, defeitos das peças e outros ajustamentos pertinentes ao cálculo de estruturas de madeira (Mascia, 1986).

No Brasil, a proposição de um sistema de classes de resistência para as madeiras nativas e cultivadas é muito recente e refere-se aos estudos realizados para a revisão da norma Brasileira NBR 7190/82 "Cálculo e Execução de Estruturas de Madeira" (Sales, 1996).

Os defeitos apresentados pela madeira podem reduzir a sua resistência, sendo que o grau dessa influência depende do tipo, tamanho e posição do defeito. Dentro os defeitos mais importantes que reduzem a resistência estão os nós, inclinação da grã, lenho de compressão e o tempo de aplicação de cargas. De forma secundária, aparecem outros fatores como ataques de fungos ou insetos que causam a deterioração da madeira (Nielsen, 1998).

Hellmeister (1973) fez referência à necessidade de se estabelecer um número mínimo de corpos de prova, com o intuito de se alcançar validade estatística para o resultados de ensaios mecânicos para uma espécie. Com base nos resultados obtidos, constatou que são necessários 6 
corpos de prova para obter resultados confiáveis e significativos para o ensaio de flexão estática.

A representatividade do valor obtido num determinado ensaio em relação à propriedade que se deseja mensurar, que recebe além da variabilidade intrínseca ao material, uma série de interferência devida à metodologia utilizada no ensaio, principalmente no que se refere à forma $e$ as dimensões dos corpos de prova e aos dispositivos de fixação e leitura, podem interferir e alterar de maneira significativa os valores obtidos nos ensaios (Sales, 1996).

A elasticidade é a propriedade que um corpo sólido possui de retornar ao seu estado inicial, de forma e tamanho, quando o esforço causador dessa deformação é removido (Nielsen, 1998).

A resistência é a capacidade de um material resistir a forças externas ou a choques ou esforços que tendem a alterar sua forma e tamanho, ou ainda, causar alguma deformação (Nielsen, 1998).

O comportamento elástico e o limite de resistência são características próprias de cada material e nas madeiras dependem de cada espécie. A determinação dessas características pode ser obtida, na prática, através dos ensaios convencionais, realizados dentro de padrões estabelecidos por normas ou especificações. Em geral, os ensaios consistem na obtenção de dados de deformação correspondente à aplicação de uma carga lenta e contínua em corpos de prova devidamente preparados e condicionados a um determinada umidade (Nielsen, 1998).

\subsubsection{Resistência ao cisalhamento radial $\left(f_{\mathrm{sr}}\right)$ e cisalhamento tangencial $\left(\mathbf{f}_{\text {st }}\right)$}

Através de ensaios de cisalhamento, determinam-se os limites de resistência da madeira ao cisalhamento, propriedade de grande 
importância nas ligações entre peças de madeira com pinos, parafusos ou encaixes. A resistência ao cisalhamento é dada pela máxima tensão de cisalhamento que pode atuar em um corpo de prova prismático (Brotero, 1945).

$\mathrm{O}$ ângulo das microfibrilas (camada S2 da fibra da madeira ou traqueídeos em coníferas) é importante e influencia várias propriedades físicas e mecânicas da madeira como a densidade básica, retratibilidade, compressão paralela às fibras e os cisalhamentos (tanto o radial como o tangencial) (Dinwoodie, 1975). Portanto, para o ensaio de cisalhamento, não só a umidade pode influenciar, como também o ângulo das microbibrilas.

\subsubsection{Resistência à compressão paralela às fibras $\left(f_{c}\right)$}

A resistência a compressão paralela às fibras da madeira é indicada pelo esforço necessário ao esmagamento de corpos de prova isentos de defeitos, comprimidos segundo a direção axial. O método consiste em aplicarem-se cargas crescentes de compressão até levar o corpo de prova à ruptura (Brotero, 1945). O valor da resistência alcançado em diferentes velocidades de carregamento diminui em, aproximadamente, $8 \%$ quando o tempo de ensaio é aumentado 10 vezes (Otto, 1986).

A influência da umidade na resistência da madeira à compressão paralela às fibras é de grande importância para a análise do comportamento de estruturas de madeira ao longo tempo. Isto se justifica pois é freqüente o emprego da madeira verde no momento da montagem da estruturas, com a redução da umidade, as propriedades do material são alteradas, exigindo muitas vezes, a reavaliação do conjunto estrutural (Lahr, 1990). 
A variação de umidade se estabiliza no teor de umidade equivalente ao ponto de equilíbrio do ar ( $8 \%$ em Brasília e $19 \%$ em Belém) (Tanaami, 1986).

\subsubsection{Resistência à flexão estática $\left(f_{f}\right)$ e Módulo de elasticidade na flexão estática $\left(E_{\mathrm{f}}\right)$}

O módulo de elasticidade é uma medida de rigidez e não de resistência. Um alto módulo de elasticidade indica que a peça pode suportar um grande esforço sem grandes deformações. Já a resistência à flexão é a tenção limite que ocorre no momento da ruptura do corpo de prova (Nielsen, 1998).

Um material difícil de encurvar ou deformar pode ser chamado de rígido. A rigidez é expressa numericamente através do módulo de elasticidade, em testes de flexão estática. $\mathrm{O}$ módulo de elasticidade na flexão estática tem sido referido como o melhor parâmetro estimador de qualidade mecânica da madeira, embora existam outros testes que podem ser empregados. Os ensaios de tração e compressão, também permitem as estimativas de módulos de elasticidade (Nielsen, 1998).

O módulo de elasticidade longitudinal da madeira ("E"), é um parâmetro necessário para a avaliação dos limites de utilização dos elementos componentes dos mais diferentes tipos de estruturas. Assim sendo, o seu conhecimento é importante, bem como os procedimentos experimentais compativeis para a sua determinação. É possivel determinar o módulo de elasticidade através dos ensaios de compressão paralela às fibras $\left(E_{c}\right)$, de tração paralela às fibras $\left(E_{t}\right)$ e de flexão $\left(E_{f}\right)$. A análise estatística realizada para determinar o módulo através destes três ensaios permitiu concluir pela equivalência estatística a nível de $95 \%$, a possibilidade de serem igualmente 
utilizados em projetos, os valores de $E_{c}, E_{t}$ ou $E_{f}$, sem incorreções significativas (Chahud \& Lahr, 1989).

$O$ valor característico do módulo de resistência à flexão $\left(E_{f}\right)$ não é influenciado pela redução da umidade da madeira, para níveis de umidade abaixo da umidade de equilíbrio. $O$ valor do módulo de resistência à flexão é influenciado pela redução da umidade, abaixo do ponto de saturação das fibras até zero (Tanaami \& Lahr, 1989).

A velocidade de aplicação da carga no ensaio de flexão em peça de madeira, deve atingir uma velocidade de $10 \mathrm{MPa}$ por minuto, não devendo ser concluído em tempo menor que 5 minutos. O corpo de prova deve receber cargas constantes (Lahr \& Mascia, 1986 ; Otto, 1986). Segundo Otto (1996), não houve mudança significativa no módulo de elasticidade à flexão, com o aumento da velocidade de carga, porém ocorre aumento da tensão limite de proporcionalidade e do módulo de ruptura na flexão.

Os valores da densidade refletem nas propriedades de resistência da madeira e na sua rigidez, portanto, como esta propriedade física varia no sentido medula - casca, o módulo de elasticidade acompanha essa variação, sendo também bastante variável nesta direção (Oliveira, 1999).

Nicholson et al. (1972) encontraram uma forte interação na associação das tensões de crescimento com diversas propriedades básicas da madeira de Eucalyptus regnans, como por ex. o módulo de elasticidade.

Muneri et al. (1999) trabalhando com E. cloeziana de 10 anos de idade na Austrália, encontraram uma correlação fraca e positiva entre as tensões de crescimento com o módulo de elasticidade e a resistência à flexão.

Chafe (1981) trabalhando com E. regnans com 39 anos de idade, constatou que as tensões de crescimento, a densidade básica e o módulo de elasticidade, crescem da base para o topo da árvore, concluindo que isto deve-se à diminuição do diâmetro das árvores ao longo da tora. 


\subsubsection{Resistência à tração paralela às fibras $\left(f_{t}\right)$}

A madeira apresenta maior capacidade de resistência quando submetida a esforços de tração (Chahud, 1986a). No ensaio de tração determina-se o limite de resistência da madeira à esforços aplicados na tração paralela às fibras em corpos de prova esbeltos (Brotero, 1945).

Chahud (1986b) sugere que para os ensaios de tração paralela às fibras, deve ser adotado um número mínimo de 32 corpos de prova, obtidos aleatoriamente de pelo menos 3 árvores e com a determinação da umidade dos mesmos no momento do ensaio. A tração paralela às fibras, alem de ser influenciada pela densidade, também sofre influência da umidade (Calori e Kikuti, 1997).

O sistema de ancoragem (ou fixação) dos corpos de prova para o ensaio de tração paralela às fibras na "Máquina Universal de Ensaios" é alertado por Chahud (1986a), devido a observação de um atrito elevado nas superfícies de contato, impedindo a ancoragem adequada dos corpos de prova,

podendo ocasionar alguns problemas como excentricidade na aplicação da carga e escorregamento do corpo de prova. Segundo o autor, este ensaio é o que mais conduz a erros experimentais. 


\section{ESTUDO DE CLONES DE Eucalyptus grandis E Eucalyptus urophylla, VISANDO O MELHORAMENTO GENÉTICO DAS CARACTERISTICAS TECNOLÓGICAS DA MADEIRA}

Resumo

Os vários segmentos do comércio relacionados com a matéria prima madeira, baseiam-se em florestas de rápido crescimento. $\mathrm{O}$ gênero Eucalyptus é um dos mais promissores para a substituição da madeira nativa para diversos propósitos, pela sua grande capacidade de adaptação às diferentes condições ambientais. O grande problema encontrado na sua utilização em serrarias, refere-se a presença marcante da tensão de crescimento existente nas árvores. Realizou-se o presente estudo objetivando a avaliação de caracteres tecnológicos da madeira de 18 clones de Eucalyptus grandis e 15 clones de Eucalyptus urophylla, utilizados como material genético, nos quais foram estudados os defeitos da madeira serrada relacionados com as tensões de crescimento. As avaliações permitiram calcular os componentes de variância $e$ as herdabilidades no sentido amplo, a nível de médias e totais, com os respectivos ganhos de seleção. De acordo com os resultados, ficou difícil conseguir indicar clones com caracteres desejáveis para todos as finalidades. Deve-se estabelecer uma ordem de prioridades, para que posteriormente ocorra a seleção. Para uma intensidade de seleção em torno de $20 \%$, os melhores clones para o Eucalyptus grandis, isto é, os que apresentaram o maior número de características desejáveis foram os 28228, 37611, 24504 e 
28261 e para o Eucalyptus urophylla, os melhores clones foram os 351,39 e o 447.

\section{STUDIES ON CLONES OF Eucalyptus grandis AND Eucalyptus urophylla, AIMING AT THE GENETIC IMPROVMENT OF WOOD TECHNOLOGICAL CHARACTERISTICS}

\section{Summary}

The several commercial segments dealing on wood as raw material rely on fast-growing forests. Eucalyptus is one of the most promising genera for replacing native wood for different purposes, due to its ability to adapt to different environmental conditions. A great problem involving its use in sawmills is related to the remarkable presence of growth stresses in the trees. The purpose of this study was to evaluate the wood technological characters in 18 and 15 clones of Eucalyptus grandis and Eucalyptus urophylla, respectively, by means of studying the sawed timber defects related to growth stress. The evaluations enabled the estimation of variance components and wide sense heritabilities, averages and totals, with their respective selection gains. According to the results, it was difficult to point out clones presenting desirable characteristics for all purposes. A priorities ranking must precede selection. The best Eucalyptus grandis clones, that is, the ones presenting the greatest number of desirable characteristics, considering selection intensity of around $20 \%$, were 28228, 37611, 24504 and 28261, while the best Eucalyptus urophylla clones were 351,39 and 447 . 


\subsection{Introdução}

Apesar de avançadas e dinâmicas as técnicas silviculturais e de produção do gênero Eucalyptus, o grande problema encontrado na sua utilização em serrarias refere-se à presença marcante da tensão de crescimento existente na árvore. As elevadas tensões de crescimento desenvolvem fissuras radiais durante e após 0 abate das árvores, que se agravam drasticamente caso a tora seja deixada sob a ação direta do sol. Isso ocorre devido à interação das tensões de crescimento com as de secagem. $\mathrm{Na}$ operação de desdobro da tora podem ocorrer fendilhamentos e empenamentos nas peças serradas, devido às tensões residuais existentes nas toras e que gradativamente vão sendo liberadas durante o processo de desdobro. Os empenamentos são do tipo encurvamento, arqueamento e encanoamento, mas podem ocorrer interações entre esses tipos, redundando em torções, (Garcia, 1995) que inutilizam grande parte da madeira. Além dos defeitos mencionados, as tensões de crescimento são responsáveis pelo aparecimento das fissuras de compressão nas paredes das fibras mais internas de um tronco de madeira, conhecidas como "brittle heart" (cerne quebradiço), o que reduz drasticamente a resistência mecânica da peça (Lelles \& Silva, 1997; Oliveira, 1999; Malan, 2000), prejudicando o seu uso para finalidades estruturais (Sanches Acosta, 1995; Garcia, 1995).

As tensões de crescimento ocorrem em três direções; longitudinal, radial e transversal (Boyd, 1950a,b). A tensão de crescimento longitudinal acontecem devido ao encurtamento das células periféricas resultante da contração do cristal celulósico nas microfibrilas da camada S2 da parede secundária, onde o ângulo da microfibrila determinará se a célula elongar-se-á (interno) ou encurtar-se-á (externo) (Wilkins, 1986). A redução do comprimento das células periféricas, enquanto são mantidas como células diferenciadas, cria uma força de tensão observada na periferia das árvores 
(Hillis, 1984). As tensões de crescimento transversais são geradas dentro do tecido lenhoso, nas deposições consecutivas das novas camadas de células a partir do câmbio, durante o desenvolvimento da parede secundária e podem ser necessárias para o desenvolvimento da árvore (Boyd, 1950c; 1973; Van Wyk, 1978). As tensões de crescimento radiais, surgem como reação às tensões de crescimento transversais (Boyd, 1950a,b).

O gênero Eucalyptus apresenta uma grande capacidade de adaptação as condições ambientais, destacando-se pelo seu rápido crescimento. Por essa razão, constitui-se num grande potencial para suprir o mercado madereiro, principalmente devido à escassez crescente das madeiras de espécies nativas. $O E$. grandis e o $E$. urophylla são originários das zonas tropicais úmidas e sub-úmidas onde são considerados produtores de madeira de múltiplo uso, utilizadas na indústria de papel e celulose, painéis reconstituídos e, principalmente, na forma sólida. (Ferreira \& Santos, 1997; Pires \& Paula, 1997; López, 1998; Tomaselli, 1998; Nahuz et al., 1999; Oliveira, 1999; Sanches Acosta, 1998, 1999).

Em virtude da possibilidade de utilização da clonagem em escala comercial, as variações entre indivíduos tornam-se muito importantes. Análises de rotina para a caracterização tecnológica de clones, de espécies e híbridos para serraria, têm demonstrado que as variabilidades são extremamente altas para a maioria das características. Isso possibilita a seleção de árvores com propriedades tecnológicas destacadamente superiores em relação à média da população (Assis, 1999).

Segundo Ferreira \& Santos (1997) e Pires \& Paula (1997), as empresas florestais concentram-se na seleção de um número reduzido de clones, visando resultados imediatos em programas de melhoramento genético florestal, com isto, espera-se que cada vez mais ocorra o emprego de madeira juvenil, com os problemas na íntegra de tensões de crescimento.

As variaçōes verificadas ocorrem de forma diferenciada, fazendo com que dificilmente se consiga encontrar grupos de árvores dotadas 
de um número elevado de características desejáveis para todas as finalidades. A união dessas características em grupos de árvores ou em poucos indivíduos, tornam-se muito importantes porque possibilitam a seleção de árvores que tenham a maior quantidade possivel de atributos tecnológicos desejáveis na sua madeira (Assis, 1999). Este é o grande desafio dos programas de melhoramento genético do gênero Eucalyptus.

Diante da perspectiva de busca de novos materiais para suprir as necessidades do mercado madereiro, $O$ presente trabalho objetivou o estudo de propriedades tecnológicas da madeira relacionadas com as tensões de crescimento, fornecendo subsídios para futuros programas de melhoramento florestal direcionados à melhoria da qualidade da madeira para serraria.

\subsection{Material e métodos}

\subsubsection{Material genético selecionado}

Para o presente estudo foram escolhidos 15 clones de $E$. urophylla e 18 clones de $E$. grandis de interesse fenotípico, visando a produção de madeira serrada.

Os clones selecionados como material genético para o presente estudo encontravam-se em três bancos clonais com 8 anos de idade, plantados no espaçamento de $3 \times 2 \mathrm{~m}$, em Bom Despacho (MG) em área de propriedade da CAF Santa Bárbara Ltda., sendo:

- 4 clones de Eucalyptus grandis no banco clonal "Garça";

- 14 clones de Eucalyptus grandis no banco clonal "Zé de Paiva";

- 15 clones de Eucalyptus urophylla, distribuídos nos talhões de $n^{\circ} 4$ e 5 (ocorrendo alguns clones repetidos em ambos os talhões) 
$\mathrm{Na}$ Tabela 4, encontram-se os dados das características climáticas da área florestal de estudo. 0 tipo predominante de solo encontrado nesta área é o latossolo vermelho escuro, com horizonte B textural bem definido.

Tabela 4. Caracterização climática da região de coleta do material de $E$. grandis e E. urophylla.

\begin{tabular}{ll}
\hline Altitude $(\mathrm{m})$ & 720 \\
Latitude Sul $\left({ }^{\circ}\right)$ & $19^{\circ} 44^{\prime}$ \\
Longitude Oeste $\left({ }^{\circ}\right)$ & $45^{\circ} 15^{\prime}$ \\
Precipitação média anual $(\mathrm{mm})$ & 1375 \\
Temperatura média anual $\left({ }^{\circ} \mathrm{C}\right)$ & 23,1 \\
\hline
\end{tabular}

A Tabela 5 mostra os clones selecionados de ambas as espécies, com as suas respectivas identificações de campo.

Foram selecionadas as árvores mais retas, tendo em vista que as tensões de crescimento são maiores em árvores inclinadas (Nicholson et al. , 1975). As árvores da bordadura foram evitadas na tentativa de obteremse árvores com menor influência ambiental. 
Tabela 5. Clones selecionados para o presente estudo e seus códigos de identificação.

\begin{tabular}{cc}
\hline $\begin{array}{c}\text { Eucalyptus grandis } \\
\text { Código de identificação }\end{array}$ & $\begin{array}{c}\text { Eucalyptus urophylla } \\
\text { Código de identificação }\end{array}$ \\
\hline 24504 & 9 \\
27254 & 39 \\
28013 & 95 \\
28228 & 113 \\
28261 & 118 \\
30543 & 203 \\
31510 & 235 \\
31574 & 275 \\
32824 & 320 \\
36366 & 351 \\
36671 & 412 \\
36838 & 440 \\
37592 & 447 \\
37611 & 478 \\
37633 & 601 \\
37753 & \\
42128 & \\
42273 & \\
\hline
\end{tabular}

\subsubsection{Delineamento experimental}

O delineamento adotado foi o inteiramente casualizado com parcelas subdivididas. Dentro de cada clone (parcela), foram selecionadas aleatoriamente 6 árvores com DAP $\geq 15 \mathrm{~cm}$. De cada árvore selecionada foram retiradas 2 toras (subparcelas) consecutivas de 2,5m de comprimento, sendo a primeira, a partir de $15 \mathrm{~cm}$ do nível do solo.

$\mathrm{Na}$ Tabela 6, encontram-se as expressões das esperanças dos quadrados médios, baseadas no modelo matemático dado pela eq. (1). 
Sempre que necessário, os dados foram transformados, visando a normalidade dos mesmos.

$Y_{i j k}=m+C_{i}+e_{i j}+T_{j}+C T_{i j}+e_{i j k}$

Onde:

$\mathbf{Y}_{\mathrm{ijk}}$ é a observação da tora $\mathbf{j}(\mathrm{j}=1,2)$ na árvore $\mathbf{k} \quad(\mathrm{k}=1, \ldots, 6)$ do clone $\mathbf{i}$ (i $=1,2,3, \ldots .15$ ou 18$)$;

m é a média geral, fixa;

$\mathbf{C}_{\mathbf{i}}$ é o efeito clone $\mathbf{i}(\boldsymbol{i}=1,2,3, \ldots .15$ ou 18$)$, aleatório;

$\mathbf{e}_{\mathbf{i j}}$ é o erro experimental associado a tora $\mathbf{j}$, do clone $\mathbf{i}$, aleatório;

$\mathbf{T}_{\mathbf{j}}$ é o efeito tora $\mathbf{j}, \operatorname{com}(\mathrm{j}=1,2)$, fixo;

$\mathrm{CT}_{\mathrm{ij}}$ é o efeito da interação da tora $\mathbf{j}$ com o clone $\mathbf{i}$, aleatório;

$\mathbf{e}_{\mathrm{ijk}}$ é o erro experimental associado com a tora $\mathbf{j}(\mathrm{j}=1,2)$ do indivíduo $\mathbf{k}(\mathrm{k}=$ $1,3, \ldots 6)$, no clone $\mathbf{i}(i=1,2, \ldots .15$ ou 18$)$. .

Tabela 6. Componentes de variância para o delineamento inteiramente casualizado com parcelas subdivididas, com i clones, $\mathbf{k}$ árvores/clone e j toras/árvore.

\begin{tabular}{|c|c|c|}
\hline $\begin{array}{l}\text { Fator de } \\
\text { variação }\end{array}$ & G.L. & $E(Q M)$ \\
\hline Clone $\left(C_{i}\right)$ & $(I-1)$ & $\sigma_{e}^{2}+J \sigma_{a}^{2}+k \sigma_{c t}^{2}+j k \sigma_{c}^{2}=Q_{5}$ \\
\hline Erro a $\left(e_{i j}\right)$ & $I(J-1)$ & $\sigma_{e}^{2}+J \sigma_{a}^{2}=Q_{4}$ \\
\hline Total a & $\mid \mathrm{J}-1$ & \\
\hline Tora $\left(T_{j}\right)$ & $(\mathrm{J}-1)$ & $\sigma_{\mathrm{e}}^{2}+k \sigma_{c t}^{2}+\Phi_{T}^{2}=Q_{3}$ \\
\hline $\mathrm{C}_{\mathrm{i}} \times \mathrm{T}_{\mathrm{j}}$ & $(I-1)(J-1)$ & $\sigma_{e}^{2}+k \sigma_{c t}^{2}=Q_{2}$ \\
\hline Erro e $\left(e_{i j k}\right)$ & $\mathrm{I}(\mathrm{J}-1)(\mathrm{K}-1)$ & $\sigma_{e}^{2}=Q_{1}$ \\
\hline Subtotal b & $\mathrm{IJ}(\mathrm{K}-1)$ & \\
\hline Total & IJK -1 & \\
\hline
\end{tabular}


Em que:

$\sigma^{2}{ }_{c}=$ Estimativa da variância genética entre clones;

$\Phi^{2}{ }_{T}=$ Componente quadrático, variância das toras (posições) ;

$\sigma_{c t}^{2}=$ Estimativa da variância da interação entre clones e toras dentro de clones;

$\sigma_{\text {eij }}^{2}$ Estimativa da variância do erro a devido a interação entre clones " $i$ " e árvores "k";

$\sigma^{2}{ }_{\text {eijk }}=$ Estimativa da variância do erro e devido a interação da tora "j" na árvore "k" do clone "i".

As estimativas dos componentes de variância foram obtidos através do método dos momentos descritos por Vencovsky \& Barriga (1992), da análise de variância (Tabela 6), de acordo com o modelo matemático da eq. 1. O procedimento da avaliação consiste em obterem-se os Quadrados Médios (QM) da análise da variância, estabelecermos a esperança matemática deste $\mathrm{QM}$, de acordo com o modelo que rege o delineamento e finalmente resolvermos as equações resultantes, que fornecem todas as estimativas dos componentes da variação.

O coeficiente de herdabilidade foi calculado no sentido amplo, por se tratar de um teste clonal. As herdabilidades no sentido amplo, a nivel de médias e totais foram calculadas através das expressões matemáticas (2) e (3), respectivamente.

$$
\begin{aligned}
& h_{m}^{2}=\frac{\sigma_{C}^{2}}{\sigma_{C}^{2}+\sigma_{C * T}^{2} / J+\sigma_{a}^{2} / K+\sigma_{e}^{2} / J K} \\
& h_{t}^{2}=\frac{\sigma_{C}^{2}}{\sigma_{C}^{2}+\sigma_{C{ }^{*} T}^{2}+\sigma_{a}^{2}+\sigma_{e}^{2}}
\end{aligned}
$$


As estimativas dos intervalos de confiança associados aos coeficientes de herdabilidade para as médias dos clones foram calculados de acordo com a expressão utilizada por Lima Neto (1998), dado pela eq. 4.

$$
I C=P\left\{1-\frac{1}{\left(\frac{Q M_{C}}{Q M_{C^{* T} T}}\right) F_{(0,975): G L_{C} ; G L_{C \cdot T}}} \leq h_{m}^{2} \leq 1-\frac{1}{\left(\frac{Q M_{C}}{Q M_{C^{* T} T}}\right) F_{(0,025): G L_{C} ; G L_{C \cdot T}}}\right\}=0,95
$$

Em que:

$\mathrm{QM}_{\mathrm{C}}=$ Quadrado Médio dos clones;

$\mathrm{QM}_{\mathrm{C}^{*} \mathrm{~T}}=$ Quadrado Médio da interação dos clones com as toras;

$\mathrm{GL}_{\mathrm{C}}=$ Graus de Liberdade dos clones;

$\mathrm{GL}_{\mathrm{C}^{*} \mathrm{~T}}=$ Graus de Liberdade da interação dos clones com as toras ;

$F(\alpha)=$ valor $F$ tabelado para probabilidade desejada em $\alpha$.

$\mathrm{Na}$ obtenção dos ganhos genéticos para cada uma das variáveis avaliadas, foi utilizada a expressão matemática 5 .

$$
\Delta \mathrm{G}=\mathrm{ds} \times \mathrm{h}^{2}
$$

Onde:

$\Delta G=$ ganho genético; $h^{2}=$ herdabilidade no sentido amplo; e ds = diferencial de seleção, dado por $X_{s}-X_{0}$.

Em que: $X_{s}=$ média dos valores selecionados; e $X_{0}=$ média geral dos dados observados;

No caso do $E$. urophylla foram selecionadas os três melhores clones dos 15 selecionados, resultando em uma intensidade de 
seleção de $20 \%$. Para o E. grandis foram selecionados os 4 melhores clones dentre os 18 , perfazendo uma intensidade de seleção de $22,22 \%$.

\subsubsection{Caracteres avaliados}

Este estudo baseou-se em metodologias que levassem a obtenção de bons indicadores, visando fornecer subsídios para programas de melhoramento florestal direcionados à melhoria da qualidade da madeira serrada.

Os caracteres avaliados, na ordem de obtenção foram:

- Conicidade da tora (Coni);

- Rachadura de extremidade de tora (RT);

- Rachadura de extremidade da prancha diametral (RPD);

- Rendimento em madeira serrada (RMS) ;

- Flecha da costaneira (FC);

- Flecha da vigota obtida da costaneira (FV);

- Densidade básica $\left(D_{b}\right)$;

- Resistência ao cisalhamento radial $\left(f_{\mathrm{sr}}\right)$;

- Resistência ao cisalhamento tangencial $\left(\mathrm{f}_{\mathrm{st}}\right)$;

- Resistência à compressão paralela às fibras $\left(f_{c}\right)$;

- Módulo de elasticidade na flexão $\left(E_{f}\right)$;

- Resistência a flexão estática $\left(f_{f}\right)$;

- Resistência à tração paralela às fibras $\left(f_{t}\right)$.

As toras obtidas das árvores selecionadas foram transportadas para a serraria do Departamento de Ciências Florestais da ESALQ/USP - Piracicaba, onde foram imediatamente desdobradas, propiciando as primeiras medições das variáveis selecionadas. Ainda na condição veride, 
foram obtidos os dados necessários para o cálculo das seguintes variáveis: Coni, RT, RPD, RMS e por fim, as flechas das costaneiras 1 e 2 (FC1 e FC2), a média entre essas duas $(\mathrm{FCm})$, as flechas das vigotas das respectivas costaneiras (FV1 e FV2), e também a média entre as duas vigotas (FVm).

O desdobro foi efetuado em serra de fita simples, com volante de $1100 \mathrm{~mm}$ de diâmetro, carro porta tora tipo pesado, velocidade de avanço de aproximadamente $7 \mathrm{~m} /$ minuto, espessura do friso de corte de $3,0 \mathrm{~mm}$, largura e comprimento da lâmina de $12,5 \mathrm{~cm}$ e $7,5 \mathrm{~m}$, respectivamente. As Figuras 4 e 5 mostram respectivamente, o início do desdobro da tora em serra de fita simples e a tora remanescente após a retirada da primeira costaneira. 


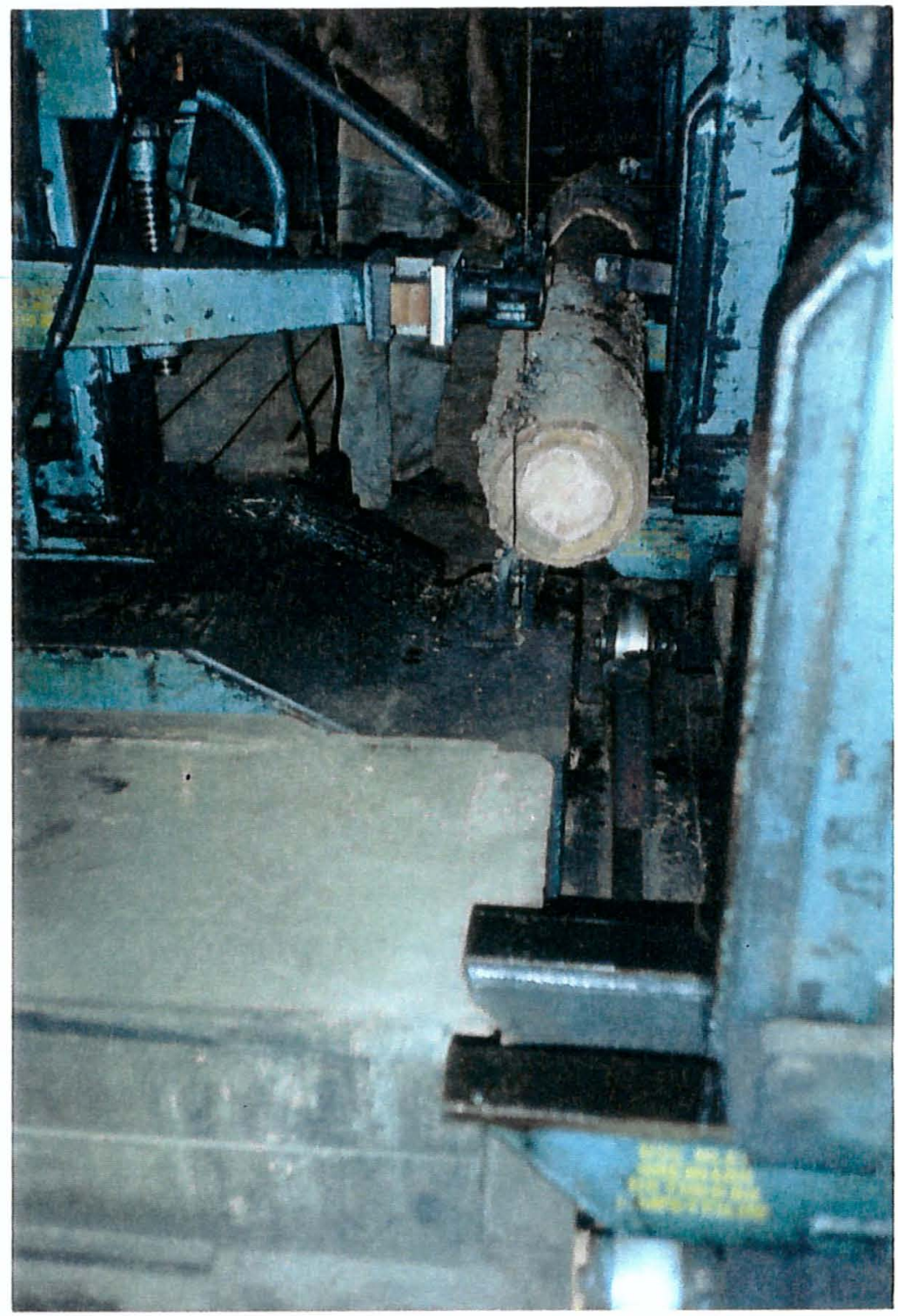

Figura 4 - Início do desdobro da tora em serra de fita simples, para a retirada da primeira costaneira . 


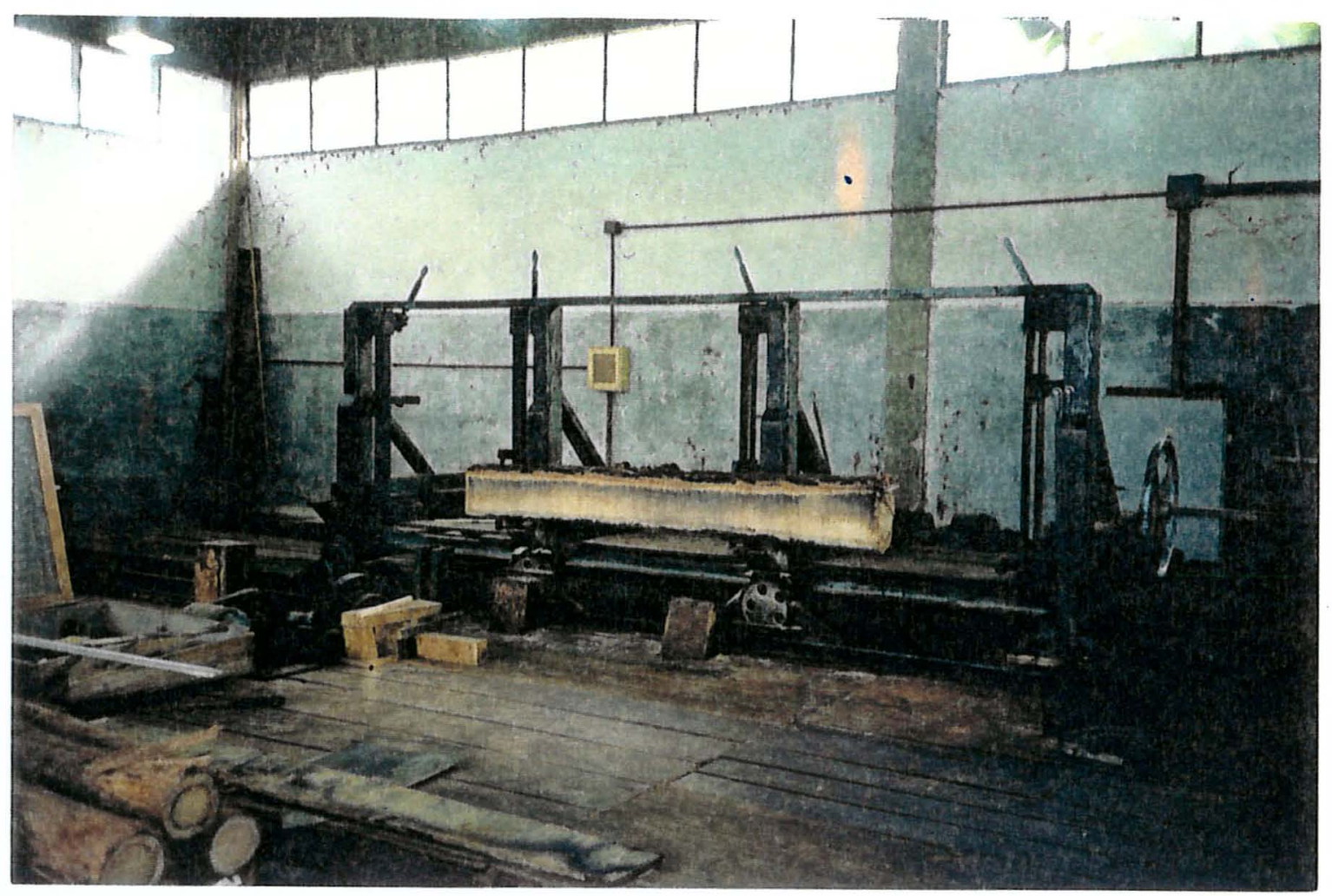

Figura 5 - Tora remanescente, no carro porta tora, após a retirada da primeira costaneira.

\subsubsection{Conicidade (Coni)}

A variável conicidade foi incluída neste estudo por se tratar de uma variável de interesse emergente e cuja medição pode ser efetivada ainda no campo. As árvores menos cônicas podem fornecer um melhor aproveitamento na linha de desdobro das toras.

A conicidade foi calculada pela diferença dos diâmetros maior e menor $(\mathrm{em} \mathrm{cm}$ ) e dividido pelo comprimento total da tora (em metros). 
Estes dados foram transformados para $1 / \sqrt{X+1}$ na análise estatística dos mesmos.

\subsubsection{Rendimento em madeira serrada (RMS) e rachadura de extremidade de tora (RT)}

O valor de rendimento em madeira serrada foi obtido através da divisão do volume das peças serradas, pelo volume total da tora antes de ser desdobrada. Para a análise estatística os valores foram transformados para $\sqrt{X+1}$.

A metodologia empregada para a avaliação da rachadura de extremidade de tora (RT) foi a medição da largura da maior abertura da rachadura observadas em ambas as extremidades de cada tora, utilizando-se um paquímetro digital com leitura em milimetros, com precisão de $0,01 \mathrm{~mm}$. Para os cálculos estatísticos, somente foi utilizada a mensuração de maior valor numérico da rachadura de topo, não se levando em conta a posição de extremidade da tora (base ou topo), perfazendo assim uma medição/tora. Os dados obtidos foram transformado para $1 / \sqrt{X+1}$.

\subsubsection{Rachadura de extremidade da prancha diametral (RPD)}

As medidas das rachaduras de extremidade da peça serrada foram efetuadas somente na prancha diametral que continham a medula. Foi medido a abertura da rachadura das duas extremidades da tábua, transversalmente ao eixo da prancha, utilizando-se um paquímetro digital com leitura em milímetros, com precisão de $0,01 \mathrm{~mm}$. O valor analisado foi a média aritmética da abertura $(\mathrm{em} \mathrm{cm}$ ) das duas extremidades da prancha, perfazendo assim um valor para cada prancha e consequentemente, um para cada tora. Os dados observados foram transformados para $1 / \sqrt{X}$. 


\subsubsection{Flecha da costaneira (FC) e flecha da vigota (FV) obtida da costaneira}

A flecha tende a aumentar com o aumento da distância da peça serrada em relação à medula, proporcionalmente ao alívio das tensões residuais. Portanto, nas peças próximas à medula ocorrem as maiores tensões residuais.

Desta forma, foram medidas apenas as flechas da primeira e segunda costaneiras retiradas das toras por serem essas as peças mais distantes da medula.

Uma régua de alumínio, leve mas de grande rigidez, foi encostada na face serrada da costaneira e eqüidistante de suas bordas. Como esta face encontrava-se convexa, mediram-se os afastamentos das extremidades da costaneira $(\mathrm{em} \mathrm{cm}$ ) em relação a régua que definia a posição original não deformada. Os dois valores obtidos foram somados e divididos por dois, evitando-se o erro de inclinação da régua no plano perpendicular à face serrada.

Portanto, para cada tora da árvore, foram obtidos 2 valores de flecha, sendo uma proveniente da primeira costaneira (FC1) e outra da segunda costaneira (FC2) . Na Figura 6, pode-se observar a realização desta medição. Para os cálculos estatísticos, utilizaram-se os valores individuais das flechas das costaneiras (FC1 e FC2), bem como a média (FCm) das duas. 


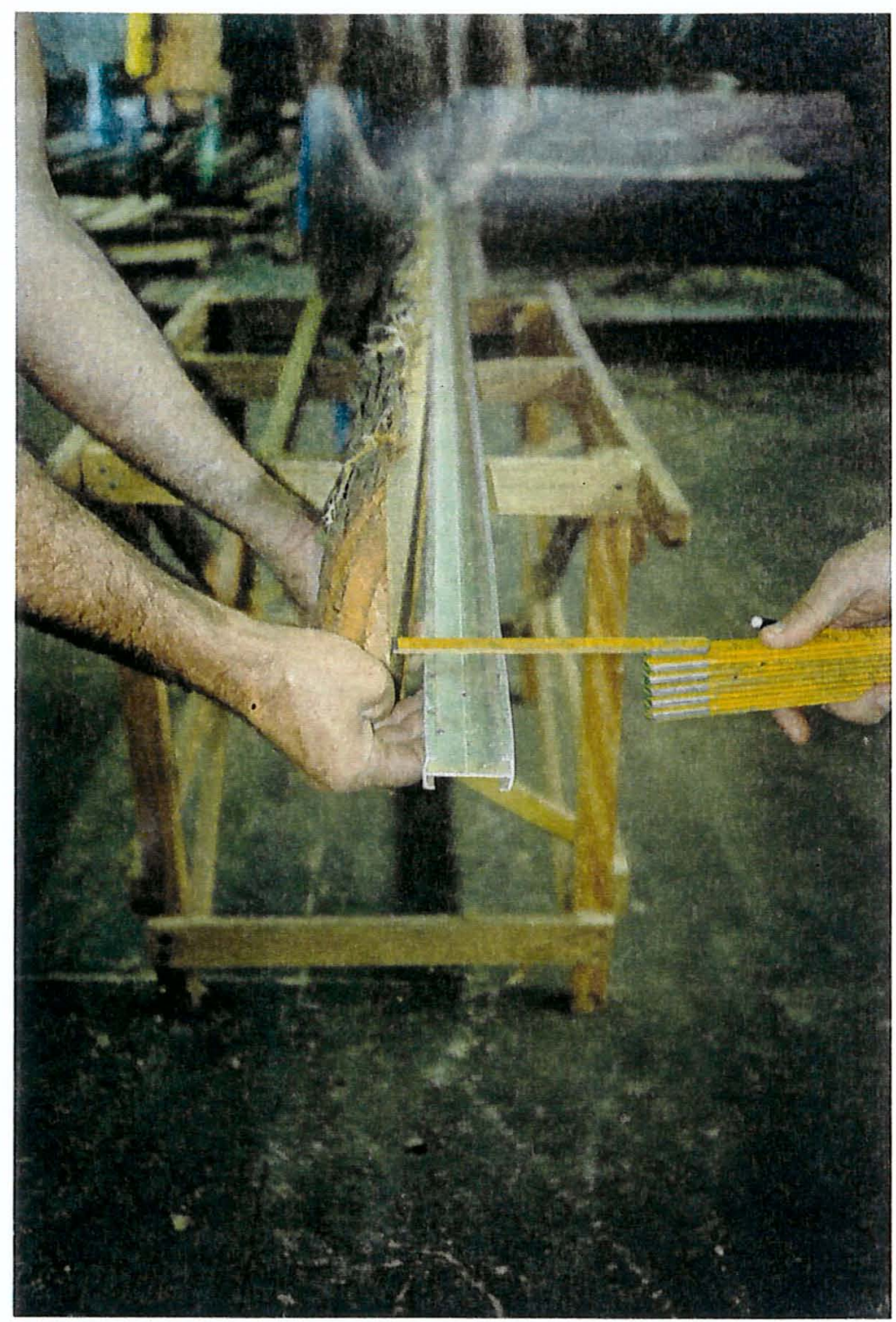

Figura 6 - Medição da flecha da costaneira em relação a uma referência indeformável. 
A flecha da vigota foi medida segundo o mesmo procedimento utilizado para a medição da flecha da costaneira. Obteve-se os valores das vigotas 1 e 2 (FV1 e FV2), retiradas das respectivas costaneiras, e a média entre as vigotas $(\mathrm{FVm})$. O material da vigota 1 foi posteriormente usado para a retirada dos corpos de prova para os demais ensaios, que foram todos realizados no laboratório de Engenharia da Madeira da ESALQ/USP. A Figura 7 mostra o procedimento de medição da flecha da vigota.

Os dados das flechas das costaneiras e vigotas foram transformados para :

E. grandis: $\mathrm{FCm}(1 / \mathrm{X}) ; \mathrm{FC} 1(1 /(\mathrm{X}+1)) ; \mathrm{FC} 2(\log \sqrt{X+1}) ; \mathrm{FVm}(1 / \sqrt{X+1})$; $F V 1(1 /(X+1))$ e FV2 $(\log X)$.

E. urophylla: $\mathrm{FCm}(\sqrt{X+1}) ; \mathrm{FC} 1(\sqrt{X})$ e $\mathrm{FC} 2(\log X)$. 


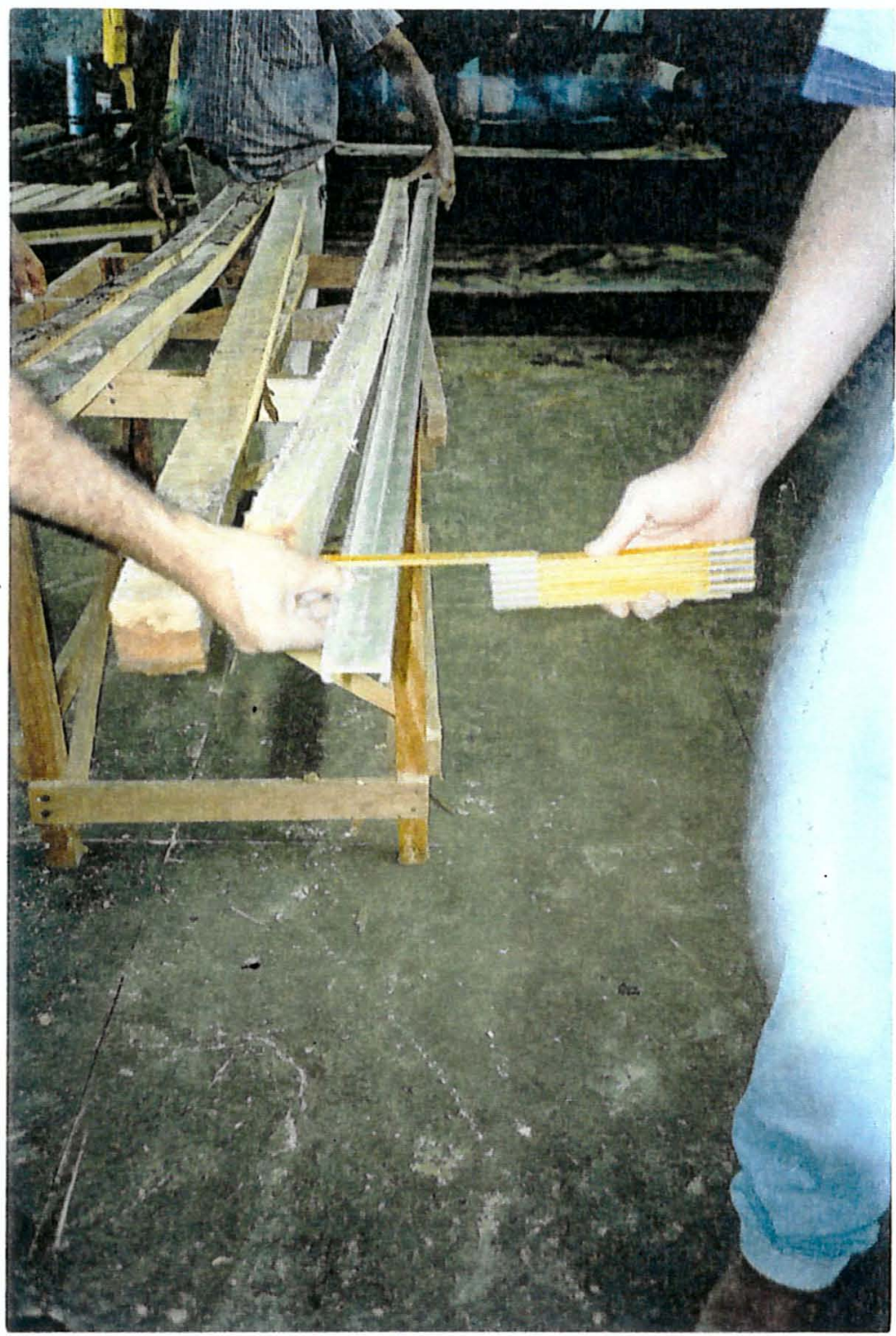

Figura 7 - Medição da flecha da vigota obtida da costaneira. 


\subsubsection{Densidade básica}

O corpo de prova para a determinação da densidade foi o primeiro a ser retirado da vigota 1, com o auxílio de máquinas de marcenaria (serra de fita e circular), numa dimensão de $2 \times 2 \times 3 \mathrm{~cm}$. Cada tora forneceu apenas um corpo de prova, totalizando portanto, 2 medições por árvore selecionada. A densidade básica foi determinada através do método da balança hidrostática descrito por Souza et al. (1986). Não houve a necessidade de transformação dos dados para as análises estatísticas.

\subsubsection{Resistência ao cisalhamento radial $\left(f_{s r}\right)$ e tangencial $\left(f_{s t}\right)$}

Foram retirados dois corpos de prova para a determinação da resistência ao cisalhamento, uma para a determinação da resistência ao cisalhamento na direção radial $\left(\mathbf{f}_{\mathrm{sr}}\right)$ e outra para a tangencial $\left(\boldsymbol{f}_{\mathrm{st}}\right)$ totalizando 4 medidas por árvore selecionada. Os corpos de prova utilizados neste ensaio, encontram-se esquematizados nas Figuras $8 \mathrm{a}$ e $8 \mathrm{~b}$.

A carga, em Newton ( $N$ ), sobre o corpo de prova foi aplicada a uma velocidade constante, evitando-se a influência de impacto e também de cargas de excessiva duração.

O objetivo de se ensaiar tanto no sentido radial como no tangencial está no fato de que na prática, a maioria das peças serradas apresentam orientações intermediárias. Assim, através desta separação, obtiveram-se os valores para as duas situações extremas. Não houve a necessidade de transformação dos dados para as análises estatísticas.

A resistência ao cisalhamento, tanto radial quanto tangencial foi calculada pela eq. (6). 


$$
\mathrm{fs}=\frac{\mathrm{P}_{\mathrm{r}}}{\mathrm{l}_{1} \times 1_{2}}
$$

Onde:

$f_{\mathrm{s}}=$ Limite de resistência ao cisalhamento $\left(\mathrm{daN} / \mathrm{cm}^{2}\right)$;

$\mathrm{P}_{\mathrm{r}}=$ Carga de ruptura em (daN);

$l_{1}$ e $l_{2}=$ Medidas do corpo de prova $(\mathrm{cm})$;

$1_{1} \times 1_{2}=$ Área cisalhada $\left(\mathrm{cm}^{2}\right)$.

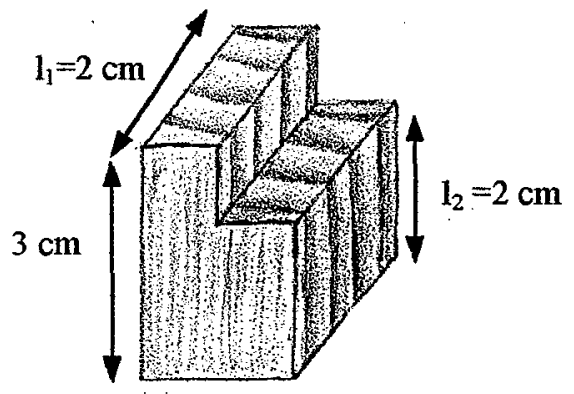

(a)

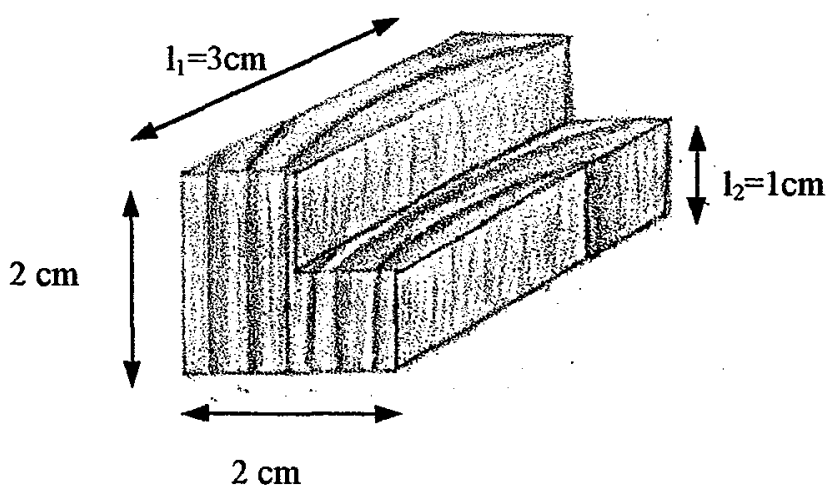

(b)

Figura 8 - Corpos de prova utilizados na determinação da resistência ao cisalhamento radial (a) e tangencial (b). 


\subsubsection{Resistência à compressão paralela às fibras $\left(f_{c}\right)$}

O ensaio consistiu na aplicação de cargas crescentes de compressão até levar o corpo de prova à ruptura. A aplicação da carga foi feita através de uma máquina universal de ensaio, provida de uma articulação conveniente em um de seus dois pratos.

Os corpos de prova possuíam as dimensões $2 \times 2 \times 3 \mathrm{~cm}$, sendo retirado somente uma amostra por tora, totalizando 2 ensaios por árvore selecionada. Não houve a necessidade de transformação dos dados para a análise estatística.

Como a umidade influência a resistência da madeira, houve a necessidade de determinar a umidade dos corpos de prova imediatamente antes da execução dos ensaios mecânicos.

A resistência à compressão paralela à fibras foi calculada pela eq. (7).

$$
\mathrm{fc}=\frac{\mathrm{P}_{\mathrm{r}}}{\mathrm{l}_{1} \times 1_{2}}
$$

Onde:

$\mathrm{f}_{\mathrm{c}}=$ Limite de resistência a compressão $\left(\mathrm{daN} / \mathrm{cm}^{2}\right)$;

$\mathrm{P}_{\mathrm{r}}=$ Carga de ruptura em (daN);

$l_{1}$ e $l_{2}=$ Medidas dos lados da base do corpo de prova $(\mathrm{cm})$;

$1_{1} \times l_{2}=$ Área da base comprimida $\left(\mathrm{cm}^{2}\right)$. 


\subsubsection{Resistência à flexão estática $\left(f_{i}\right)$ e módulo de elasticidade na flexão estática $\left(E_{i}\right)$}

Estas variáveis foram obtidas simultaneamente em um único ensaio utilizando-se o mesmo corpo de prova para a obtenção desses valores, sendo que suas dimensões foram $2 \times 2 \times 80 \mathrm{~cm}(\mathrm{~b} \times \mathrm{h} \times \mathrm{c})$. $\mathrm{O}$ ensaio baseou-se na metodologia descrita por Brotero (1945), que consistiu na aplicação de uma carga concentrada na seção média do corpo de prova, apoiado nas extremidades, e portanto sujeito à flexão (Figura 9). A carga era aumentada gradativamente, medindo-se, a cada acréscimo de 5 daN, a flecha correspondente através de um relógio digital com precisão $0,01 \mathrm{~mm}$. $\mathrm{O}$ ensaio prosseguia até a ruptura do corpo de prova. A carga foi aplicada tangencialmente aos anéis de crescimento. Os apoios extremos são cutelos de aço, de forma cilíndrica de $1,5 \mathrm{~cm}$ de raio e o cutelo central possui o mesmo formato e dimensões daqueles dos apoios. O vão (L) utilizado para se processar a flexão foi de $60 \mathrm{~cm}$. A velocidade de aplicação da carga foi constante e o tempo mínimo até a ruptura foi de aproximadamente 20 minutos.

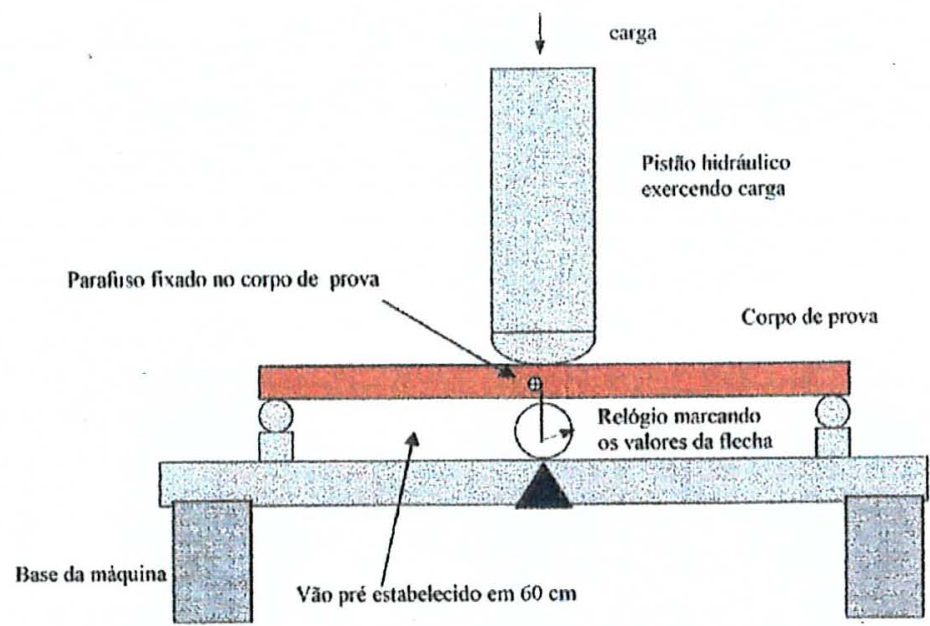

Figura 9 - Esquema do ensaio de flexão estática para obtenção da resistência à flexão $\left(\mathrm{f}_{\mathrm{f}}\right)$ e do módulo de elasticidade na flexão $\left(\mathrm{E}_{\mathrm{f}}\right)$. 
A eq. (8) da norma Brasileira NBR(6230), fornece diretamente o valor da resistência à flexão estática em daN/ $/ \mathrm{cm}^{2}$. Para a obtenção dos valores de "b" e " $h$ ", utilizou-se um paquímetro digital com precisão de 0,01 milímetro.

$$
f_{f}=\frac{3 \times P_{r} \times L}{2 \times b \times h^{2}}
$$

em que:

$f_{f}=$ Resistência à flexão estática $\left(\right.$ daN $\left./ \mathrm{cm}^{2}\right)$;

$P r=$ Carga aplicada no instante da ruptura (daN);

$L=$ Vão da viga biapoiada $(\mathrm{cm})$;

$b=$ Base de seção transversal do corpo de prova $(\mathrm{cm})$;

$h=$ Altura de seção transversal do corpo de prova $(\mathrm{cm})$.

De posse dos valores encontrados plotou-se o diagrama carga-flecha para cada um dos corpos de prova ensaiados, ajustando-se uma regressão linear expressa através da eq. 9 , no trecho considerado elástico. Posteriormente, através da eq. 10 obteve-se o valor do módulo de elasticidade na flexão estática para o mesmo corpo de prova.

$P=A+B . f$

Em que:

$P=$ Carga aplicada $($ daN $)$;

$A=$ Coeficiente linear da reta (intersecção com o eixo $Y$ );

$\mathrm{B}=$ Coeficiente angular da reta;

$f=$ Valores do deslizamento vertical do ponto central do corpo de prova (daN/cm). 


$$
E_{f}=\frac{B \times L^{3}}{4 \times b \times h^{3}}
$$

Onde :

$E_{f}=$ Módulo de elasticidade na flexão estática $\left(\mathrm{daN} / \mathrm{cm}^{2}\right)$;

$B=$ coeficiente angular da reta encontrada através da regressão linear da eq. 9;

$L, b$ e $h=$ os mesmo valores da eq. 8 , para o comprimento, base e altura, respectivamente.

\subsubsection{Resistência à tração paralela às fibras $\left(f_{t}\right)$}

O ensaio de tração paralela as fibras foi baseado na mesma metodologia utilizada por Chahud (1986b) onde determina-se o limite de resistência da madeira na tração paralela às fibras, fixando-se o corpo de prova de formato esbelto, mostrado na Figura 10, aumentando-se gradativamente a carga "P" de tração até leva-lo à ruptura. $O$ valor da resistência à tração foi obtido pela eq. 11.

$$
f_{f}=\frac{P_{r}}{b \times h}
$$

Em que:

Pr é a carga de ruptura na tração e "b" e " $\mathrm{h}$ " as dimensões transversais tomadas na provável posição de ruptura.

As dimensōes dos corpos de prova utilizados neste ensaio estão de acordo com a BSI "British Standard Institution", propriedades físicas e 
mecânicas da madeira, onde apresenta a norma BS 373 para os ensaios de pequenos corpos de prova de madeira, isentos de defeitos. A "BSI" recomenda que os valores de "b" e " $h$ " sejam de 6 e 3 milimetros, respectivamente (Otto, 1986).

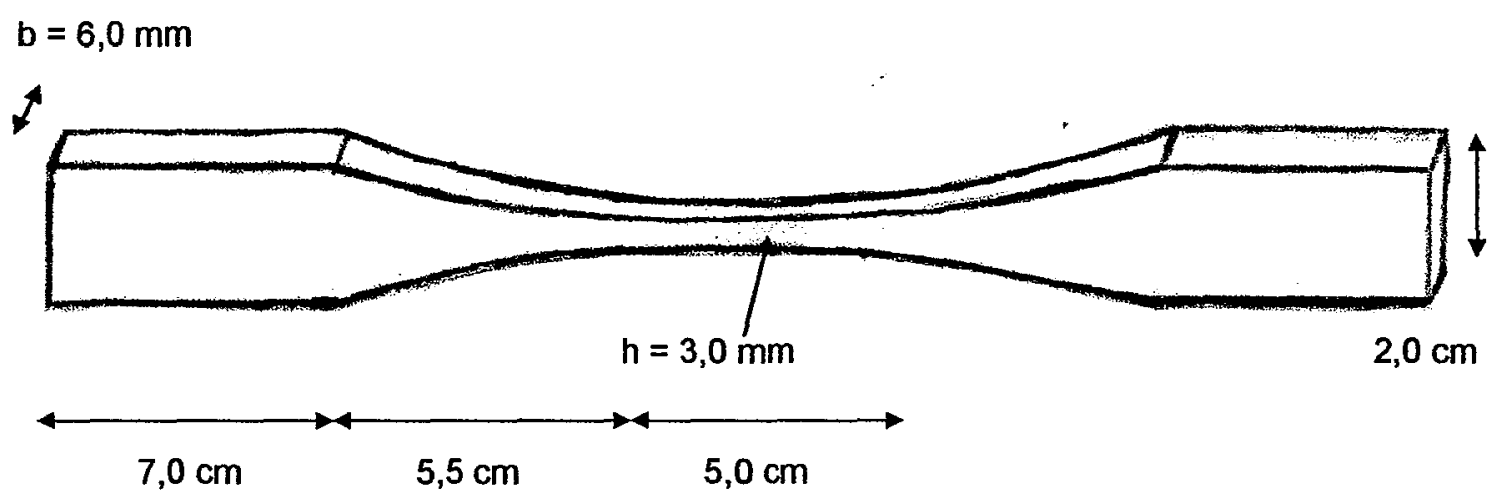

Figura 10 - Corpo de prova adotado no ensaio de tração paralela às fibras, especificado pela norma Britânica "BSI"

Esta dimensão foi adotada devido à baixa capacidade da Máquina Universal de Ensaio ( 6 toneladas) do laboratório de Engenharia da Madeira ESALQ/USP e também para evitar rupturas complexas como aquelas que normalmente ocorre em corpos de prova de dimensões maiores, inclusive naqueles recomendados pela ABNT (Associação Brasileira de Normas Técnicas). $O$ interesse foi $O$ de desenvolver um padrão de ensaio para possibilitar uma avaliação relativa dos clones. 


\subsection{Resultados e discussão}

Os valores de umidade da madeira, determinados previamente à execução dos ensaios laboratoriais, mostraram-se homogêneos e não interferiram nos resultados dos ensaios referentes às resistências da madeira dos clones. A média foi de $12,20 \%$ para ambas as espécies. Como a umidade influencia nas propriedades mecânicas, houve a necessidade de sua determinação e averiguação de sua estabilização no ponto de equilíbrio do ar (no intervalo de 10 a $15 \%$ para Piracicaba - SP).

A influência da umidade na resistência da madeira à compressão paralela às fibras é de grande importância. Entretanto é muito freqüente o emprego de madeira verde no momento da montagem da estrutura. Com a conseqüente redução da umidade, alteram-se as propriedades e dimensões da madeira exigindo, muitas vezes, a reavaliação do conjunto estrutural (Lahr, 1990).

$\mathrm{Na}$ Tabela 7, encontram-se as médias de todas a variáveis ensaiadas, com a amplitude de variação (valores máximos e mínimos dos dados coletados) para ambas as espécies. Pode-se observar que os valores encontrados estão suportados por diversas referências consultadas (Ferreira \& Kageyama,1978; Chahud, 1986b; Chahud \& Lahr,1989; Lahr,1990; Nielsen,1998; Schacht et al., 1998 e Assis, 1999).

Comparando os resultados médios da Tabela 7 , pode-se observar valores métricos superiores do Eucalyptus urophylla em relação as características ensaiadas em laboratório, onde para o E. grandis, os melhores resultados foram observados em relação aos ensaios de desdobro das toras na serraria.

A espécie $E$. urophylla apresentou-se, em média, menos cônica do que o E. grandis, mas mesmo assim o seu rendimento em madeira serrada (RMS) foi inferior. Segundo Mello(1978), a conicidade só influencia o 
RMS quando o seu valor for igual ou maior que um. Para Balooni \& Simões (1980) a conicidade pode influenciar no rendimento em madeira serrada, mas não necessariamente é influenciada devido a fatores ambientais.

$\mathrm{Na}$ análise dos dados, obtiveram-se as melhores médias e as estimativas das médias dos melhores clones, baseadas nas intensidades de seleção estabelecidas, objetivando os cálculos dos diferenciais de seleção para cada uma das variáveis em estudo. As médias dos clones, para cada variável, foram comparadas pelo teste de Duncan a $5 \%$ de probabilidade e os resultados encontram-se na Tabela 8.

Tabela 7. Valores médios e amplitude de variação (valores máximo e mínimo), de todas as variáveis estudadas.

\begin{tabular}{|c|c|c|c|c|c|c|}
\hline \multirow[t]{2}{*}{ Variável } & \multicolumn{3}{|c|}{$\begin{array}{c}\text { Eucalyptus grandis } \\
\text { Amplitude }\end{array}$} & \multicolumn{3}{|c|}{$\begin{array}{r}\text { Eucalyptus urophylla } \\
\text { Amplitude }\end{array}$} \\
\hline & Média & Mínimo & Máximo & Média & Mínimo & Máximo \\
\hline Coni $(\mathrm{cm} / \mathrm{m})$ & 0,85 & 0 & 3,03 & 0,64 & 0 & 3,15 \\
\hline $\mathrm{RPD}(\mathrm{cm})$ & 0,9 & 0 & 11,65 & 1,44 & 0 & 13,1 \\
\hline $\mathrm{RT}(\mathrm{cm})$ & 1,77 & 1,0 & 7,0 & 2,33 & 1,0 & 8,0 \\
\hline RMS & 0,28 & 0 & 0,61 & 0,27 & 0 & 0,5 \\
\hline $\mathrm{FCm}(\mathrm{cm})$ & 1,49 & 0,42 & 3,27 & 2,38 & 0,8 & 3,95 \\
\hline $\mathrm{FC} 1(\mathrm{~cm})$ & 1,82 & 0,7 & 4,8 & 2,647 & 1,0 & 4,85 \\
\hline $\mathrm{FC} 2(\mathrm{~cm})$ & 1,15 & 0 & 3,4 & 2,12 & 0 & 5,25 \\
\hline $\mathrm{FVm}(\mathrm{cm})$ & 2,3 & 0,8 & 4,65 & 3,29 & 1,6 & 5,25 \\
\hline FV1 $(\mathrm{cm})$ & 2,72 & 1,05 & 6,85 & 3,6 & 0 & 6,55 \\
\hline $\mathrm{FV} 2(\mathrm{~cm})$ & 1,89 & 0 & 5,65 & 2,88 & 0 & 5,75 \\
\hline $\mathrm{Db}\left(\mathrm{g} / \mathrm{cm}^{3}\right)$ & 0,35 & 0,12 & 0,57 & 0,38 & 0,27 & 0,59 \\
\hline $\mathrm{f}_{\mathrm{sr}}\left(\mathrm{daN} / \mathrm{cm}^{2}\right)$ & 68,32 & 28,9 & 94,82 & 69,63 & 44,11 & 88,08 \\
\hline $\mathrm{f}_{\mathrm{st}}\left(\mathrm{daN} / \mathrm{cm}^{2}\right)$ & 78,88 & 29,96 & 109,86 & 80,81 & 32,81 & 107,76 \\
\hline$f_{c}\left(d a N / c^{2}\right)$ & 572,17 & 370,78 & 799,08 & 595,12 & 321,76 & 752,87 \\
\hline$f_{f}\left(d a N / c^{2}\right)$ & 1276,3 & 589,43 & 1946,76 & 1376,4 & 731,69 & 2079,34 \\
\hline $\mathrm{E}_{\mathrm{f}}\left(\mathrm{daN} / \mathrm{cm}^{2}\right)$ & 198547 & 83670,6 & 639579 & 215464 & 150270,9 & 335352 \\
\hline$f_{f}\left(d a N / c^{2}\right)$ & 1531,9 & 348,35 & 3018,69 & 2021 & 470,71 & 3473,37 \\
\hline
\end{tabular}


Tabela 8. Melhores médias e as médias estimadas, juntamente com o resultado do teste de Duncan (5\%).

\begin{tabular}{|c|c|c|c|c|c|c|c|}
\hline \multirow[t]{2}{*}{$\begin{array}{l}\text { Variável } \\
\text { Transf. }\end{array}$} & \multicolumn{3}{|c|}{$\begin{array}{l}\text { Eucalyptus grandis } \\
\text { com } \mathrm{i}=22,22 \%\end{array}$} & \multirow[t]{2}{*}{$\begin{array}{l}\text { Variável } \\
\text { Transf. }\end{array}$} & \multicolumn{3}{|c|}{$\begin{array}{l}\text { Eucalyptus urophylla } \\
\text { com i }=20 \%\end{array}$} \\
\hline & Médias & $\begin{array}{c}\text { Média } \\
\text { estimada }\end{array}$ & $\begin{array}{c}\text { Melhores } \\
\text { Clones }\end{array}$ & & Médias & $\begin{array}{c}\text { Média } \\
\text { estimada }\end{array}$ & $\begin{array}{c}\text { Melhores } \\
\text { Clones }\end{array}$ \\
\hline $\begin{array}{l}\text { Coni } \\
\mathrm{cm} / \mathrm{m} \\
1 / \sqrt{X+1}\end{array}$ & $\begin{array}{l}0,81 \\
0,81 \\
0,81 \\
0,81\end{array}$ & 0,81 & $\begin{array}{l}37592 \mathrm{a} \\
37753 \mathrm{a} \\
28228 \mathrm{a} \\
37633 \mathrm{a}\end{array}$ & $\begin{array}{l}\text { Coni } \\
\mathrm{cm} / \mathrm{m} \\
1 / \sqrt{X+1}\end{array}$ & $\begin{array}{l}0,84 \\
0,83 \\
0,83\end{array}$ & 0,833 & $\begin{array}{l}351 a \\
203 a b \\
95 a b\end{array}$ \\
\hline $\begin{array}{l}\text { RMS } \\
\sqrt{X+1}\end{array}$ & $\begin{array}{l}1,17 \\
1,16 \\
1,15 \\
1,15\end{array}$ & 1,16 & $\begin{array}{l}24504 a \\
27254 a \\
28228 a b \\
36671 a b\end{array}$ & $\begin{array}{l}\text { RMS } \\
\qquad \sqrt{X+1}\end{array}$ & $\begin{array}{l}1,16 \\
1,15 \\
1,15\end{array}$ & 1,158 & $\begin{array}{l}118 a \\
39 a b \\
9 a b c\end{array}$ \\
\hline $\begin{array}{l}\text { RT } \\
\text { cm } \\
1 / \sqrt{X}\end{array}$ & $\begin{array}{l}0,97 \\
0,95 \\
0,92 \\
0,90\end{array}$ & 0,935 & $\begin{array}{l}37633 a \\
28228 a b \\
37592 a b c \\
36366 a b c\end{array}$ & $\begin{array}{l}\mathrm{RT} \\
\mathrm{cm} \\
1 / \sqrt{X+1}\end{array}$ & $\begin{array}{l}0,639 \\
0,636 \\
0,632\end{array}$ & 0,635 & $\begin{array}{l}39 a \\
235 a b \\
412 a b\end{array}$ \\
\hline $\begin{array}{l}\text { RPD } \\
\mathrm{cm} \\
1 / \sqrt{X}\end{array}$ & $\begin{array}{l}3,15 \\
3,05 \\
2,81 \\
2,70\end{array}$ & 2,92 & $\begin{array}{l}37633 a \\
27254 a \\
31574 a b \\
28228 a b c\end{array}$ & $\begin{array}{l}\text { RPD } \\
\mathrm{cm} \\
1 / \sqrt{X}\end{array}$ & $\begin{array}{l}2,49 \\
2,13 \\
2,10\end{array}$ & 2,24 & $\begin{array}{l}447 a \\
412 a b \\
275 a b\end{array}$ \\
\hline $\begin{array}{l}\mathrm{FCm} \\
\mathrm{cm} \\
1 /(X+1)\end{array}$ & $\begin{array}{l}0,48 \\
0,47 \\
0,47 \\
0,46\end{array}$ & 0,475 & $\begin{array}{l}24504 a \\
28228 a b \\
32824 a b \\
3761.1 a b\end{array}$ & $\begin{array}{l}\mathrm{FCm} \\
\mathrm{cm} \\
\sqrt{X+1}\end{array}$ & $\begin{array}{l}1,29 \\
1,45 \\
1,52\end{array}$ & 1,42 & $\begin{array}{l}351 a \\
447 b \\
118 b c\end{array}$ \\
\hline $\begin{array}{l}\text { FC1 } \\
\mathrm{cm} \\
1 /(X+1)\end{array}$ & $\begin{array}{l}0,84 \\
0,84 \\
0,84 \\
0,83\end{array}$ & 0,837 & $\begin{array}{l}24504 a \\
32824 a \\
28228 a \\
36336 a\end{array}$ & $\begin{array}{l}\mathrm{FC1} \\
\mathrm{cm} \\
\sqrt{X}\end{array}$ & $\begin{array}{l}1,29 \\
1,45 \\
1,52\end{array}$ & 1,42 & $\begin{array}{l}351 \mathrm{a} \\
447 \mathrm{~b} \\
118 \mathrm{bc}\end{array}$ \\
\hline $\begin{array}{l}\mathrm{FC} 2 \\
\mathrm{~cm} \\
\qquad \log \sqrt{X+1}\end{array}$ & $\begin{array}{l}0,25 \\
0,26 \\
0,28 \\
0,29\end{array}$ & 0,27 & $\begin{array}{l}24504 \mathrm{a} \\
37611 \mathrm{ab} \\
28228 \mathrm{abc} \\
31574 \mathrm{abc}\end{array}$ & $\begin{array}{l}\mathrm{FC} 2 \\
\mathrm{~cm} \\
\log X\end{array}$ & $\begin{array}{l}0,31 \\
0,49 \\
0,56\end{array}$ & 0,45 & $\begin{array}{l}351 a \\
447 a b \\
39 a b c\end{array}$ \\
\hline
\end{tabular}


Tabela 8. Melhores médias e as médias estimadas, juntamente com o resultado do teste de Duncan (5\%).

\begin{tabular}{|c|c|c|c|c|c|c|c|}
\hline \multirow[t]{2}{*}{$\begin{array}{l}\text { Variável } \\
\text { Transf. }\end{array}$} & \multicolumn{3}{|c|}{$\begin{array}{l}\text { Eucalyptus grandis } \\
\text { Com } \mathrm{i}=22,22 \%\end{array}$} & \multirow[t]{2}{*}{$\begin{array}{l}\text { Variável } \\
\text { Transf. }\end{array}$} & \multicolumn{3}{|c|}{$\begin{array}{l}\text { Eucalyptus urophylla } \\
\text { com i }=20 \%\end{array}$} \\
\hline & Médias & $\begin{array}{c}\text { Média } \\
\text { estimada }\end{array}$ & $\begin{array}{l}\text { Melhores } \\
\text { Clones }\end{array}$ & & Médias & $\begin{array}{c}\text { Média } \\
\text { estimada }\end{array}$ & $\begin{array}{c}\text { Melhores } \\
\text { Clones }\end{array}$ \\
\hline $\begin{array}{l}\mathrm{FVm} \\
\mathrm{cm} \\
\qquad / \sqrt{X+1}\end{array}$ & $\begin{array}{l}0,62 \\
0,61 \\
0,59 \\
0,59\end{array}$ & 0,605 & $\begin{array}{l}24504 a \\
32824 a b \\
31574 a b c \\
28228 a b c\end{array}$ & $\begin{array}{l}\text { FVm } \\
\mathrm{cm} \\
\text { s/transf. }\end{array}$ & $\begin{array}{l}2,26 \\
2,73 \\
2,97\end{array}$ & 2,65 & $\begin{array}{l}351 a \\
447 a b \\
601 b c\end{array}$ \\
\hline $\begin{array}{l}\text { FV1 } \\
\mathrm{cm} \\
1 /(X+1)\end{array}$ & $\begin{array}{l}0,34 \\
0,34 \\
0,32 \\
0,31\end{array}$ & 0,328 & $\begin{array}{l}32824 a \\
24504 a \\
36366 a b \\
28013 a b c\end{array}$ & $\begin{array}{l}\text { FV1 } \\
\mathrm{cm} \\
\text { s/transf. }\end{array}$ & $\begin{array}{l}2,43 \\
2,97 \\
3,02\end{array}$ & 2,81 & $\begin{array}{l}351 a \\
447 a b \\
601 a b c\end{array}$ \\
\hline $\begin{array}{l}\text { FV2 } \\
\mathrm{cm} \\
\log X\end{array}$ & $\begin{array}{l}0,11 \\
0,28 \\
0,38 \\
0,36\end{array}$ & 0,27 & $\begin{array}{l}24504 a \\
32824 a b \\
28228 a b c \\
37611 a b c\end{array}$ & $\begin{array}{l}\text { FV2 } \\
\text { cm } \\
\text { s/transf. }\end{array}$ & $\begin{array}{l}2,1 \\
2,37 \\
2,45\end{array}$ & 2,31 & $\begin{array}{l}351 \mathrm{a} \\
601 \mathrm{ab} \\
39 \mathrm{ab}\end{array}$ \\
\hline $\begin{array}{l}\mathrm{Db} \\
\mathrm{g} / \mathrm{cm}^{3} \\
\text { s/transf. }\end{array}$ & $\begin{array}{l}0,48 \\
0,45 \\
0,42 \\
0,39\end{array}$ & 0,43 & $\begin{array}{l}37611 \mathrm{~A} \\
28261 \mathrm{AB} \\
37592 \mathrm{BC} \\
27254 \mathrm{CD}\end{array}$ & $\begin{array}{l}\mathrm{Db} \\
\mathrm{g} / \mathrm{cm}^{3} \\
\text { s/transf. }\end{array}$ & $\begin{array}{c}0,46 \\
0,42 \\
0,4\end{array}$ & 0,43 & $\begin{array}{l}39 a \\
351 b \\
118 b c\end{array}$ \\
\hline $\begin{array}{l}\mathrm{f}_{\mathrm{sr}} \\
\mathrm{daN} / \mathrm{cm}^{2} \\
\text { s/transf. }\end{array}$ & $\begin{array}{c}81,55 \\
77,91 \\
73,84 \\
72,2\end{array}$ & 76,37 & $\begin{array}{l}27254 \mathrm{a} \\
28261 \mathrm{ab} \\
37611 \mathrm{bc} \\
36366 \mathrm{bcd}\end{array}$ & $\begin{array}{l}f_{\mathrm{sr}} \\
\text { daN/cm } \\
\text { s/transf. }\end{array}$ & $\begin{array}{l}73,66 \\
73,55 \\
73,26\end{array}$ & 73,49 & $\begin{array}{l}320 a \\
203 a \\
440 a b\end{array}$ \\
\hline $\begin{array}{l}\mathrm{f}_{\mathrm{st}} \\
\mathrm{daN} / \mathrm{cm}^{2} \\
\text { s/transf. }\end{array}$ & $\begin{array}{l}97,26 \\
97,19 \\
88,68 \\
83,55\end{array}$ & 91,67 & $\begin{array}{l}37592 A \\
37611 A \\
28261 A B \\
28013 B C\end{array}$ & $\begin{array}{l}\mathrm{f}_{\mathrm{st}} \\
\mathrm{daN} / \mathrm{cm}^{2} \\
\text { s/transf. }\end{array}$ & $\begin{array}{l}92,28 \\
89,28 \\
87,17\end{array}$ & 89,58 & $\begin{array}{l}39 a \\
95 a b \\
440 a b\end{array}$ \\
\hline $\begin{array}{l}f_{c} \\
\text { daN/cm } \\
\text { s/transf. }\end{array}$ & $\begin{array}{l}715,05 \\
655,44 \\
628,84 \\
617,28\end{array}$ & 654,15 & $\begin{array}{l}37611 \mathrm{a} \\
28261 \mathrm{~b} \\
28228 \mathrm{bc} \\
24504 \mathrm{bcd}\end{array}$ & $\begin{array}{l}f_{c} \\
\text { daN/cm } \\
\text { s/transf. }\end{array}$ & $\begin{array}{l}658,76 \\
642,72 \\
615,11\end{array}$ & 638,95 & $\begin{array}{l}351 \mathrm{a} \\
39 \mathrm{ab} \\
118 \mathrm{abc}\end{array}$ \\
\hline
\end{tabular}


Tabela 8. Melhores médias e as médias estimadas, juntamente com o resultado do teste de Duncan (5\%).

\begin{tabular}{|c|c|c|c|c|c|c|c|}
\hline \multirow[t]{2}{*}{$\begin{array}{l}\text { Variável } \\
\text { Transf. }\end{array}$} & \multicolumn{3}{|c|}{$\begin{array}{c}\text { Eucalyptus grandis } \\
\text { com } \mathrm{i}=22,22 \%\end{array}$} & \multirow[t]{2}{*}{$\begin{array}{l}\text { Variável } \\
\text { Transf. }\end{array}$} & \multicolumn{3}{|c|}{$\begin{array}{l}\text { Eucalyptus urophylla } \\
\text { com i }=20 \%\end{array}$} \\
\hline & Médias & $\begin{array}{c}\text { Média } \\
\text { estimada }\end{array}$ & $\begin{array}{c}\text { Melhores } \\
\text { Clones }\end{array}$ & & Médias & $\begin{array}{l}\text { Média } \\
\text { estimada }\end{array}$ & $\begin{array}{c}\text { Melhores } \\
\text { Clones }\end{array}$ \\
\hline $\begin{array}{l}f_{f} \\
\text { daN/cm }{ }^{2} \\
\text { s/transf. }\end{array}$ & $\begin{array}{l}1683,4 \\
1492,2 \\
1464,8 \\
1427,5\end{array}$ & 1517 & $\begin{array}{l}37611 \mathrm{a} \\
28261 \mathrm{~b} \\
36366 \mathrm{~b} \\
37592 \mathrm{bc}\end{array}$ & $\begin{array}{l}\mathrm{F}_{\mathrm{f}} \\
\text { daN/cm } \\
\text { s/transf. }\end{array}$ & $\begin{array}{l}1518,3 \\
1444,9 \\
1417,5\end{array}$ & 1460,2 & $\begin{array}{l}39 a \\
275 a b \\
351 a b\end{array}$ \\
\hline $\begin{array}{l}\mathrm{E}_{\mathrm{f}} \\
\text { daN/cm } \\
\text { s/transf. }\end{array}$ & $\begin{array}{l}254632 \\
240692 \\
231158 \\
212761\end{array}$ & 234810 & $\begin{array}{l}37611 \mathrm{a} \\
37592 \mathrm{a} \\
28261 \mathrm{ab} \\
28228 \mathrm{bc}\end{array}$ & $\begin{array}{l}E_{f} \\
\text { daN/cm }{ }^{2} \\
\text { s/transf. }\end{array}$ & $\begin{array}{l}235645 \\
230206 \\
227516\end{array}$ & 231122 & $\begin{array}{l}39 a \\
601 a b \\
478 a b c\end{array}$ \\
\hline $\begin{array}{l}\mathrm{f}_{\mathrm{t}} \\
\mathrm{daN} / \mathrm{cm}^{2} \\
\quad \sqrt{X+1}\end{array}$ & $\begin{array}{l}48,68 \\
44,84 \\
43,83 \\
43,72\end{array}$ & 45,27 & $\begin{array}{l}37611 \mathrm{a} \\
36366 \mathrm{ab} \\
37753 \mathrm{abc} \\
28261 \mathrm{abc}\end{array}$ & $\begin{array}{l}\mathrm{ft}_{\mathrm{t}} \\
\mathrm{daN} / \mathrm{cm}^{2} \\
\sqrt{X+1}\end{array}$ & $\begin{array}{l}50,37 \\
49,11 \\
48,92\end{array}$ & 49,47 & $\begin{array}{l}275 a \\
351 a b \\
203 a b c\end{array}$ \\
\hline
\end{tabular}

Obs. $\mathrm{i}$ = intensidade de seleção dentro de clone.

As médias seguidas das mesmas letras, não diferem estatisticamente entre si através do teste de Duncan a $5 \%$ de probabilidade.

Os resultados da Tabela 8, corroboram as afirmações de Assis (1999) de que é difícil encontrarem-se grupos de árvores dotadas de um número elevado de caracteres desejados para todas as finalidades, e que clones, espécies e híbridos para serraria demonstram níveis de variabilidade extremamente altos para a maioria das características tecnológicas.

Como exemplo, cita-se o clone 37592 do Eucalyptus grandis, que apesar de possuir valores médios desejáveis para as características tecnológicas Coni, $R T, D b, f_{s t}, f_{f}$ e $E_{f}$, não apresentou bons valores de RMS e RPD. Na Figura 11, pode-se observar a RPD e as toras do clone 37592, caracterizando-o como sendo um clone de baixo rendimento, mesmo apresentando toras com as extremidades pouco rachadas. Essa 
alternância de comportamento tem dificultado a eleição dos melhores clones, fato esse que exige o estabelecimento de uma ordem de prioridades das variáveis, levando-se em consideração os valores dos coeficientes de herdabilidade dessas variáveis, que são de extrema importância.

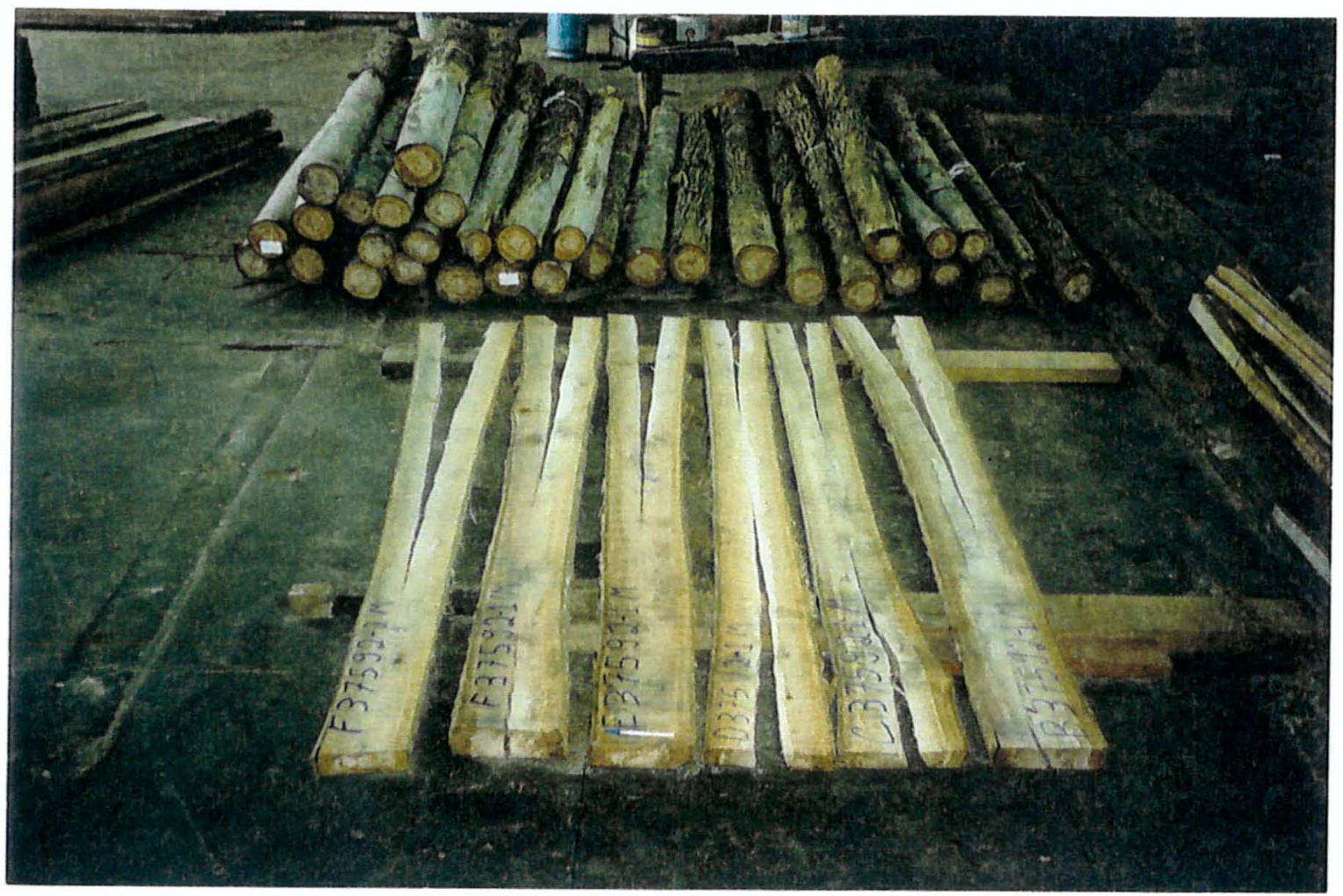

Figura 11 - Rachaduras de extremidades das pranchas diametrais (RPD) com algumas toras ainda a serem desdobradas (ao fundo da Figura) do clone 37592 de E. grandis . 
Os melhores clones para o Eucalyptus grandis foram: 28228 (com 11 características favoráveis), 37611 (com 10), 24504 (com 8) e o 28261 (com 7). Os piores clones foram 30543, 31510, 36838, 42128 e o 42273, que não se destacaram em nenhum das características analisadas.

Para o Eucalyptus urophylla, destacam-se os clones 351 (com 11 características favoráveis), 39 (com 10) e o 447 (com 6). O pior clone foi o 113 , não se destacando em nenhuma das características analisadas.

Na Figura 12, pode-se observar o comportamento fenotípico do clone 28228, considerado o melhor clone selecionado do E. grandis, principalmente para as características RMS e RPD.

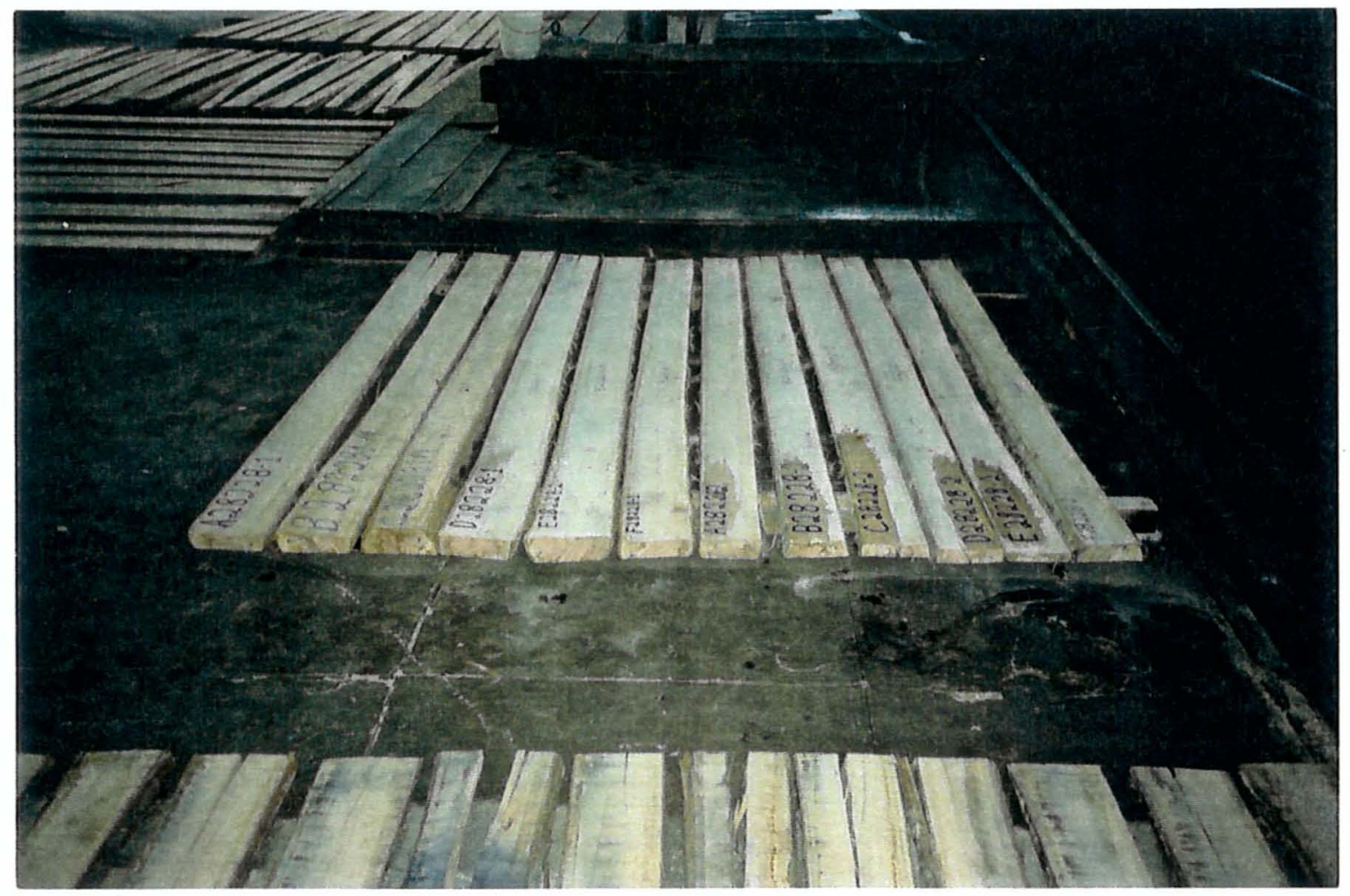

Figura 12 - Pranchas diametrais não rachadas do clone 28228 de Eucalyptus grandis 
Nas Tabelas 9 e 10 encontram-se todos os clones contendo todas as características tecnológicas que lhe são favoráveis. Estes agrupamentos foram efetuados com base nos resultados obtidos pelo teste de Duncan (5\%), vistos na Tabela 8.

Tabela 9. Classificação dos clones do Eucalyptus grandis, de acordo com o número e a importância das características tecnológicas que the são favoráveis.

\begin{tabular}{ll}
\hline Clone & Característica \\
\hline 28228 & Coni RMS RT RPD FCm FC1 FC2 FVm FV2 $f_{c} E_{f}$ \\
37611 & FCm FC2 FV2 Db $f_{s r} f_{s t} f_{c} f_{f} E_{f} f_{t}$ \\
24504 & RMS FCm FC1 FC2 FVm FV1 FV2 $f_{c}$ \\
28261 & Db $f_{s r} f_{s t} f_{c} f_{f} E_{f} f_{t}$ \\
36366 & RT FC1 FV1 $f_{s r} f_{f} f_{t}$ \\
37592 & Coni RT Db $f_{s t} f_{f} E_{f}$ \\
32824 & FCm FC1 FVm FV1 FV2 \\
27254 & RMS RPD Db $f_{s r}$ \\
31574 & RPD FC2 FVm \\
37633 & Coni RT RPD \\
28013 & FV1 $f_{s t}$ \\
37753 & Coni $f_{t}$ \\
36671 & RMS \\
30543 & - \\
31510 & - \\
36838 & - \\
42128 & - \\
42273 & - \\
\hline
\end{tabular}


Tabela 10. Classificação dos clones do Eucalyptus urophylla, de acordo com o número e a importância das características tecnológicas que the são favoráveis.

\begin{tabular}{cl}
\hline Clone & Caracteristica \\
\hline 351 & Coni FCm FC1 FC2 FVm FV1 FV2 Db $f_{\mathrm{C}} f_{\mathrm{f}} \mathrm{f}_{\mathrm{t}}$ \\
39 & RMS RT FC1 FC2 FV2 Db $\mathrm{f}_{\mathrm{st}} \mathrm{f}_{\mathrm{c}} \mathrm{f}_{\mathrm{f}} \mathrm{E}_{\mathrm{f}}$ \\
447 & RPD FCm FC1 FC2 FVm FV1 \\
118 & RMS FCm Db $\mathrm{f}_{\mathrm{c}}$ \\
601 & FVm FV1 FV2 $E_{\mathrm{f}}$ \\
203 & Coni $\mathrm{f}_{\mathrm{sr}} \mathrm{f}_{\mathrm{t}}$ \\
275 & RPD $\mathrm{f}_{\mathrm{f}} \mathrm{f}_{\mathrm{t}}$ \\
95 & Coni $\mathrm{f}_{\mathrm{st}}$ \\
412 & RT RPD \\
440 & $\mathrm{f}_{\mathrm{sr}} \mathrm{f}_{\mathrm{st}}$ \\
9 & RMS \\
235 & RT \\
320 & $\mathrm{f}_{\mathrm{sr}}$ \\
478 & $\mathrm{E}_{\mathrm{f}}$ \\
113 & - \\
\hline
\end{tabular}

Na tabela 11, pode-se observar os resultados obtidos através do teste de Tukey, na comparação entre médias das flechas das costaneiras e das vigotas obtidas das costaneiras. Através deste teste, optou-se por utilizar o material da vigota 1 para a amostragem dos corpos de prova para os testes laboratoriais, pois a mesma apresentou valores extremos de flecha devido ao maior alivio das tensões de crescimento. Depreende-se, portanto, que as demais flechas não representam o nível de tensões residuais que existiam nas toras antes do desdobro. Os autores Garcia $(1992,1995)$ e 
Schacht et al.(1998), consideram as flechas das costaneiras e das peças serradas como importantes indicadores de seleção.

Tabela 11. Comparação das flechas das costaneiras (FC1 e FC2) e das vigotas obtidas das costaneiras (FV1 e FV2).

\begin{tabular}{lcc}
\hline $\begin{array}{l}\text { Eucalyptus grandis } \\
\text { Grupos Tukey }\end{array}$ & Média & Variável \\
\hline A & 2,717 & FV1 \\
B & 1,891 & FV2 \\
B & 1,821 & FC1 \\
C & 1,158 & FC2 \\
\hline Eucalyptus urophylla & Média & Variável \\
Grupos Tukey & 3,600 & FV1 \\
\hline A & 2,880 & FV2 \\
B & 2,647 & FC1 \\
B & 2,126 & FC2 \\
C & mesmas letras, não apresentam diferenças \\
\hline Obs. Médias seguidas das & mesmo dukey a 5\% de probabilidade.
\end{tabular}

Nas Tabelas 12 a 17, encontram-se os valores encontrados na análise de variância, segundo o modelo matemático adotado, realizadas para ambas as espécies. Nas tabelas 12 e 13, encontram-se os números de Graus de Liberdade dos dados analisados. Nas Tabelas 14 e 15 estão os quadrados médios obtidos para todas as variáveis e nas Tabelas 16 e 17, estão os valores das estimativas dos componentes das variância e os coeficientes de variação genético $\left(C V_{g}\right)$, fenotípico $\left(C V_{f}\right)$ e experimental $\left(C V_{\text {exp }}\right)$.

Para a maioria das características estudadas a interação Tora $\times$ Clone, não foram significativos, exceto para a conicidade e densidade, indicando que para os clones estudados, estas duas características possuem um determinado padrão de variação ao longo do fuste. 
A conicidade que varia em função da posição da tora, sofre bastante influenciada ambiental. Segundo Gurgel e Gurgel (1970), Montagna et al. (1973), Van Laar (1978), Grosser (1979), Balooni \& Simões (1980) e Sanches Acosta (1995) variam em função ao espaçamento de plantio. A densidade básica variou ao longo da altura da tora (Ferreira \& Kageyama, 1978; Souza et al., 1986 e Trugilho \& Vital, 1996), apesar de não haver interação $\left(\mathrm{QM}_{\mathrm{CX} T}\right)$ para o Eucalyptus urophylla, mas apresentando a nivel de posição. Para o Eucalyptus grandis, aconteceu o inverso. Este resultado demonstra que as duas espécies possuem comportamentos tecnologicamente diferenciados.

A interação $C \times T\left(Q_{C \times T}\right)$ para a resistência à flexão estática $\left(f_{f}\right)$ foi significativa, a $5 \%$ somente para o Eucalyptus urophylla, mas não foi significativo para clones $\left(Q_{C}\right)$, indicando que entre os clones do $E$. urophylla houve pouca variação genética. As estimativas das variâncias genéticas $\left(\sigma^{2} \mathrm{c}\right.$ ) (Tabela 17) apresentaram valores negativos e segundo Pereira (1983), quando o quadrado médio (QMc) não é significativo e a estimativa da variância é negativa $\left(-\sigma_{c}^{2}\right)$, admite-se que o verdadeiro valor da variância é zero, deste modo, conclui-se não haver diferenças entre os clones, mas somente diferenças ao longo do fuste. Segundo o mesmo autor, caso seja não significativo um determinado $\mathrm{QM}$, o parâmetro correspondente, pode ser eliminado do modelo matemático.

Kalil (1963), estudando linhagens de touros, encontrou uma estimativa negativa de variância entre touros, mas considerou-a como sendo nula, interpretando que a causa da estimativa negativa poderia ser atribuída ao erro de amostragem. Assim, para este estudo, pode-se também supor que o resultado negativo foi conseqüência de alguma deficiência da amostragem pois houve muitas parcelas perdidas nos ensaios de flexão estática e módulo de elasticidade na flexão do $E$. urophylla.

O resultado negativo da variância genética para a característica flexão estática, impediram os cálculos da herdabilidade, do 
coeficiente de variação genético e o respectivo ganho de seleção do $E$. urophylla.

Tabela 12. Números de Graus de Liberdade (G.L) utilizados no modelo matemático de todas as variáveis do Eucalyptus grandis

\begin{tabular}{lccccc}
\hline Código & G.Lc & G.L $L_{a}$ & G.L & G.LCxT & G. Le $_{e}$ \\
\hline Coni & 17 & 90 & 1 & 17 & 90 \\
RT & 17 & 90 & 1 & 17 & 90 \\
RPD & 17 & 90 & 1 & 17 & 84 \\
RMS & 17 & 90 & 1 & 17 & 90 \\
FCm & 17 & 90 & 1 & 17 & 89 \\
FC1 & 17 & 90 & 1 & 17 & 89 \\
FC2 & 17 & 90 & 1 & 17 & 89 \\
FVm & 17 & 90 & 1 & 17 & 89 \\
FV1 & 17 & 90 & 1 & 17 & 89 \\
FV2 & 17 & 90 & 1 & 17 & 86 \\
Db & 17 & 90 & 1 & 17 & 71 \\
$f_{s r}$ & 17 & 90 & 1 & 17 & 80 \\
$f_{s t}$ & 17 & 90 & 1 & 17 & 78 \\
$f_{c}$ & 17 & 90 & 1 & 17 & 69 \\
$f_{f}$ & 17 & 90 & 1 & 17 & 74 \\
$E_{\mathrm{f}}$ & 17 & 90 & 1 & 17 & 72 \\
$\mathrm{f}_{\mathrm{f}}$ & 17 & 90 & 1 & 17 & 73 \\
\hline
\end{tabular}


Tabela 13. Números de Graus de Liberdade (G.L) utilizados no modelo matemático de todas as variáveis do Eucalyptus urophylla.

\begin{tabular}{lccccc}
\hline Código & G.Lc & G.La & G.L $L_{T}$ & G.LCXT & G.Le \\
\hline Coni & 14 & 75 & 1 & 14 & 69 \\
RT & 14 & 75 & 1 & 14 & 70 \\
RPD & 14 & 75 & 1 & 14 & 67 \\
RMS & 14 & 75 & 1 & 14 & 69 \\
FCm & 14 & 75 & 1 & 14 & 69 \\
FC1 & 14 & 75 & 1 & 14 & 69 \\
FC2 & 14 & 75 & 1 & 14 & 65 \\
FVm & 14 & 75 & 1 & 14 & 66 \\
FV1 & 14 & 75 & 1 & 14 & 69 \\
FV2 & 14 & 65 & 1 & 14 & 69 \\
Db & 14 & 74 & 1 & 14 & 43 \\
$\mathrm{f}_{\mathrm{sr}}$ & 14 & 73 & 1 & 14 & 48 \\
$\mathrm{f}_{\mathrm{st}}$ & 14 & 74 & 1 & 14 & 42 \\
$\mathrm{f}_{\mathrm{c}}$ & 14 & 74 & 1 & 14 & 43 \\
$\mathrm{f}_{\mathrm{f}}$ & 14 & 74 & 1 & 14 & 45 \\
$\mathrm{E}_{\mathrm{f}}$ & 14 & 74 & 1 & 14 & 45 \\
$\mathrm{f}_{\mathrm{t}}$ & 14 & 74 & 1 & 14 & 43 \\
\hline
\end{tabular}


Tabela 14. Valores dos QM (Quadrados Médios) obtidos segundo o modelo matemático adotado para as caracteristicas do Eucalyptus grandis

\begin{tabular}{|c|c|c|c|c|c|}
\hline Variável & Q.Mc & Q.Ma & Q.MT & Q.M CXT & Q.Me \\
\hline Coni & 0,021428 ** & 0,00453 & $0,8637^{\star \star}$ & $0,0144^{*}$ & 0,00682 \\
\hline RT & 0,1866 ** & 0,0149 & $0,10104^{*}$ & 0,0057 n.s & 0,0177 \\
\hline RPD & $5,7228^{\star *}$ & 0,4411 & 0,0945 n.s & 0,4049 n.s & 0,736 \\
\hline RMS & $0,00847^{* *}$ & 0,00152 & 0,01918 ** & 0,001616 n.s & 0,00242 \\
\hline $\mathrm{FCm}$ & 0,03571 ** & 0,002 & $0,0963^{\text {** }}$ & 0,0032 n.s & 0,00246 \\
\hline FC1 & 0,0565 ** & 0,0068 & $0,285^{* *}$ & 0,0077 n.s & 0,00813 \\
\hline $\mathrm{FC} 2$ & $0,08815^{\star \star}$ & 0,0083 & $0,0974^{* *}$ & 0,00718 n.s & 0,01137 \\
\hline $\mathrm{FVm}$ & $0,0212^{* *}$ & 0,00114 & $0,0359^{* \star}$ & 0,00145 n.s & 0,00118 \\
\hline FV1 & $0,0176 * *$ & 0,002 & $0,0549 * *$ & 0,00161 n.s & 0,00186 \\
\hline FV2 & $0,7357 * *$ & 0,073 & $0,7517^{\star *}$ & 0,084 n.s & 0,1006 \\
\hline $\mathrm{Db}$ & $0,0523^{* *}$ & 0,00415 & 0,000026 n.s & $0,0046^{\star \star *}$ & 0,0022 \\
\hline$f_{s r}$ & $479,28^{* *}$ & 69,966 & 75,978 n.s & 45,123 n.s & 52,636 \\
\hline$f_{s t}$ & 907,146 ** & 137,815 & 189,842 n.s & 104,4 n.s & 101,531 \\
\hline$f_{C}$ & 36781,16 ** & 3781,46 & 14759,76 * & 2620,44 n.s & 2981,18 \\
\hline$f_{f}$ & 370509,6 * & 28154,74 & 423,99 n.s & 26276,7 n.s & 35681,68 \\
\hline$E_{f}$ & $9,7 \times 10^{9 * *}$ & $5,9 \times 10^{8}$ & $7,5 \times 10^{9 * \star}$ & $8 \times 10^{8}$ n.s & $7,3 \times 10^{8}$ \\
\hline$f_{t}$ & $321,634^{\text {** }}$ & 34,653 & 30,868 n.s & 55,927 n.s & 33,179 \\
\hline
\end{tabular}

QMc Quadrado médio do clone; $\mathrm{QM}_{\mathrm{a}}$ Quadrado médio do erro a; $\mathrm{QM} T$ Quadrado médio de tora; $\mathrm{QM} \mathrm{CXT}_{\mathrm{T}}$ Quadrado médio da interação; $\mathrm{QM}_{\mathrm{e}}$ Quadrado médio do erro e.

** significativo a $1 \%$; * significativo a $5 \%$; e "n.s" não significativo. 
Tabela 15. Valores dos QM (Quadrados Médios) obtidos segundo o modelo matemático adotado para os caracteres do Eucalyptus urophylla

\begin{tabular}{|c|c|c|c|c|c|}
\hline Variável & Q.Mc & Q.M & Q.M $M_{T}$ & Q.M. $M_{C X T}$ & Q.Me \\
\hline Coni & $0,0265^{* *}$ & 0,0032 & $0,149^{* *}$ & $0,0218^{\star *}$ & 0,0029 \\
\hline $\mathrm{RT}$ & 0,034 ** & 0,008 & 0,0047 n.s & 0,01 n.s & 0,0064 \\
\hline RPD & $3,075^{\star \star}$ & 0,815 & 1,211 n.s & 0,59 n.s & 0,661 \\
\hline RMS & 0,0064 * & 0,0021 & $0,028^{\star \star}$ & 0,0013 n.s & 0,0033 \\
\hline $\mathrm{FCm}$ & $0,1229 * *$ & 0,02 & $0,129^{* *}$ & 0,0125 n.s & 0,023 \\
\hline $\mathrm{FC} 1$ & $0,195^{\star *}$ & 0,036 & $0,273^{\star \star}$ & 0,039 n.s & 0,03 \\
\hline $\mathrm{FC} 2$ & $0,368^{* *}$ & 0,119 & 0,0239 n.s & 0,157 n.s & 0,14 \\
\hline $\mathrm{FVm}$ & $2,534^{\star \star}$ & 0,362 & 1,596 ** & 0,301 n.s & 0,464 \\
\hline FV1 & 4,396 ** & 0,869 & 8,02 ** & 0,672 n.s & 0,877 \\
\hline FV2 & $2,033^{\star \star}$ & 1,004 & 2,314 n.s & 0,621 n.s & 1,159 \\
\hline $\mathrm{Db}$ & $0,0067^{* *}$ & 0,0025 & 0,00467 ** & 0,00132 n.s & 0,00086 \\
\hline$f_{s r}$ & 89,25 * & 45,847 & 26,441 n.s & 56,923 n.s & 36,156 \\
\hline$f_{s t}$ & $465,5^{\star \star}$ & 103,331 & 93,184 n.s & 45,626 n.s & 71,046 \\
\hline$f_{c}$ & $7837,62 *$ & 3497,5 & 8387,33 n.s & 1383,94 n.s & 2881,925 \\
\hline$f_{f}$ & 36411,5 n.s & 37450,8 & 24245,8 n.s & $57870,6^{*}$ & 22040,22 \\
\hline$E_{f}$ & $1,52 \times 10^{9}$ n.s & $8,78 \times 10^{8}$ & $4,48 \times 10^{9 *}$ & $8,64 \times 10^{8}$ n.s & $6,69 \times 10^{8}$ \\
\hline$f_{t}$ & $76,937^{\star}$ & 40,818 & 12,381 n.s & 45,279 n.s & 50,907 \\
\hline
\end{tabular}


Tabela 16. Componentes de variância para as propriedades do Eucalyptus grandis, com os coeficientes de variação.

\begin{tabular}{lcccccccc}
\hline Variável & $\sigma^{2} c$ & $\sigma_{a}^{2}$ & $\Phi_{T}$ & $\sigma^{2}{ }_{c x}$ & $\sigma_{e}^{2}$ & $C V_{\text {exp. }}$ & $C V_{g}$ & $C V_{f}$ \\
\hline Coni & 0,00077 & $-0,0011$ & 0,8493 & 0,0012 & 0,0068 & 10,879 & 3,65 & 5,56 \\
RT & 0,0153 & $-0,0014$ & 0,095 & $-0,0019$ & 0,017 & 21,08 & 15,05 & 15,17 \\
RPD & 0,494 & $-0,1525$ & $-0,3127$ & $-0,0584$ & 0,736 & 48,078 & 33,81 & 34,052 \\
RMS & 0,00064 & $-0,00045$ & 0,0175 & $-0,00013$ & 0,0024 & 4,3425 & 2,44 & 2,34 \\
FCm & 0,00277 & $-0,000227$ & 0,0831 & 0,000124 & 0,0024 & 11,94 & 12,66 & 13,185 \\
FC1 & 0,00421 & $-0,00064$ & 0,2773 & $-0,000066$ & 0,0081 & 11,77 & 8,469 & 8,997 \\
FC2 & 0,00706 & $-0,00154$ & 0,0899 & $-0,0007$ & 0,0113 & 28,99 & 22,864 & 23,315 \\
FVm & 0,001665 & $-0,000017$ & 0,0345 & 0,000046 & 0,00118 & 6,1558 & 7,311 & 7,57 \\
FV1 & 0,00132 & 0,000114 & 0,0532 & $-0,000042$ & 0,00186 & 15,284 & 12,916 & 13,647 \\
FV2 & 0,0583 & $-0,01409$ & 0,6672 & $-0,00287$ & 0,10063 & 54,483 & 41,479 & 43,13 \\
Db & 0,001 & 0,00457 & $-0,00442$ & 0,000487 & 0,0022 & 13,4 & 19,319 & 20,8 \\
f f & 38,371 & 9,175 & 30,761 & $-1,38$ & 52,636 & 10,61 & 9,066 & 9,723 \\
$f_{s t}$ & 71,684 & 19,437 & 85,487 & 0,538 & 101,53 & 12,77 & 10,73 & 11,693 \\
$f_{c}$ & 2683,29 & 452,98 & 12119,67 & $-74,85$ & 2981,18 & 9,54 & 9,053 & 9,618 \\
$f_{f}$ & 33752,58 & $-4130,68$ & $-26167,59$ & $-1843,27$ & 35681,68 & 14,8 & 14,39 & 14,725 \\
$E_{f}$ & $8,8 \times 10^{8}$ & $-8,0 \times 10^{7}$ & $6,7 \times 10^{8}$ & $1,2 \times 10^{7}$ & $7,3 \times 10^{8}$ & 13,98 & 15,329 & 15,874 \\
$f_{f}$ & 25,71 & 0,813 & $-24,435$ & 4,507 & 33,179 & 15,011 & 13,21 & 14,68 \\
\hline
\end{tabular}

Onde: $\sigma^{2}$ variância entre clones; $\sigma_{a}^{2}$ variância do erro a; $\Phi_{T}$ componente quadrático relativo à posição; $\sigma^{2}{ }_{C x T}$ variância da interação $\mathrm{C} \times \mathrm{T} ; \sigma_{\mathrm{e}}^{2}$ variância do erro e; $C V_{\text {exp. }}$ coeficiente de variação experimental; $C V_{g}$ coeficiente de variação genético; $\mathrm{CV}_{\mathrm{f}}$ coeficiente de variação fenotípico . 
Tabela 17. Componentes de variância para as propriedades do Eucalyptus urophylla, com os coeficientes de variação.

\begin{tabular}{lcccccccc}
\hline Código & $\sigma^{2} \mathrm{c}$ & $\sigma_{\mathrm{a}}^{2}$ & $\Phi_{T}$ & $\sigma^{2} \mathrm{CxT}$ & $\sigma_{\mathrm{e}}^{2}$ & $\mathrm{CV}_{\text {exp. }}$ & $\mathrm{CV}_{\mathrm{g}}$ & $\mathrm{CV}_{\mathrm{f}}$ \\
\hline Coni & 0,00036 & 0,00019 & 0,128 & 0,0033 & 0,0029 & 6,7875 & 2,39 & 6,2108 \\
RMS & 0,00054 & $-0,00059$ & 0,026 & $-0,00035$ & 0,0033 & 5,141 & 2,076 & 2,081 \\
RT & 0,0019 & 0,0008 & $-0,0054$ & 0,00066 & 0,0064 & 17,18 & 7,69 & 8,91 \\
RPD & 0,2139 & 0,0812 & 0,619 & $-0,0128$ & 0,661 & 61,15 & 29,21 & 33,55 \\
FCm & 0,01 & $-0,00149$ & 0,117 & $-0,0018$ & 0,023 & 8,294 & 5,4652 & 5,6718 \\
FC1 & 0,0131 & 0,0033 & 0,234 & 0,00171 & 0,03 & 10,753 & 7,121 & 8,168 \\
FC2 & 0,0211 & 0,01127 & $-0,133$ & 0,0032 & 0,1404 & 53,194 & 20,645 & 26,077 \\
FVm & 0,2118 & $-0,0544$ & 1,288 & $-0,03$ & 0,4647 & 20,676 & 13,958 & 14,469 \\
FV1 & 0,3302 & $-0,004$ & 7,341 & $-0,0366$ & 0,877 & 26,012 & 15,961 & 17,294 \\
FV2 & 0,285 & $-0,08$ & 1,676 & $-0,096$ & 1,159 & 37,389 & 18,535 & 19,7085 \\
Db & 0,00047 & 0,00104 & 0,003414 & 0,00012 & 0,00086 & 7,57 & 5,6 & 7,79 \\
$f_{s r}$ & 2,565 & 5,847 & $-27,312$ & 4,966 & 36,156 & 8,635 & 2,3 & 4,834 \\
$f_{s t}$ & 48,355 & 20,594 & 43,77 & $-6,73$ & 71,046 & 10,43 & 8,605 & 9,3616 \\
$f_{c}$ & 726,418 & 389,338 & 6789,01 & $-389,358$ & 2881,925 & 9,02 & 4,52 & 5,0 \\
$f_{f}$ & $-4423,76$ & 9583,11 & $-28151,15$ & 9005,79 & 22040,22 & 10,78 & - & 5,95865 \\
$E_{f}$ & $5,3 \times 10^{7}$ & $1,29 \times 10^{8}$ & $3,6 \times 10^{9}$ & $4,8 \times 10^{7}$ & $6,6 \times 10^{8}$ & 12,01 & 3,4 & 6,522 \\
$f_{t}$ & 4,925 & $-6,381$ & $-33,735$ & $-1,463$ & 50,907 & 16,059 & 4,99 & 6,544 \\
\hline
\end{tabular}

Onde: $\sigma^{2}$ variância entre clones; $\sigma^{2}$ a variância do erro $a ; \Phi_{T}$ componente quadrático relativo à posição; $\sigma^{2}{ }_{c x}$ variância da interação; $\sigma_{b}^{2}$ variância do erro b; $C V_{\text {exp }}$ coeficiente de variação experimental; $C V_{g}$ coeficiente de variação genético; $\mathrm{CV}_{\mathrm{f}}$ coeficiente de variação fenotípico. 
Para os clones do Eucalyptus grandis, houveram diferenças estatísticas para todas as características estudadas.

A interação entre as toras do Eucalyptus urophylla, não houveram diferenças estatísticas para as características RPD, Db, $\mathrm{f}_{\mathrm{sr}}, \mathrm{f}_{\mathrm{st}}, \mathrm{f}_{\mathrm{f}}$ e $\mathrm{E}_{\mathrm{f}}$, onde para todas as demais características, houveram diferenças entre as duas toras.

Para a interação Clone $\mathrm{x}$ Tora do E. grandis, houve diferença estatística somente para a conicidade e densidade básica.

Para a variação entre clones do $E$. urophylla, só não houve diferença estatística para a variável flexão estática $\left(\mathfrak{f}_{\mathrm{f}}\right)$ e módulo na flexão $\left(\mathrm{E}_{\mathrm{f}}\right)$.

Para as toras do $E$. urophylla, houve diferença estatística para as características Coni, RMS, FCm, FC1, FVm, FV1, Db e Ef. Os resultados obtidos para a conicidade em relação a posição (tora), foi suportado por Purnell (1988), onde também encontrou diferenças da tora 1 em relação a tora 2.

Observou-se uma diferenciação entre o rendimento em madeira serrada, segundo a posição da tora, para ambas as espécies, onde os mesmos resultados foram obtidos por Miranda \& Nahuz 1997).

Para a interação Clone $\mathrm{x}$ Tora do $E$. urophylla, somente para a conicidade e $E_{f_{\mathrm{r}}}$ os resultados foram estatisticamente significativos.

Fernandes (1986a), Combes et al. (1997) e Lima (2000) encontraram diferenças entre as toras para a característica rachadura de extremidade da tora, onde neste estudo para o $E$. urophylla, este resultado não foi observado, e sim para o E. grandis.

Um resultado que contradiz o esperado, para ambas as espécies, refere-se ao comportamento da RPD, sendo não significativo entre as toras, onde segundo Fernandes (1982) e Schacht(1998), encontraram diferenças significativas para as rachaduras de extremidades de tábuas, sendo que estas foram maiores no topo que na base das tábuas. Para ambas as espécies, foi não significativo a interação do clones com a tora para a 
característica RPD, mostrando que há um único padrão de variação da RPD para a tora 1 e a tora 2 .

As duas espécies apresentaram discrepância, principalmente em relação ao $\mathrm{QM}_{\mathrm{T}}$ (Tora 1 e Tora 2), para as características $R T, F C 2, F V 2$, e $f_{c}$, indicando comportamentos distintos entre estas duas espécies em relação as características tecnológicas. Para o Eucalyptus urophylla foram não significativas as variáveis citadas, enquanto que para o Eucalyptus grandis, ocorreu o inverso.

Várias características apresentaram componentes de variância negativos (variância genética ou fenotípica), em ambas as espécies. Isso provavelmente ocorreu devido a baixa amostragem elou a baixa variabilidade para estas características.

De posse destes resultados, foram calculados os valores do coeficiente " $b$ " $\left(\mathrm{CV}_{g} / \mathrm{CV}_{f}\right)$ que segundo Vencovsky e Barriga (1992) indica a efetividade da seleção para a característica estudada, isto é, quando esta razão apresentar valores próximos de 1 , a seleção será efetiva.

Nas Tabelas 18 e 19 encontram-se os resultados obtidos para os coeficientes " $b$ ", as herdabilidades no sentido amplo e a nivel de médias com seus intervalos de confiança (IC) e as herdabilidades a nivel de totais.

Os ganhos genéticos a nivel de totais $\left(G s_{t} \%\right.$ ), os diferenciais de seleção utilizados para cálculo dos ganhos de seleção, e os ganhos genéticos a nível de médias $\left(\mathrm{Gs}_{\mathrm{m}} \%\right)$ com seus intervalos de confiança (IC) destes ganhos, encontram-se nas Tabelas 20 e 21. 
Tabela 18. Valores do coeficiente "b" $\left(\mathrm{CV}_{\mathrm{g}} / \mathrm{CV}_{\mathrm{f}}\right)$ e das herdabilidades a nivel de médias, com seus respectivos intervalos de confiança (IC) e a herdabilidades a nível de totais para o Eucalyptus grandis

\begin{tabular}{lccccc}
\hline Código & "b" & $\mathrm{h}_{\mathrm{m}}^{2}$ & \multicolumn{2}{c}{$\mathrm{IC}$} & $\mathrm{h}_{\mathrm{t}}^{2}$ \\
\hline Coni & 0,656 & 0,431 & 0 & 0,74 & 0,099 \\
RT & 0,992 & 0,980 & 0,918 & 0,988 & 0,518 \\
RPD & 0,992 & 0,985 & 0,810 & 0,98 & 0,485 \\
RMS & 0,956 & 0,915 & 0,480 & 0,928 & 0,260 \\
FCm & 0,960 & 0,920 & 0,760 & 0,966 & 0,539 \\
FC1 & 0,941 & 0,885 & 0,635 & 0,949 & 0,361 \\
FC2 & 0,980 & 0,961 & 0,782 & 0,969 & 0,436 \\
FVm & 0,965 & 0,933 & 0,817 & 0,974 & 0,579 \\
FV1 & 0,946 & 0,895 & 0,755 & 0,965 & 0,407 \\
FV2 & 0,961 & 0,924 & 0,694 & 0,957 & 0,410 \\
Db & 0,928 & 0,862 & 0,764 & 0,967 & 0,547 \\
$f_{s r}$ & 0,932 & 0,869 & 0,748 & 0,964 & 0,388 \\
$f_{s t}$ & 0,917 & 0,842 & 0,692 & 0,956 & 0,371 \\
$f_{c}$ & 0,941 & 0,880 & 0,809 & 0,973 & 0,440 \\
$f_{f}$ & 0,977 & 0,950 & 0,810 & 0,973 & 0,531 \\
$E_{f}$ & 0,965 & 0,932 & 0,778 & 0,969 & 0,569 \\
$f_{t}$ & 0,900 & 0,810 & 0,535 & 0,934 & 0,400 \\
\hline
\end{tabular}

Onde: $h_{m}^{2}$ herdabilidade a nível de médias; $h_{m i}^{2}$ herdabilidade limite inferior; $h_{m s}^{2}$ herdabilidade limite superior; $h^{2}$ herdabilidade a nível de totais. 
Tabela 19. Valores do coeficiente "b" $\left(\mathrm{CV}_{g} / \mathrm{CV}_{f}\right)$ e das herdabilidades a nivel de médias, com seus respectivos intervalos de confiança (IC) e a herdabilidade a nível de totais para o Eucalyptus urophylla

\begin{tabular}{lccccc}
\hline Código & "b" & $\mathrm{h}_{\mathrm{m}}^{2}$ & $\mathrm{~h}_{\mathrm{mi}}^{2} \mathrm{IC}$ & $\mathrm{h}_{\mathrm{ms}}^{2}$ & $\mathrm{~h}_{\mathrm{t}}^{2}$ \\
\hline Coni & 0,385 & 0,148 & 0 & 0,723 & 0,003 \\
RT & 0,860 & 0,746 & 0,123 & 0,901 & 0,197 \\
RPD & 0,870 & 0,757 & 0,428 & 0,935 & 0,227 \\
RMS & 0,990 & 0,995 & 0,394 & 0,931 & 0,500 \\
FCm & 0,960 & 0,928 & 0,697 & 0,965 & 0,337 \\
FC1 & 0,871 & 0,760 & 0,404 & 0,932 & 0,273 \\
FC2 & 0,791 & 0,626 & 0 & 0,856 & 0,137 \\
FVm & 0,964 & 0,930 & 0,646 & 0,960 & 0,357 \\
FV1 & 0,922 & 0,851 & 0,544 & 0,948 & 0,283 \\
FV2 & 0,940 & 0,884 & 0,090 & 0,897 & 0,224 \\
Db & 0,718 & 0,516 & 0,413 & 0,933 & 0,188 \\
$f_{s r}$ & 0,475 & 0,226 & 0 & 0,785 & 0,052 \\
$f_{s t}$ & 0,919 & 0,844 & 0,708 & 0,967 & 0,363 \\
$f_{c}$ & 0,900 & 0,817 & 0,474 & 0,940 & 0,201 \\
$f_{f}$ & - & - & 0 & 0,466 & - \\
E $_{\mathrm{f}}$ & 0,520 & 0,270 & 0 & 0,809 & 0,059 \\
$\mathrm{f}_{\mathrm{f}}$ & 0,760 & 0,582 & 0 & 0,802 & 0,102 \\
\hline
\end{tabular}

Onde: $h_{m}^{2}$ herdabilidade a nível de médias; $h_{\text {mi }}^{2}$ herdabilidade limite inferior; $h_{m s}^{2}$ herdabilidade limite superior; $h^{2} t$ herdabilidade a nível de totais. 
Tabela 20. Valores dos diferenciais de seleção "ds" e dos ganhos de seleção a nivel de totais $\left(G s_{t} \%\right)$ e a nível de médias $\left(G s_{m} \%\right)$, com seus respectivos limites inferiores e superiores do intervalo de confiança (IC) para o Eucalyptus grandis.

\begin{tabular}{|c|c|c|c|c|c|c|c|}
\hline Código & $\begin{array}{c}\text { Média } \\
\text { dos } \\
\text { dados }\end{array}$ & $\begin{array}{c}\text { Média } \\
\text { estimada }\end{array}$ & $\begin{array}{c}\text { Diferencial } \\
\text { de seleção } \\
\text { "ds" }\end{array}$ & $\mathrm{Gs}_{t}(\%)$ & $G s_{m}(\%)$ & $G s_{\mathrm{mi}}(\%)$ & $\mathrm{Gs}_{\mathrm{ms}}(\%)$ \\
\hline Coni & 0,76 & 0,81 & 0,055 & 0,71 & 3,11 & 0 & 5,32 \\
\hline RT & 0,81 & 0,94 & 0,13 & 8,11 & 15,39 & 14,36 & 15,45 \\
\hline RPD & 2,08 & 2,93 & 0,85 & 19,86 & 40,36 & 33,46 & 40,5 \\
\hline RMS & 1,13 & 1,16 & 0,026 & 0,61 & 2,15 & 1,13 & 2,18 \\
\hline $\mathrm{FCm}$ & 0,41 & 0,47 & 0,059 & 7,78 & 13,3 & 10,9 & 13,93 \\
\hline $\mathrm{FC} 1$ & 0,76 & 0,84 & 0,079 & 3,74 & 9,16 & 6,56 & 9,81 \\
\hline $\mathrm{FC} 2$ & 0,37 & 0,27 & 0,093 & 11,12 & 24,51 & 19,93 & 24,69 \\
\hline $\mathrm{FVm}$ & 0,56 & 0,61 & 0,048 & 5,0 & 8,05 & 7,05 & 8,41 \\
\hline FV1 & 0,28 & 0,33 & 0,046 & 6,72 & 14,77 & 12,45 & 15,92 \\
\hline FV2 & 0,58 & 0,27 & 0,31 & 21,79 & 49,08 & 36,83 & 50,78 \\
\hline $\mathrm{Db}$ & 0,35 & 0,43 & 0,087 & 13,67 & 21,54 & 19,08 & 24,14 \\
\hline $\mathrm{f}_{\mathrm{sr}}$ & 68,32 & 76,37 & 8,06 & 4,58 & 10,25 & 8,82 & 11,37 \\
\hline$f_{\text {st }}$ & 78,88 & 91,67 & 12,79 & 6,02 & 13,66 & 11,22 & 15,5 \\
\hline$f_{c}$ & 572,17 & 654,15 & 81,98 & 6,36 & 12,69 & 11,59 & 13,94 \\
\hline$f_{f}$ & 1276,2 & 1516,96 & 240,68 & 10,03 & 18,02 & 15,27 & 18,35 \\
\hline$E_{f}$ & 194169 & 234810 & 40641 & 11,92 & 19,52 & 16,30 & 20,28 \\
\hline $\mathrm{f}_{\mathrm{t}}$ & 38,37 & 45,27 & 6,90 & 7,2 & 14,57 & 9,95 & 16,79 \\
\hline
\end{tabular}


Tabela 21. Valores dos diferenciais de seleção "ds" e dos ganhos de seleção a nivel de totais $\left(G s_{t} \%\right)$ e a nível de médias $\left(G s_{m} \%\right)$, com seus respectivos limites inferiores e superiores do intervalo de confiança (IC) para o Eucalyptus urophylla.

\begin{tabular}{|c|c|c|c|c|c|c|c|}
\hline Código & Média & $\begin{array}{c}\text { Média } \\
\text { estimada }\end{array}$ & $\begin{array}{l}\text { Diferencial } \\
\text { de seleção } \\
\text { "ds" }\end{array}$ & $\mathrm{Gs}_{\mathrm{t}}(\%)$ & $G s_{m}(\%)$ & $\begin{array}{r}I C \\
\mathrm{Gs}_{\mathrm{mi}}(\%)\end{array}$ & $G s_{m s}(\%)$ \\
\hline Coni & 0,79 & 0,84 & 0,043 & 0,29 & 0,81 & 0 & 3,91 \\
\hline RT & 0,57 & 0,64 & 0,063 & 2,17 & 8,23 & 1,36 & 9,95 \\
\hline RPD & 1,58 & 2,24 & 0,66 & 9,46 & 31,64 & 17,87 & 39,03 \\
\hline RMS & 1,12 & 1,16 & 0,032 & 1,43 & 2,86 & 1,38 & 2,67 \\
\hline $\mathrm{FCm}$ & 1,83 & 1,42 & 0,40 & 7,45 & 20,51 & 15,39 & 21,32 \\
\hline $\mathrm{FC} 1$ & 1,61 & 1,42 & 0,18 & 3,13 & 8,71 & 4,63 & 10,68 \\
\hline $\mathrm{FC2}$ & 0,70 & 0,45 & 0,24 & 4,85 & 22,08 & 0 & 30,16 \\
\hline $\mathrm{FVm}$ & 3,29 & 2,65 & 0,68 & 6,92 & 18,0 & 12,49 & 18,57 \\
\hline FV1 & 3,6 & 2,81 & 0,79 & 6,21 & 18,69 & 11,94 & 20,81 \\
\hline FV2 & 2,88 & 2,31 & 0,57 & 4,42 & 17,41 & 1,77 & 17,65 \\
\hline $\mathrm{Db}$ & 0,39 & 0,43 & 0,39 & 2,19 & 6,02 & 4,81 & 10,87 \\
\hline$f_{s r}$ & 69,63 & 73,49 & 3,86 & 0,29 & 1,26 & 0 & 4,36 \\
\hline$f_{s t}$ & 80,81 & 89,58 & 8,77 & 3,94 & 9,17 & 7,68 & 10,49 \\
\hline$f_{c}$ & 595,12 & 638,96 & 43,83 & 1,48 & 6,02 & 3,49 & 6,92 \\
\hline$f_{f}$ & 1376,4 & 1460,23 & 83,80 & - & - & 0 & 2,67 \\
\hline$E_{f}$ & 215464 & 231122 & 15657 & 0,43 & 1,98 & 0 & 5,88 \\
\hline $\mathrm{ft}_{\mathrm{t}}$ & 44,43 & 49,47 & 5,04 & 1,16 & 6,61 & 0 & 9,11 \\
\hline
\end{tabular}


A grande variabilidade das características analisadas em ambas as espécies foram altas, resultando em herdabilidades também altas e consequentemente, os ganhos de seleção foram bons.

Todas as propriedades analisadas neste estudo apresentaram altos valores de herdabilidade, para ambas as espécies, corroborando com diversos autores, que afirmam ser as características tecnológicas da madeira altamente herdáveis (Ferreirinha, 1961; Ferreira \& Kageyama, 1978; Malan, 1984, 1988abc, 1990, 1995, 2000; Fernandes, 1982, 1986a,b; Moraes, 1997; Garcia \& Lima, 1990; Lahr, 1990; Ferreira, 1992; Malan \& Verry (1996); Combes et al., 1997; Lelles \& Silva, 1997; Pires \& Paula (1997); Schacht e Garcia, 1997a,b; Oliveira, 1998; Schacht, 1998; Assis, 1999 e Lima, 2000).

Assim, para ambas as espécies, as variáveis que forneceram os maiores ganhos com a seleção do material, sem levar em conta as possiveis correlações indesejáveis foram para o E. grandis : FV1, RPD, FC2, $\mathrm{Db}, \mathrm{E}_{\mathrm{f}}$ e $\mathrm{f}_{\mathrm{f}}$ e para o $E$. urophylla foram: RPD, FC2, FCm, FV1, FVm e FV2.

Dos resultados obtidos nos ganhos de seleção, juntamente com os resultados dos componentes de variância (Tabela 15) do $E$. grandis (com maiores variâncias), pode-se afirmar que se trata de um material mais propicio ao melhoramento do que o $E$. urophylla, que apresentou diferenças não significativas entre clones $\left(Q_{c}\right)$ para algumas propriedades $e$ menores resultados numéricos das estimativas de variâncias para a maioria das variáveis estudadas.

Para ambas as espécies os coeficientes "b", mostraram-se próximos de 1, exceto para a conicidade, indicando que os materiais apresentarão ganhos efetivos no melhoramento genético para as variáveis estudadas. 


\subsection{Conclusões}

- Os melhores clones em ordem decrescente para o E. grandis foram 28228 , 37611,24504 e o 28261. Para o E. urophylla foram 351, 39 e o 447.

- Os piores clones do $E$. grandis foram os $30543,31510,36838,42128$ e o 42273. Para o E. urophylla foi o 113, que não se destacou em nenhum ensaio realizado.

- A maioria das variáveis estudadas mostraram-se altamente herdáveis, propiciando altos ganhos com a seleção para a rachadura da prancha diametral, da ordem de $40 \%$ para o E. grandis e $31 \%$ para o E. urophylla, em uma intensidade de seleção relativamente baixa, de aproximadamente 1:5, para ambas as espécies, podendo estar superestimado em função dos valores negativos encontrados para os componentes da variância da posição da tora e também para a interação do clone com a posição.

- Apesar do E. urophylla apresentar-se menos cônico, o seu rendimento em madeira serrada foi interior ao do E. grandis, mostrando que nem sempre o material menos cônico proporciona melhores rendimentos.

- Ambas as espécies apresentaram altas herdabilidades para todas as características estudadas, exceto a conicidade.

- Há necessidade de estabelecer uma ordem de prioridades das variáveis tecnológicas, no melhoramento do E. grandis e E. urophylla para serraria, uma vez que é muito difícil encontrarem-se clones dotados de um número elevado de características favoráveis.

- A flecha da vigota obtida da primeira costaneira serrada da tora foi mais representativa do nível de tensão residual que existia na tora antes do desdobro.

- Os coeficientes "b" $\left(\mathrm{CV}_{\mathrm{g}} / \mathrm{CV}_{\mathrm{f}}\right)$, mostraram-se próximos de 1 para a maioria das características testadas, exceto conicidade, indicando que o material é 
efetivo no caso de seleção visando o melhoramento da madeira para a serraria.

- Para todas as características testadas o Quadrado Médio devido a interação entre os clones $\left(Q_{\mathrm{C}}\right)$, para ambas as espécies, apresentaram diferenças estatísticas para todas as características estudadas, indicando variabilidade do material .

- Através dos resultados dos Quadrados Médios devido a posição $\left(\mathrm{QM}_{\mathrm{T}}\right)$ e os da interação Clone $x$ Tora $\left(\mathrm{QM}_{\mathrm{CXT}}\right)$, pode-se observar a discrepância de resultados obtidos para ambas as espécies, em relação as várias características tecnológicas, indicando que não se pode extrapolar os resultados obtidos de uma espécie para outra espécie do mesmo gênero, os comportamentos são diferenciados. 


\section{CORRELAÇÕES ENTRE AS PRINCIPAIS CARACTERISTICAS TECNOLÓGICAS DA MADEIRA DE CLONES DE Eucalyptus grandis E Eucalyptus urophylla}

\section{Resumo}

A homogeneidade da madeira facilita o processamento mecânico e aumenta $\circ$ rendimento em madeira serrada. As propriedades mecânicas são requisitos básicos para a utilização da madeira para diversos fins e o gênero Eucalyptus atende às mais diferentes exigências destas propriedades. Para o presente estudo utilizou-se como material genético, 18 clones de Eucalyptus grandis e quinze clones de Eucalyptus urophylla, para o estudo de propriedades tecnológicas da madeira relacionadas e as tensões de crescimento, através do estudo das correlações genéticas, fenotípicas e correlações de Pearson para treze características tecnológicas da madeira, sendo uma propriedade física (densidade básica) e doze mecânicas (ensaios de desdobro de toras em serraria e ensaios mecânicos laboratoriais). As correlações lineares, genéticas e fenotípicas encontradas demonstram a possibilidade de obterem-se ganhos em uma propriedade importante, a partir da seleção de outra variável de obtenção mais fácil. Nenhum clone apresentou bons resultados para todas as características simultaneamente. Portanto, é necessário estabelecer prioridades para a condução de programas de melhoramento genético. As duas espécies mostraram-se discrepantes para os 
diversos tipos de correlação, provando que não se pode extrapolar os resultados obtidos em espécie para outras espécies do mesmo gênero.

\section{FOUR CORRELATIONS AMONG THE MAIN TECHNOLOGICAL CHARACTERISTICS OF WOOD FOR CLONES OF Eucalyptus grandis AND Eucalyptus urophylla}

\section{Summary}

The wood homogeneity facilitates the mechanical processing and enhances the sawed timber yield. Good mechanical properties are basic requirements when using wood for different purposes and the Eucalyptus genus satisfies the most varied needs as to such characteristics. Eighteen clones of Eucalyptus grandis and fifteen clones of Eucalyptus urophylla were taken as genetic material for evaluating the wood technological properties related to growth stresses, by means of studying genetic and phenotypic correlations, as well as Pearson's correlations, for thirteen wood technological characteristics, being one physical (basic density) and twelve mechanical properties (log sawing tests in sawmill and mechanical tests in laboratory). The linear, genetic and phenotypic correlations evidence the possibility of achieving gains for an important property through the selection of a more easily obtainable variable. None of the clones presented good results for all characteristics simultaneously. Therefore, the establishment of priorities is necessary when genetic improvement programs are to be carried out. Both species showed to be discrepant as to the different correlation types, proving that results cannot be extrapolated between species of the same genus. 


\subsection{Introdução}

A uniformidade é uma das características mais valorizadas em serrarias em função do aumento da produtividade e no rendimento em madeira serrada. O processamento mecânico é facilitado, chegando a atingir uma melhor qualidade quando a madeira é uniforme dentre as suas várias propriedades mecânicas (Ponce, 1995).

A combinação da busca de uniformidade da matéria-prima, com a melhoria da qualidade do produto final e busca de novas fontes de abastecimento, uma vez que a madeira nativa passou a ser escassa em determinadas regiōes, gerou uma reação econômica, com a busca de maiores valores agregados para a madeira produzida nas florestas plantadas. Isso resultou na introdução da madeira de eucalipto na indústria moveleira, produzida especialmente para o uso industrial e de localização próxima aos centros de processamento e consumo. Algumas empresas optaram pelo desenvolvimento de clones provenientes de matrizes selecionadas e melhoradas para usos especificos, como aqueles destinados à produção de madeira para serraria (Malan, 1995; Obino, 1996; Assis, 1999; Oliveira, 1999; e Malan, 2000).

A variabilidade genética é também um ponto fundamental a ser considerado no desenvolvimento de programas de melhoramento genético. Existindo variabilidade e principalmente, se a participação de componentes genéticos na manifestação das características for expressiva, pode-se prever as possibilidades de ocorrerem alterações desejadas nas características sob seleção (Resende \& Vencovsky, 1990).

Diante da variabilidade natural entre e dentro de populações, espera-se encontrar consideráveis variações genéticas entre árvores para as propriedades da madeira nas várias espécies de Eucalyptus (Malan, 1995). 
Para Shimoyama \& Barrichelo (1989) é de grande importância para o melhoramento conhecer as correlações genéticas e fenotípicas entre as características a serem melhoradas, e as demais características da árvore, como por exemplo, a densidade básica e as características de crescimento.

A existência de variabilidade fenotípica entre espécies, procedência, famílias e indivíduos para diversas características tecnológicas de interesse (Malan, 1998) e o forte controle genético envolvido na expressão da grande maioria dessas mesmas características, asseguram a possibilidade de obtenção de madeira de alta qualidade para suprir as necessidades industriais, a partir da implementação de programas de melhoramento genético.

As rachaduras e empenamentos da madeira serrada estão entre os principais problemas que afetam a qualidade e o rendimento em madeira serrada do eucalipto e que têm como causa fundamental as tensões de crescimento.

São poucos os trabalhos que quantificam os efeitos genéticos das tensões de crescimento (Fernandes, 1982; Malan, 1984 e 1987), onde Schacht (1998), encontrou para as características rachaduras e empenamentos da madeira serrada verde em clones de $E$. urophylla, uma alta herdabilidade concluindo que estas características podem ser selecionados geneticamente ainda no campo através das rachaduras de extremidade das toras.

As variações verificadas nos diferentes materiais genéticos ocorrem de forma diferenciada, fazendo com que dificilmente se consiga encontrar grupos de árvores ou indivíduos, dotados de um número elevado de características desejadas e que sejam também favoravelmente correlacionadas. A junção de características torna-se muito importante para possibilitar a seleção de árvores que tenham maior quantidade de atributos tecnológicos na sua madeira. Este deve ser o grande desafio dos programas de melhoramento do 
gênero Eucalyptus, voltados à produção de madeira para a obtenção de produtos sólidos.

O presente trabalho objetivou fornecer um melhor embasamento para os programas de melhoramento genético visando a melhoria da qualidade da madeira serrada, desta forma, dando subsídios para serrarias que dependem do abastecimento de madeira de eucalipto com baixas tensões de crescimento, com preços acessiveis e de boa qualidade, buscando sempre um material genético que proporcione menores perdas na linha de desdobro. Assim, pretendeu-se através do estudo das correlações lineares, genéticas e fenotípicas, avaliar as principais características tecnológicas da madeira e encontrar as melhores correlações entre as mesmas, visando principalmente, a possibilidade de se aplicar a seleção indireta no material estudado.

\subsection{Material e métodos}

Para o presente estudo foram escolhidos 15 clones de $E$. urophylla e 18 de E. grandis de interesse fenotípico visando a sua utilização em serrarias.

Os clones foram selecionados em bancos clonais, situados em Bom Despacho-MG, que apresenta as seguintes características climáticas: altitude de $720 \mathrm{~m}$, latitude de $19^{\circ} 44^{\prime} \mathrm{S}$, longitude de $45^{\circ} 15^{\prime} \mathrm{W}$, precipitação média anual de $1375 \mathrm{~mm}$ e temperatura média anual de $23,1^{\circ} \mathrm{C}$. O tipo predominante de solo é o latossolo vermelho escuro com horizonte $\mathrm{B}$ textural bem definido.

$O$ delineamento experimental adotado foi $O$ inteiramente casualizado com parcelas subdivididas, e dentro de cada clone foram selecionados aleatoriamente 6 árvores com DAP $\geq 15 \mathrm{~cm}$, na idade de 8 anos, plantados no espaçamento $2 \times 3 \mathrm{~m}$. De cada árvore selecionada foram retiradas 
2 toras (subparcela) consecutivas de $2,5 \mathrm{~m}$ de comprimento, sendo a primeira a partir de $15 \mathrm{~cm}$ do nivel do solo.

Para a análise de covariância entre duas variáveis qualquer, utilizaram-se as expressōes das esperanças dos Produtos Médios (PM) explanados na Tabela 22, baseando-se no modelo matemático dado pela eq. (12).

$Y_{i j k}=m+C_{i}+e_{i j}+T_{j}+C T_{i j}+e_{i j k}$

Em que:

$\mathbf{Y}_{\mathbf{i j k}}$ é a observação na Tora (posição) $\mathbf{j}(\mathrm{j}=1,2)$ da árvore $\mathbf{k}(\mathbf{k}=1, \ldots, 6)$ no Clone $\mathbf{i}$ (i=1,2,3,...15 ou 18);

m é a média geral, fixa;

$\mathbf{C}_{\mathbf{I}}$ é o efeito Clone i ( $\mathrm{i}=1,2,3, \ldots .15$ ou 18$)$, aleatório;

$\mathbf{e}_{\mathrm{ij}}$ é o erro experimental associado ao Clone i na Tora j, aleatório;

$T_{\mathbf{j}}$ é o efeito Tora $\mathbf{j}$ (posição), com ( $\mathrm{j}=1,2$ ), fixo;

$\mathrm{CT}_{\mathrm{j}}$ é o efeito da interação da Tora (posição) j com o Clone i, aleatório;

$\mathbf{e}_{\mathrm{ijk}}$ é o erro experimental associado na Tora (posição) j o indivíduo k do Clone i.

Tabela 22. Componentes de variância dos produtos médios para as variáveis $X$ e $\mathrm{Y}$, segundo o modelo matemático, com i Clones, $\mathbf{k}$ árvores/Clone e j Toras/árvore

\begin{tabular}{lll}
\hline $\begin{array}{l}\text { Fator de } \\
\text { variação }\end{array}$ & G.L. & $E(P M)$ \\
\hline Clone $\left(C_{i}\right)$ & $(I-1)$ & $\operatorname{Var}(X+Y)_{e}+J \operatorname{Var}(X+Y)_{a}+k \operatorname{Var}(X+Y)_{c t}+j k \operatorname{Var}(X+Y)_{c}$ \\
Erro a $\left(e_{i j}\right)$ & $I(J-1)$ & $\operatorname{Var}(X+Y)_{e}+J \operatorname{Var}(X+Y)_{a}$ \\
Total a & $(J-1$ & \\
Tora $\left(T_{j}\right)$ & $(J-1)$ & $\operatorname{Var}(X+Y)_{e}+k \operatorname{Var}(X+Y)_{c t}+\Phi(X+Y)_{T}$ \\
$C_{i} X T_{j}$ & $(I-1)(J-1)$ & $\operatorname{Var}(X+Y)_{e}+k \operatorname{Var}(X+Y)_{c t}$ \\
Erro e $\left(e_{i j k}\right)$ & $I(J-1)(K-1)$ & $\operatorname{Var}(X+Y)_{e}$ \\
Subtotal b & $I J(K-1)$ & \\
Total & $I J K-1$ & \\
\hline
\end{tabular}


Assim:

$\operatorname{Var}(X+Y)_{c}=$ Estimativa da variância genética entre Clones para as variáveis $X$ e $Y$;

$\Phi(X+Y)_{T}=$ Componente quadrático, variância das Toras (posições) para as variáveis $(X, Y)$, numa mesma árvore;

$\operatorname{Var}(X+Y)_{\mathrm{cp}}=$ Estimativa da variância da interação entre Clones e a Tora dentro de clones, das variáveis $X$ e $Y$;

$\operatorname{Var}(X+Y) a($ eij $)=$ Estimativa da variância do erro a devido à interação entre clones $(i=1,2, \ldots 15$ ou 18$)$ para as variáveis $X$ e $Y$;

$\left.\operatorname{Var}(X+Y) e_{(e i j k}\right)=$ Estimativa da variância do erro e devido a interação na tora $\mathbf{j}$ dos indivíduos $\mathbf{k}$ no clone $\mathbf{i}$ do experimento, para as variáveis $X$ e Y;

Os parâmetros dos componentes dos produtos médios da variação fenotípica para as variáveis $X$ e $Y$ foram estimados através da análise da variância da soma dos dados experimentais, provenientes de ensaios com seis repetições. O procedimento da avaliação consistiu em obterem-se os Produtos Médios $(P M)$ da soma de duas variáveis $(X+Y)$ da análise de variância, onde estabeleceram-se as esperanças matemáticas destes $P M$, de acordo com o modelo que rege o delineamento e finalmente resolveram-se as equações resultantes, que posteriormente forneceram as covariâncias através da eq. 13. Para o cálculo das correlações genéticas $\left(r_{G \times Y}\right)$ e fenotípicas $\left(r_{f X Y}\right)$, utilizaram-se as equações 14 e 15 respectivamente, utilizando-se os resultados das covariâncias calculadas na eq. 13.

Os coeficientes de correlação genético e fenotípico, para este estudo, foram referenciados como indicadores de baixa correlação quando apresentarem valores de 0 a 0,49 . Os valores entre 0,50 e 0,69 foram considerados de média correlação e os valores entre 0,70 e 0,90, considerados como sendo de boa correlação. Os valores acima de 0,90 foram considerados 
de alta correlação. Assim, as correlações genéticas e fenotípicas que encontram-se nas Tabelas 25 e 26, foram classificadas em 4 categorias.

$$
\begin{aligned}
& \operatorname{Var}(\mathrm{X}+\mathrm{Y})=\operatorname{Var}(\mathrm{X})+\operatorname{Var}(\mathrm{Y})+2 \operatorname{Cov}(\mathrm{X}, \mathrm{Y}) \\
& r_{G_{X, Y}}=\frac{\operatorname{COV}_{G(X, Y)}}{\sqrt{\sigma_{G(X)}^{2} \times \sigma_{G(Y)}^{2}}} \\
& r_{f_{X, Y}}=\frac{\operatorname{COV}_{f(X, Y)}}{\sqrt{\sigma_{f(X)}^{2} \times \sigma_{f(Y)}^{2}}}
\end{aligned}
$$

Realizaram-se, através do procedimento PROC CORR do programa SAS, correlações lineares entre as características estudadas da madeira, obtendo-se os coeficientes de correlação de Pearson entre os dados obtidos. Os resultados encontram-se nas Tabelas 23 e 24.

Os caracteres da madeira avaliados foram a $\mathrm{Db}$ (propriedade física) e onze propriedades mecânicas da madeira, além da conicidade. Assim, este estudo procurou a obtenção de bons indicadores, visando fornecer subsídios para programas de melhoramento direcionados à melhoria da qualidade da madeira para serraria.

Os caracteres avaliados foram:

- Conicidade (Coni) $(\mathrm{cm} / \mathrm{m})$;

- Rendimento em madeira serrada (RMS) ;

- Rachadura de extremidade de tora (RT) (cm);

- Rachadura de extremidade da prancha diametral (RPD) (cm);

- Flecha da costaneira $(F C)$, em valores médios $(F C m)$ e valores obtidos da primeira $(F C 1)$ e da segunda costaneira $(F C 2)(\mathrm{cm})$; 
- Flecha da vigota (FV) obtida a partir das respectivas costaneiras, sendo os valores médios (FVm) e os valores da primeira e da segunda vigota (FV1 e FV2) (cm);

- Densidade básica $\left(D_{b}\right)\left(\mathrm{g} / \mathrm{cm}^{3}\right)$;

- Cisalhamento radial $\left(f_{\mathrm{sr}}\right)\left(\mathrm{daN} / \mathrm{cm}^{2}\right)$;

- Cisalhamento tangencial $\left(\mathrm{f}_{\mathrm{st}}\right)\left(\mathrm{daN} / \mathrm{cm}^{2}\right)$;

- Resistência à compressão paralela às fibras $\left(f_{c}\right)\left(\right.$ daN $\left./ \mathrm{cm}^{2}\right)$;

- Módulo de elasticidade na flexão estática $\left(E_{f}\right)\left(\right.$ daN $\left./ \mathrm{cm}^{2}\right)$;

- Resistência à flexão estática $\left(\mathrm{f}_{\mathrm{f}}\right)\left(\mathrm{daN} / \mathrm{cm}^{2}\right)$;

- Resistência à tração paralela às fibras $\left(f_{t}\right)\left(\mathrm{daN} / \mathrm{cm}^{2}\right)$.

As toras obtidas das árvores selecionadas foram transportadas para a serraria do Departamento de Ciências Florestais da ESALQ/USP - Piracicaba, onde foram imediatamente desdobradas, propiciando as primeiras medições das variáveis selecionadas. Ainda na condição verde, foram obtidos os dados necessários para o cálculo das seguintes variáveis: Coni, RMS, RT, RPD, e por fim, flecha das costaneiras 1 e 2 ( $F C 1$ e FC2) e flecha das vigotas obtidas a partir das respectivas costaneiras (FV1 e FV2).

O desdobro foi efetuado em serra de fita simples de diâmetro de volante de $1100 \mathrm{~mm}$, carro porta tora tipo pesado.

A determinação da densidade básica foi realizada pelo método da balança hidrostática descrito por Souza et al. (1986).

As variáveis resistência ao cisalhamento, flexão estática, módulo de elasticidade na flexão estática e a resistência a tração, foram executados em máquina universal de ensaio da marca Losenhausenwerk, com capacidade de 6 toneladas. Antes do início dos testes laboratoriais com os corpos de prova, determinou-se a umidade dos mesmos. Para os ensaios laboratoriais, confeccionaram-se 2 corpos de prova por árvore, totalizando 12 ensaios por clone. 


\subsection{Resultados e Discussão}

Nas Tabelas 23 e 24, encontram-se os resultados dos coeficientes de correlação de Pearson, da correlação linear entre as características da madeira, para o E. grandis e E. urophylla, respectivamente.

As correlações lineares mais procuradas foram aquelas observadas entre as propriedades físico-mecânicas com as variáveis do processamento mecânico da madeira.

Não houve correlação da conicidade com a propriedade física densidade básica (Db) e nem com as propriedades mecânicas da madeira, exceto para o E. grandis que apresentou correlações negativas e significativas da conicidade com as flechas das costaneiras e as respectivas vigotas. Entretanto, Malan (1984) e Purnell (1988), não encontraram correlações da conicidade com as tensões de crescimento. Para o E. grandis, diminuindo-se a conicidade das toras, aumenta-se a flecha, indicando que a seleção através da conicidade não é desejável.

Os coeficientes de correlação do E. urophylla para a característica rendimento (RMS), não foram significativos em nenhuma correlação existente com as outras características, exceto com a RT e a RPD , que mostraram-se positivas e significativas, concluindo que, a uma diminuição das rachaduras, diminuir-se-á em RMS, apesar dos valores dos coeficiente serem baixos. Para o E. grandis, ocorreu uma correlação significativa e positiva $(0,17)$ do RMS com a FC1, indicando que a um aumento em flecha, corresponde a uma pequeno aumento em RMS, o que também não é desejável.

Somente para o E. grandis foi positiva e significativa $(0,30)$ a correlação entre a RPD com a RT, corroborando com Malan (2000) que alega que a rachadura em topo de tora não é controlada somente pelos niveis de 
tensão de crescimento, mas por outros fatores, tais como diferenças na resistência ao cisalhamento e/ou presença de grã reversa.

Segundo Malan (2000), não encontrou correlações entre RT com a RPD, porém as que observou foram muito pequenas e não significativas, independente da posição ao longo da árvore. As toras que apresentam baixos niveis de rachaduras não necessariamente produziram tábuas serradas com baixos niveis de rachaduras. Outros pesquisadores encontraram resultados semelhantes (Crespo, 2000; Lopes, 2000 e Lima, 2000).

O módulo de elasticidade não se correlacionou com as características de desdobro da tora de E. urophylla, mas para o E. grandis, apresentou uma correlação negativa e significativa com a RPD, indicando que a um aumento no módulo de elasticidade, corresponde a uma diminuição em rachadura de extremidade da prancha, portanto favorável ao melhoramento.

A Db apresentou correlação positiva e significativa com todas as propriedades mecânicas avaliadas no laboratório, para ambas as espécies. Boyd (1979) encontrou correlação entre a Db e o módulo de elasticidade. Brotero (1945), Hillis (1984), Mendes (1984), Sales (1991) e Nascimento (1993), mostraram que quanto maior a densidade, maiores são as propriedades mecânicas de resistência da madeira. Para o E. grandis a Db não se correlacionou com nenhuma outra característica do processamento mecânico da tora, exceto com a RPD, cujo coeficiente foi de $-0,32$, onde aumentando-se a Db, diminuir-se-á a RPD .

No caso do $E$. urophylla, houveram correlações da $\mathrm{Db}$ com as variáveis do processamento mecânico em serraria, sendo estas correlações negativas e significativas para FCm, FC1, FVm, FV1 e FV2, com valores de $-26,7 \% ;-31,8 \%, 36,1 \% ;-24,4 \%$, e $-17,1 \%$, respectivamente. Do ponto de vista do melhoramento, estas correlações são de interesse pois, através de medições de flechas, pode-se melhorar a densidade do material, que para este trabalho, a Db do material apresentou-se baixa. 
Neste trabalho não foi encontrada uma correlação da $\mathrm{Db}$ com as rachaduras de toras (RT), para ambas as espécies, concordando com o trabalho de Fernandes (1986a) que também não detectou correlação entre as rachaduras de extremidades dos toretes com a densidade básica média da madeira para o E. urophylla. Segundo Fernandes (1982), a Db apresentou correlação alta e positiva com o $\mathbb{R}$ (índice de rachadura) em duas das cinco progênies estudadas de E. urophylla. Purnell (1988) encontrou correlação da $\mathrm{Db}$ com as rachaduras de tora.

A resistência à compressão paralela às fibras do $E$. grandis, não se correlacionou com nenhuma variável do processo de desdobro e nem com as características tecnológicas da madeira, diferindo do $E$. urophylla, onde ocorreram correlações positivas e significativas com todas as características tecnológicas de resistência da madeira. Para o E. urophylla, ocorreram correlações inversas entre a compressão e as variáveis das flechas ( $F C m, F C 1$ e FV1), sendo estas favoráveis ao melhoramento, pois aumentandose a compressão, melhora-se o material que menos flete. Lopes (2000) encontrou para o E. saligna uma correlação positiva entre a densidade básica $(\mathrm{Db})$ e a resistência à compressão paralela às fibras, onde este resultado foi observado para o E. urophylla.

A resistência à flexão apresentou o mesmo comportamento do módulo de elasticidade na flexão com relação às suas correlações com as demais variáveis. Em princípio pode-se concluir que é desnecessária a realização dos dois ensaios, pois uma pode ser relativamente bem estimada pela outra. Somente para o $E$. grandis estas duas propriedades correlacionaram-se e foram negativas e significativas com a RPD, sendo portanto, favorável ao melhoramento, pois aumentando-se a resistência a flexão ou o módulo de elasticidade, diminuir-se-á a RPD.

As variáveis cisalhamento $\left(f_{s r}\right.$ e $f_{s t}$ ), para o E. grandis mostraram-se correlacionadas e foram positivas e significativas com todas as propriedades de resistência mecânica testas em laboratório, exceto com a 
resistência à tração, fato esse que não foi verificado para o $E$. urophylla, sendo estas correlações não significativas. No E. urophylla, verificou-se somente a correlação positiva e significativa entre o cisalhamento tangencial $\left(f_{s t}\right)$ e a resistência à flexão $\left(\mathrm{f}_{\mathrm{f}}\right)$.

A variável resistência à tração $\left(\mathrm{f}_{\mathrm{t}}\right)$ correlacionou-se com as variáveis do processamento mecânico RMS, RT, RPD, FCm, FC2, FVm, FV1 e $F V 2$, e também com as variáveis $D b, f_{s t}, f_{f}$ e $E_{f}$ no $E$. grandis. Para o $E$. urophylla, essas correlações não foram verificadas, que se correlacionou somente com as variáveis $\mathrm{Db}, \mathrm{f}_{\mathrm{c}}, \mathrm{f}_{\mathrm{f}} \in \mathrm{E}_{\mathrm{f}}$. Portanto, pode-se dizer que para o $E$. grandis a variável resistência à tração se correlaciona linearmente com a maioria das outras propriedades mecânicas e com a $\mathrm{Db}$, sendo assim, uma variável ideal para predizer o comportamento tecnológico da espécie.

Nas Tabelas 25 e 26 encontram-se os resultados das correlações genéticas (triângulo superior) e fenotípicas (triângulo inferior) entre as características da madeira estudadas neste trabalho, para $\circ E$. grandis e o $E$. urophylla, respectivamente.

As interações que estão simbolizadas por um traço nas Tabelas 25 e 26, foram consideradas não satisfatórias, sendo o módulo de elasticidade na flexão $\left(E_{f}\right)$ a variável que menos se correlacionou com outras variáveis para o E. grandis. Para o E. urophylla isso aconteceu com a variável resistência à flexão $\left(f_{f}\right)$. Estes resultados foram devidos aos valores negativos dos componentes de variância. Segundo Kalil (1963), atribui-se a um erro de amostragem o fato de uma estimativa ser negativa, podendo considerá-la como nula. Isso gera a impossibilidade de calcular as herdabilidades e consequentemente, ganhos genéticos e as correlações genéticas e fenotípicas.

Não há na literatura disponivel resultados experimentais que possam auxiliar na discussão dos resultados obtidos neste trabalho, no que se diz respeito às correlações genéticas e fenotípicas entre as propriedades mecânicas com as propriedades do processamento mecânico de toras de Eucalyptus . 
Foram diversas as correlações genéticas e fenotípicas encontradas neste trabalho, pàra ambas as espécies, porém os resultados não foram iguais para as mesmas, isto é, nem todas as características que apresentaram boas correlações para o $E$. grandis, apresentaram para o $E$. urophylla, indicando uma diferença genética e fenotípica no comportamento das espécies. Estes resultados indicam que não se pode extrapolar as correlações encontradas em uma espécie, para outras do mesmo gênero. 
Tabela 23. Coeficientes de correlação de Pearson, obtidos nas correlações entre as variáveis estudadas no E. grandis

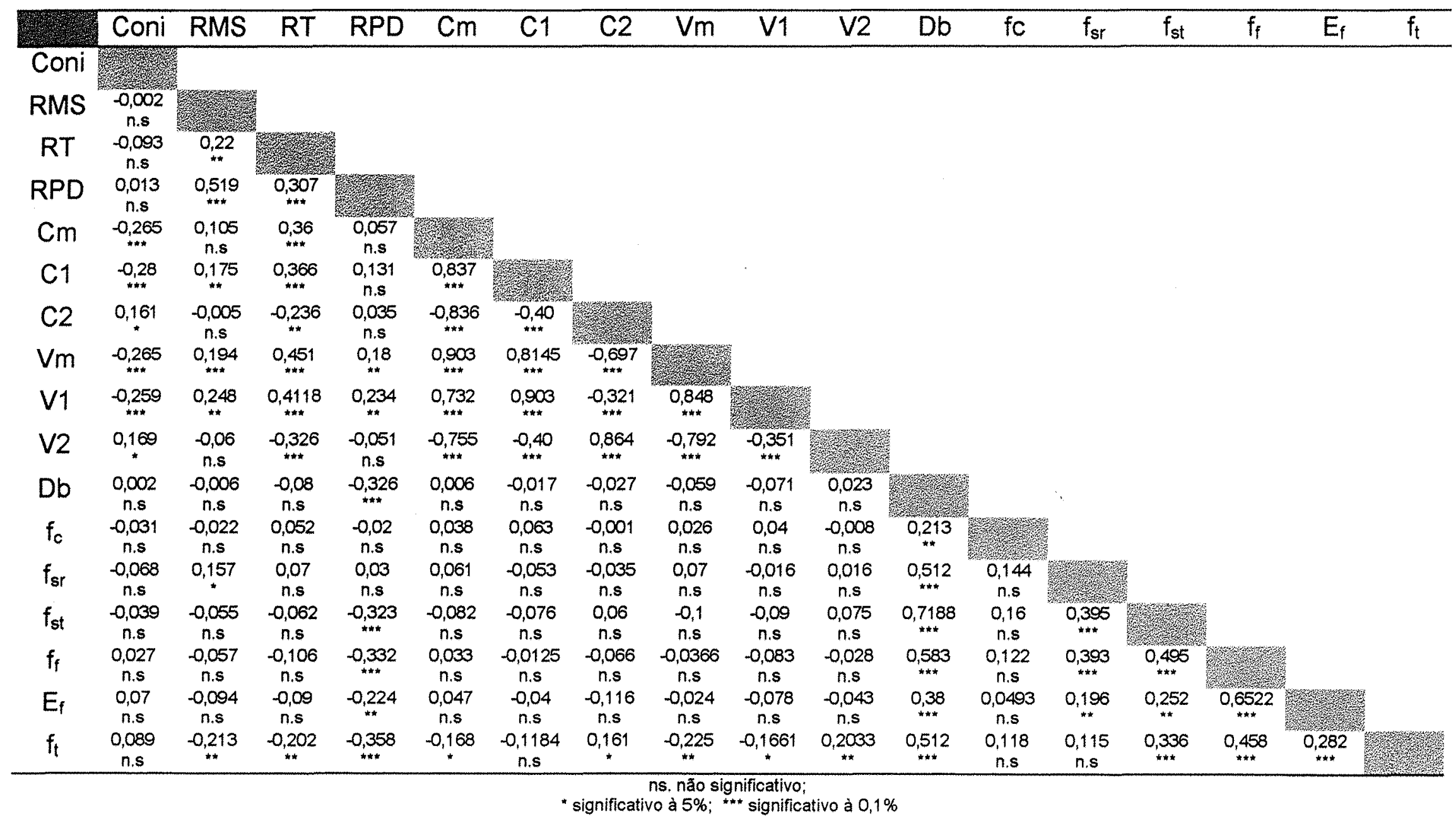


Tabela 24. Coeficientes de correlação de Pearson, obtidos nas correlações entre as variáveis estudadas no E. urophylla

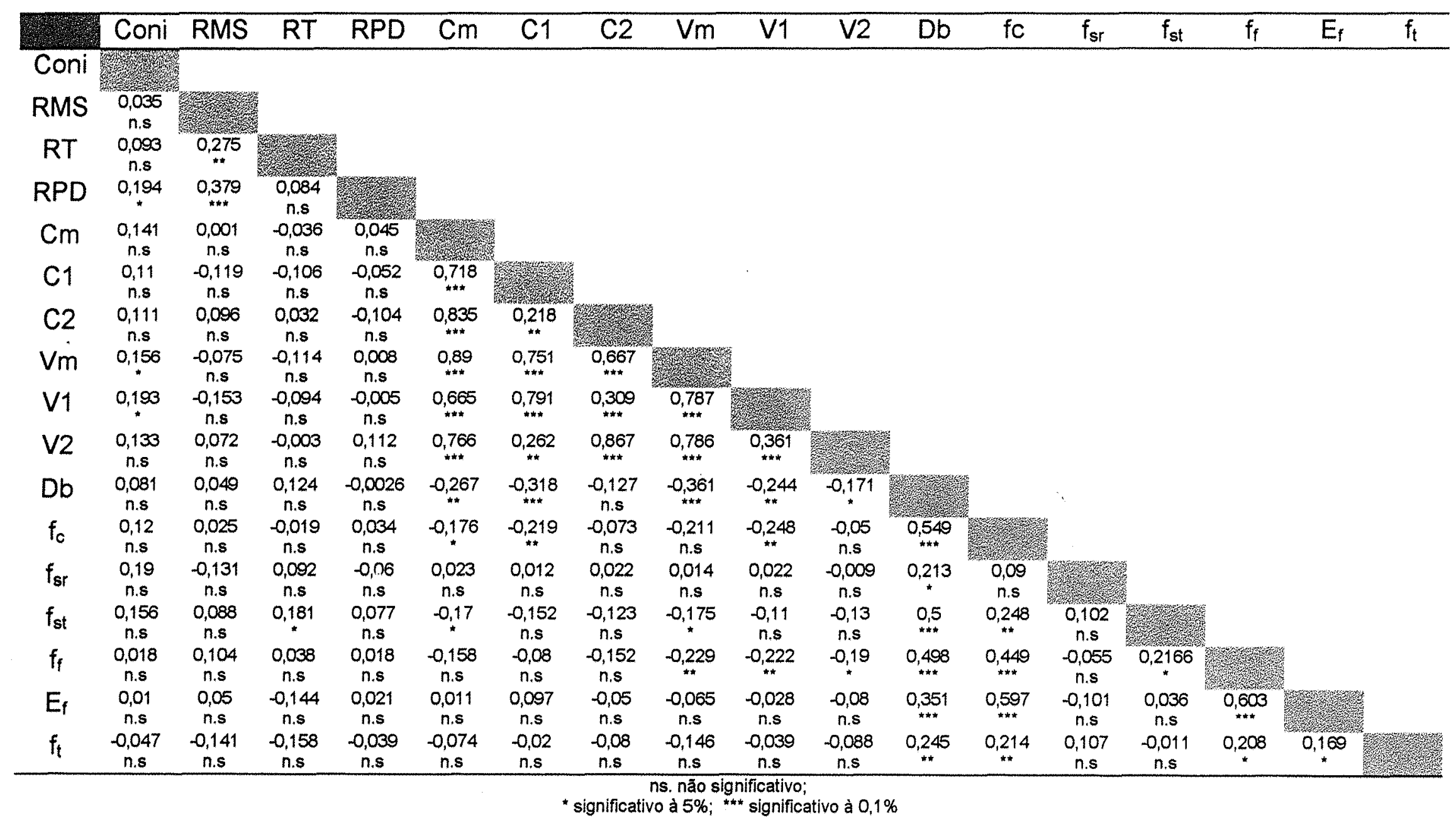


Tabela 25. Coeficientes de correlações genéticas (triângulo superior) e fenotípicas (triângulo inferior) entre as características avaliadas da madeira do $E$. grandis

\begin{tabular}{|c|c|c|c|c|c|c|c|c|c|c|c|c|c|c|c|c|c|}
\hline 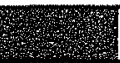 & Coni & RMS & $\mathrm{RT}$ & RPD & $\mathrm{FCm}$ & FC1 & $\mathrm{FC2}$ & $\mathrm{FVm}$ & FV1 & FV2 & $\mathrm{Db}$ & FC & $f_{s r}$ & $f_{s t}$ & $f_{f}$ & $E_{f}$ & $f_{t}$ \\
\hline Coni & 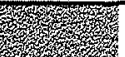 & 0,43 & 0,13 & $-0,27$ & $-0,27$ & $-0,93$ & $\overline{-}$ & $-0,34$ & $-0,42$ & - & $-0,33$ & 7 & 0,95 & - & - & - & $=$ \\
\hline RMS & 0,33 & & $-0,52$ & $-0,77$ & $-0,36$ & 0,55 & - & $-0,506$ & $-0,59$ & - & $-0,326$ & - & $-0,90$ & - & - & - & - \\
\hline RT & 0,17 & $-0,44$ & & 0,56 & 0,38 & 0,12 & 0,40 & 0,56 & 0,58 & $-0,09$ & 0,20 & - & 0,005 & 0,68 & - & - & 0,35 \\
\hline RPD & $-0,15$ & $-0,67$ & 0,55 & 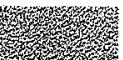 & 0,36 & 0,31 & $-0,04$ & 0,69 & 0,86 & 0,28 & 0,62 & - & 0,21 & 0,64 & - & - & 0,47 \\
\hline $\mathrm{FCm}$ & $-0,24$ & $-0,40$ & 0,38 & 0,30 & $y^{2}$ & 0,19 & - & 0,93 & 0,85 & $-0,28$ & $-0,07$ & - & 0,37 & - & - & - & 0,55 \\
\hline FC1 & $-0,70$ & 0,53 & 0,10 & 0,25 & 0,18 & (3) & 0,99 & 0,07 & 0,007 & $-0,33$ & - & - & 0,26 & 0,98 & - & - & 0,46 \\
\hline FC2 & - & - & 0,41 & 0,005 & - & 0,98 & & - & - & 0,70 & $-0,63$ & - & $-0,22$ & $-0,82$ & , & - & $-0,36$ \\
\hline $\mathrm{FVm}$ & $-0,27$ & $-0,53$ & 0,54 & 0,57 & 0,93 & 0,05 & 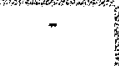 & & 0,95 & $-0,47$ & 0,11 & - & 0,48 & - & - & - & 0,95 \\
\hline FV1 & $-0,33$ & $-0,59$ & 0,54 & 0,68 & 0,84 & $-0,005$ & & & אי & $-0,80$ & 0,19 & - & 0,49 & - & - & . & - \\
\hline FV2 & - & - & 0,09 & 0,29 & 0,10 & 0,003 & & & $-0,21$ & & - & - & $-0,71$ & $-0,99$ & - & - & $-0,40$ \\
\hline $\mathrm{Db}$ & $-0,14$ & $-0,29$ & 0,12 & 0,66 & $-0,09$ & - & - & $-0,95$ & 0,13 & 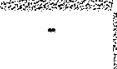 & & - & . & - & - & - & - \\
\hline$f_{c}$ & - & - & - & - & - & - & 0,42 & 0,02 & - & - & - & & - & - & 0,97 & - & - \\
\hline$f_{s r}$ & 0,46 & - & $-0,03$ & 0,31 & 0,26 & 0,19 & $-0,14$ & 0,32 & 0,33 & $-0,86$ & $-0,19$ & - & & 0,44 & 0,69 & - & 0,04 \\
\hline$f_{s t}$ & - & - & 0,54 & 0,59 & 0,46 & 0,38 & $-0,27$ & $-0,70$ & 0,80 & $-0,90$ & - & - & 0,51 & Wratry & 0,99 & - & 0,44 \\
\hline$f_{f}$ & - & - & - & - & - & - & - & - & - & - & - & 0,88 & 0,67 & 0,83 & & - & 0,06 \\
\hline$E_{f}$ & - & - & - & - & - & - & - & - & - & - & - & - & - & - & - & (3) & - \\
\hline$f_{t}$ & - & - & 0,49 & 0,63 & 0,85 & 0,67 & $-0,47$ & - & - & $-0,44$ & - & - & 0,04 & 0,41 & 0,05 & - & 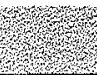 \\
\hline
\end{tabular}


Tabela 26. Coeficientes de correlações genéticas (triângulo superior) e fenotípicas (triângulo inferior) entre as características avaliadas da madeira do E. urophylla

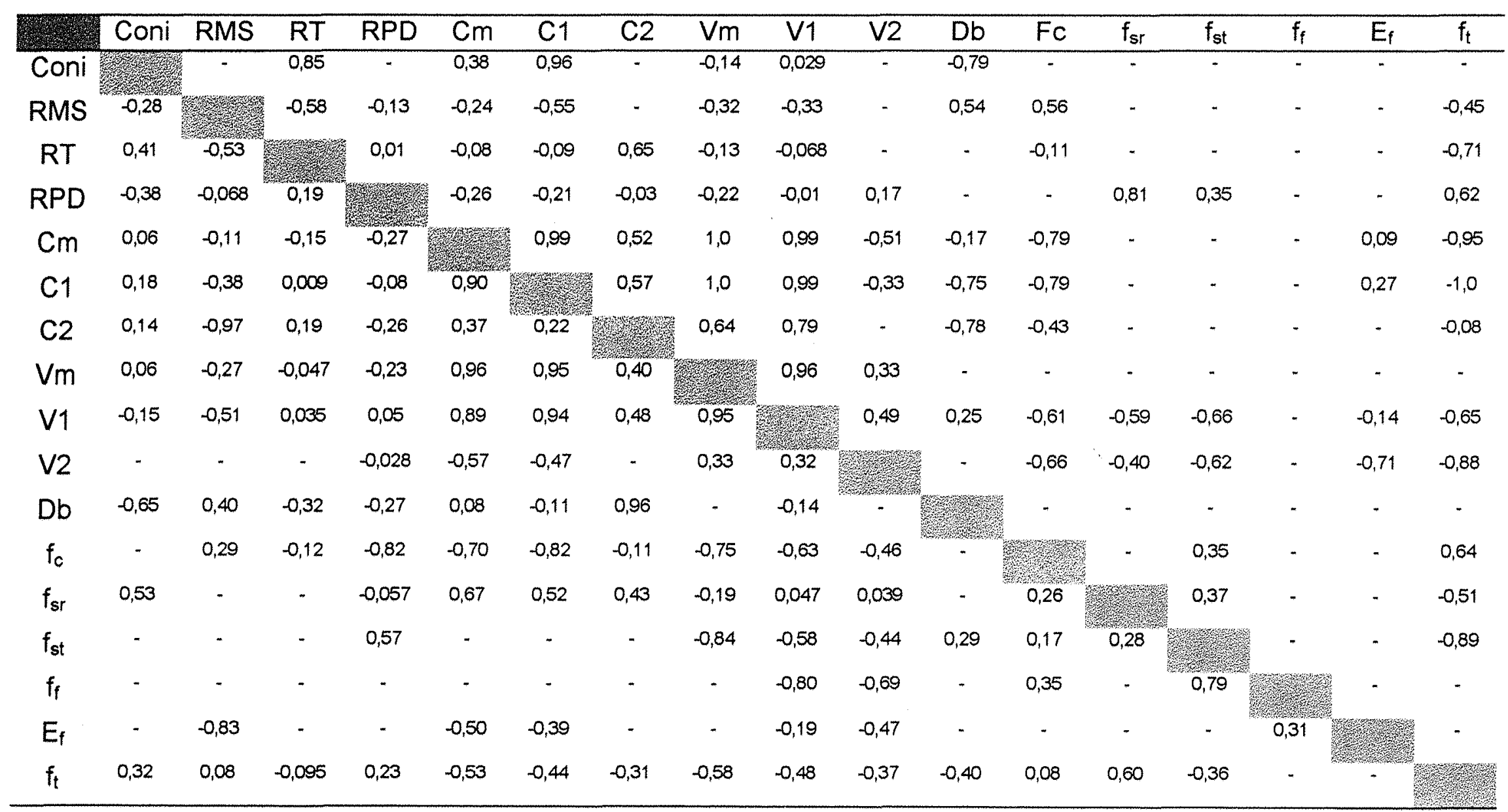


Para o E. grandis, as principais correlações genéticas e fenotípicas foram:

- A variável a conicidade correlacionou-se geneticamente com a flecha da costaneira 1 (FC1) e com o cisalhamento radial $\left(f_{\mathrm{sr}}\right)$, sendo de alta correlação com os valores genéticos de $r_{g}==-0,93$ e $r_{g}=0,95$, e correlações fenotípicas de $r_{f}=-0,70$ e $r_{f}=0,46$, respectivamente. Isto indica que, a uma diminuição na conicidade diminuir-se-á o cisalhamento e isto é desfavorável ao melhoramento, mas por outro lado, com a diminuição do cisalhamento, ocorrerá um aumentou na $\mathrm{FC} 1$, sendo também desfavorável, pois a FC1 correlaciona-se com o cisalhamento tangencial com uma alta e positiva correlação genética $(0,98)$.

- Verificou-se uma alta e negativa correlação genética do RMS com o cisalhamento radial $\left(r_{g}=-0,90\right)$, sendo isto desfavorável ao melhoramento. Em compensação, houve uma boa e negativa correlação genética dessa variável com a rachadura da prancha diametral $\left(r_{g}=-0,77\right)$, indicando que, diminuindo a incidência da RPD, aumenta-se o rendimento em madeira serrada. As correlaçōes genética e fenotípica do RMS com a FC1, podem ser consideradas médias ( $r_{g}=0,55$ e $r_{f}=0,53$, respectivamente), indicando que ao se diminuir a flecha da costaneira, tem-se uma diminuição em RMS, onde também foi observado para o coeficiente de correlação linear.

- A rachadura de topo de tora (RT) apresentou uma média e positiva correlação genética e fenotípica com a RPD e FV1 sendo de $r_{g}=0,56$ e $r_{f}$ $=0,55$ com a RPD e de $r_{g}=0,58$ e $r_{f}=0,54$, com a FV1, respectivamente. Estes resultados indicam que a RT é uma característica ideal para o melhoramento genético, podendo conduzir ao melhoramento de outras duas características ligadas as tensões de crescimento, mas pelos valores de seus coeficientes, somente corresponderia a $50 \%$ em melhoramento. Outra correlação observada foi em relação a RT com o cisalhamento tangencial $\left(\mathrm{f}_{\mathrm{st}}\right)$, sendo este desfavorável ao melhoramento, por apresentar- 
se positivo para ambas as correlações, onde diminuindo-se a RT, consequentemente ocorrerá uma diminuição do cisalhamento tangencial.

- Em relação a RPD, houve uma boa e positiva correlação genética e média e positiva correlação fenotípica com a flecha da vigota 1 (FV1), sendo isto favorável ao melhoramento. Selecionando-se clones que possuam menores valores de flechas de peça serrada, obter-se-á pranchas serradas com menores rachaduras, aumentando em RMS. Outro resultado não esperado foi em relação a RPD com a densidade básica (Db) e com o cisalhamento tangencial $\left(f_{\mathrm{st}}\right)$, que apresentaram correlação genética e fenotípica média e positiva, indicando que, ao se diminuir a incidência de RPD, diminuir-se-á a Db e o cisalhamento, sendo desfavorável ao melhoramento, já que a espécie apresentou uma baixa densidade básica para a fabricação de móveis e a característica cisalhamento é favorável a estrutura de peças trabalhadas, principalmente nos encaixes. Outra correlação observada foi entre a RPD com a tração $\left(\mathfrak{f}_{t}\right)$ onde apresentou uma média e positiva correlação fenotípica $\left(r_{f}=0,68\right)$ e uma baixa e positiva correlação genética $\left(r_{g}=0,47\right)$, indicando que através da seleção de pranchas diametrais com menor abertura da rachadura de topo da tábua, selecionarse-á um material com propriedade mecânica de mais baixa tração, onde esta propriedade está associada à estrutura de peças de madeira para a fabricação de móveis.

- Observou-se que o valor da flecha da costaneira média (FCm) correlacionou-se geneticamente e fenotipicamente $\left(r_{g}=0,55\right.$ e $r_{f}=0,85$, respectivamente) melhor com a tração do que os valores com as FC1 e FC2, porém correlacionou-se desfavoravelmente ao melhoramento com a característica tração do que com as próprias costaneiras FC1 e FC2. Ocorreu uma correlação desfavorável entre a FC1 com o cisalhamento tangencial, apresentando uma alta positiva correlação genética $\left(r_{\mathrm{g}}=0,98\right)$, onde já para a FCm não foi observado, somente uma baixa correlação fenotípica $\left(r_{g}=0,38\right)$. 
- No que diz respeito as correlações encontradas em relação a flecha das vigotas (FVm, FV1 e FV2), pode-se destacar a boa e a alta correlação fenotípica encontrada entre a FV1 e a FV2 $\left(r_{f}=0,80\right.$ e $r_{f}=-0,90$ respectivamente) com o cisalhamento tangencial $\left(f_{s t}\right)$, indicando que ao serrar as peças obtidas a partir das costaneiras, é possivel predizer se o material possuirá um bom cisalhamento para os encaixes. Somente a FV2 possuiu uma alta negativa correlação genética com as características cisalhamento $\left(f_{\mathrm{sr}}\right.$ e $\left.f_{\mathrm{st}}\right)$ sendo de $r_{\mathrm{g}}=-0,71$ e $r_{\mathrm{g}}=-0,99$, respectivamente. Portanto, deve-se escolher qual a prioridade do melhoramento para depois direcioná-lo adequadamente .

- Neste estudo a densidade básica não se correlacionou com nenhuma característica tecnológica ensaiada em laboratório. Somente ocorreu uma baixa e negativa correlação fenotípica com a característica cisalhamento radial $\left(\mathrm{f}_{\mathrm{sr}}\right)$.

- Não houve correlação genética e nem fenotípica da característica compressão $\left(f_{c}\right)$ com as outras características, somente ocorreu uma alta correlação genética positiva $\left(r_{g}=0,97\right)$ e uma boa correlação fenotípica positiva $\left(r_{f}=0,88\right)$ com a caracteristica resistência a flexão $\left(f_{f}\right)$, sendo favorável em relação ao seu uso para finalidades estruturais. Observou-se também uma alta e positiva correlação genética da flexão $\left(f_{f}\right)$ com o cisalhamento tangencial, sendo $r_{g}=0,99$, e conclui-se que o melhoramento de uma característica mecânica testada em laboratório, conduz ao melhoramento de outras características ligadas a resistência da madeira.

Para o E. urophylla, as principais correlações genéticas e fenotípicas foram:

- Para a conicidade as principais correlações genética foram com a flecha da costaneira 1 ( $F C 1$ ), rachadura de tora $(R T)$ e densidade básica $(D b)$, sendo de alta correlação genética $\left(r_{g}=0,96\right)$ e boa correlação genética $\left(r_{g}=0,85\right.$ e $r_{g}=-0,79$, respectivamente). As respectivas correlações fenotípicas foram 
de $0,18,0,41$ e $-0,65$. Isto indica que, com a diminuição da conicidade, diminuir-se-á a RT e a FC1 e aumentar-se-á a $\mathrm{Db}$, sendo favorável ao melhoramento, além disso, tem-se um boa correlação genética negativa ( $r_{\mathrm{g}}$ $=-0,75$ ) entre a FC1 com a Db, isto é, diminuindo-se a flecha da costaneira, aumentar-se-á a $\mathrm{Db}$, que mostrou-se baixa para o material estudado. Outras correlações genéticas e negativas observadas foram entre a FC1 com a tração e com a compressão, sendo também favorável, pois diminuindo-se a flecha, aumentar-se-á em resistência a tração e também em relação a compressão. Portanto, pode-se considerar a FC1 como sendo uma boa característica a ser correlacionada para esta espécie, corroborando com o trabalho de Schacht (1998).

- O rendimento em madeira serrada (RMS) não apresentou nenhuma alta correlação genética com as características estudadas. O RMS apresentou uma média e negativa correlação genética com a rachadura de tora $\left(r_{g}=-\right.$ $0,58)$, e positiva correlação genética com a densidade básica $\left(r_{g}=0,54\right)$ e a compressão $\left(r_{g}=0,56\right)$, sendo favorável a seleção de RT através do ensaio de RMS, porém apresentou uma média e negativa correlação genética com a flecha da costaneira $1\left(r_{g}=-0,55\right)$, indicando que, diminuindo-se a $F C 1$, aumentar-se-á o rendimento em madeira serrada. O RMS apresentou uma alta e também boa correlação negativa fenotípica com a FC2 e com o módulo de elasticidade (Ef), sendo de $r_{\mathrm{f}}=-0,97$ e $r_{\mathrm{f}}=-0,83$, respectivamente, indicando que a uma diminuição da flecha da costaneira 2, tem-se o aumento em RMS, por outro lado, sendo desfavorável pois, diminuir-se-á o módulo de elasticidade.

- Observou-se uma boa e negativa correlação genética da RT com a tração $\left(f_{t}\right)$, sendo de $r_{g}=-0,71$ e uma média correlação negativa com o rendimento (RMS) de $r_{g}=-0,58$. Para esta espécie as correlações genéticas e fenotípicas não apresentaram bons resultados, onde a RT somente correlacionou-se geneticamente com a flecha da costaneira $2\left(r_{g}=-0,65\right)$ e com a tração $\left(r_{g}=-0,71\right)$ e fenotipicamente correlacionou-se com a 
densidade $\left(r_{f}=-0,32\right)$. A correlação observada entre a RT e $f_{t}$ é favorável ao melhoramento, por ser negativa. Diminuindo-se a RT, consequentemente ocorrerá um aumento da tração $\left(f_{t}\right)$, sendo favorável para as estruturas de madeira. A RT é uma boa variável para a condução do melhoramento genético para ambas as espécies, corroborando com Malan $(1995,2000)$ e Schacht (1998).

- Em relação a RPD, houve uma boa e positiva correlação genética com o cisalhamento radial $\left(r_{g}=0,82\right)$ e média correlação positiva com a tração $\left(r_{g}=\right.$ 0,62), sendo desfavorável pois diminuindo-se a RPD, diminuir-se-á as características de cisalhamento e tração. Houve uma boa e negativa correlação fenotípica entre a RPD com a compressão $\left(r_{f}-0,82\right)$, mas não obteve-se nenhuma correlação genética entre estas duas variáveis, indicando que, mesmo diminuindo a RPD e aumentando-se a compressão, esta correlação será favorável. Outro resultado desfavorável foi em relação a RPD com o cisalhamento tangencial $\left(f_{s t}\right)$ que apresentou uma média correlação positiva fenotípica $\left(r_{\mathrm{f}}=0,57\right)$ e baixa genética $\left(r_{g}=0,35\right)$, indicando que ao se diminuir a incidência de RPD, diminuir-se-á o cisalhamento tangencial, prejudicando o melhoramento. Outra correlação observada foi entre a RPD com a Rachadura de tora (RT) onde foi insignificante a correlação genética e fenotípica $\left(r_{g}=0,01\right.$ e $r_{f}=0,19$, respectivamente), portanto, a seleção de toras que não apresentam rachaduras, não necessariamente apresentarão rachaduras nas tábuas (Malan, 2000).

- Observou-se que o valor da flecha da costaneira média correlacionou-se geneticamente $\left(r_{g}=-0,79\right.$ e $\left.r_{g}=-0,95\right)$ e fenotipicamente $\left(r_{f}=-0,70\right.$ e $r_{f}=-$ 0,53), com a compressão e com a tração, sendo favorável ao melhoramento. Porém a FC1 em relação a FC2 apresentou um valor absoluto muito melhor para estas características. A FC1 apresentou uma boa correlação genética negativa com a densidade $\left(r_{g}=-0,75\right)$, sendo favorável, pois através de uma propriedade mecânica obtida em serraria, 
pode-se melhorar uma propriedade física da madeira, já que para este material estudado seria conveniente aumentar a densidade básica, que mostrou-se baixo.

- No que se diz respeito as correlações encontradas em relação a flecha das vigotas (FVm, FV1 e FV2), pode-se destacar as correlações entre a FV1 e FV2 com a compressão, e com os cisalhamentos, sendo de correlações genéticas médias e negativas, onde para a FV1 são $\left(r_{g}=-0,61,-0,59\right.$ e $0,66)$ e para a FV2 $\left(r_{g}=-0,66,-0,40\right.$ e $\left.-0,62\right)$, respectivamente, indicando que na obtenção das peças serradas, pode-se predizer a resistência mecânica em compressão e aos cisalhamentos. Além destas características, destaca-se a boa correlação genética da FV2 com o módulo de elasticidade na flexão $\left(r_{g}=-0,71\right)$ e também com a tração $\left(r_{g}=-0,88\right)$. Apresentou uma média correlação genética negativa entre FV1 com a tração, sendo de $r_{g}=-$ 0,65 . Portanto, deve-se escolher qual a prioridade do melhoramento e para que finalidade destina-se a madeira.

- Para esta espécie, não houveram boas correlações da densidade básica com nenhum ensaio de resistência mecânica. Somente ocorreu uma baixa correlação fenotípica e negativa com a característica tração $\left(r_{f}=-0,40\right)$ e uma baixa e favorável correlação positiva fenotípica com o cisalhamento tangencial $\left(r_{\mathrm{f}}=0,29\right)$.

- Somente houveram baixas correlações fenotípicas da característica compressão $\left(f_{c}\right)$ com as outras características da resistência mecânica, e também somente ocorreu uma média correlação genética positiva $\left(r_{g}=0,64\right)$ com a característica tração $\left(\mathfrak{f}_{\mathrm{t}}\right)$, sendo favorável esta correlação em relação ao uso do material para estruturas. Obteve-se uma boa correlação genética negativa $\left(r_{g}=-0,89\right)$ e baixa correlação fenotípica negativa $\left(r_{f}=-0,36\right)$ entre o cisalhamento tangencial $\left(\mathrm{f}_{\mathrm{st}}\right)$ com a tração $\left(\mathrm{f}_{\mathrm{t}}\right)$, indicando que ao selecionar os materiais que possuam valores maiores de cisalhamento, tem-se um material com valores menores de tração, onde conclui-se que nem sempre o 
melhoramento de uma característica de resistência mecânica ensaiada em laboratório, conduz ao melhoramento de outras características ligadas também a resistência da madeira.

\subsection{Conclusões}

- Diversas são as correlações genéticas e fenotípicas existentes entre as características avaliadas das espécies estudadas, não permitindo a seleção de clones baseados em todas as propriedades simultaneamente. $\dot{E}$ necessário portanto, estabelecer as prioridades para uma evolução mais eficiente em programas de melhoramento genético.

- As duas espécies mostraram-se discrepantes tanto em relação as correlações lineares como também nas correlações genéticas e fenotípicas, provando que não se pode extrapolar os resultados obtidos para uma espécie, para outras do mesmo gênero.

- Dentre as correlações estudadas, as correlações lineares, genéticas e fenotipicas entre a RT com a RPD foram geralmente baixas, confirmando resultados obtidos de outros pesquisadores. As toras que apresentam baixos niveis de rachaduras de topo, não necessariamente produzem peças serradas com baixos níveis de rachaduras nas extremidades das tábuas. Somente para a correlação genética e fenotípica do $E$. grandis contradiz estes resultados, onde a correlação entre a RT com a RPD resultou em um coeficiente de correlação genético e fenotípico de $r_{g}=0,56$ e $r_{f}=0,55$, respectivamente.

- A conicidade apresentou uma alta correlação negativa genética com a flecha da costaneira 1 (FC1) para ambas as espécies, indicando que, com a diminuição da conicidade, aumentar-se-á a flecha da costaneira que é um 
indicador das tensões de crescimento. Com este resultado, precisa-se tomar cuidado para a seleção de árvores menos cônicas.

- As correlações mais interessantes foram aquelas observadas entre as propriedades de resistência da madeira com as características do processamento mecânico de desdobro em serraria, pois, através de dados práticos observados com as técnicas de desdobro de toras, pode-se prever qual será a manifestação do material e para que finalidade destina-se a madeira.

- A tração $\left(f_{t}\right)$ para o $E$. grandis, apresentou correlações lineares com a maioria das outras características ensaiadas, sendo portanto, uma variável boa para predizer o comportamento tecnológico do material estudado. Para o E. urophylla, não foram observadas estas correlações lineares.

- Observou-se uma correlação genética discrepante entre as espécies para o RMS com a flecha da costaneira 1 (FC1). Para o E. urophylla, através da seleção de uma material que possua menores valores de flecha, obter-se-á um material com maior rendimento em madeira serrada. Por sua vez, para o E. grandis, a correlação entre a FC1 com o RMS foi positiva, indicando que, quanto maior for os valores de flecha (FC1), maiores serão o rendimentos em madeira serrada, onde deve ser devido a liberação imediata através do primeiro corte das tensões residuais, evitando o surgimento de rachaduras indesejáveis, gerando maiores rendimentos.

- Pelos resultados obtidos para a variável rachadura de tora (RT), pode-se considerar como sendo boa para a condução do melhoramento genético das espécie E. grandis e E. urophylla, mas existe exceções, pois o $E$. urophylla não apresentou bons resultados nas correlações genéticas e nem fenotípicas para as várias características estudadas, sendo estas muitos baixas ou inexistentes. 


\section{CONCLUSÕES GERAIS}

- Para ambas as espécies, pode-se observar clones que apresentam ótimas características tecnológicas, porém, alguns não se destacaram em nenhum dos ensaios. Assim, nenhum dos clones em relação as características avaliadas, apresentaram ao mesmo tempo, elevado número de caracteres desejados para o uso em serrarias.

- Diversas foram as correlações observadas entre as características avaliadas para ambas as espécies, corroborando com diversos autores que afirmam ser muito trabalhosa a seleção de clones baseados em todas as propriedades simultaneamente, sendo necessário o estabelecimento de prioridades para uma evolução mais eficiente nos programas de melhoramento genético .

- A maioria das características estudadas mostraram-se altamente herdáveis, exceto a conicidade, proporcionando em alguns casos, como para a RPD (rachadura de prancha diametral) do E. grandis, ganhos na ordem de $40 \%$, em uma intensidade de seleção de 1:5 (22.22\%).

- Apesar do E. urophylla apresentar-se menos cônico, o seu rendimento em madeira serrada foi inferior em relação ao $E$. grandis, onde conclui-se que nem sempre o material menos cônico proporciona bons rendimentos e produz menor valor de flecha da costaneira no momento do desdobro.

- Algumas correlações negativas indesejáveis devem forçar a procura de indivíduos discrepantes para não prejudicar uma variável a partir do melhoramento de outra não ou igualmente importante. 
- Para o E. grandis a variável resistência à tração se correlacionou linearmente com a maioria das outras propriedades mecânicas e com a propriedade física $\mathrm{Db}$, sendo assim, uma variável ideal para predizer o comportamento tecnológico da espécie.

- Os resultados não foram distintos entre as espécies, isto é, nem todas as características que apresentaram boas correlações para o E. grandis, apresentaram para o E. urophylla, indicando uma diferença genética e fenotípica no comportamento das espécies. Estes resultados indicam que não se pode extrapolar as correlações encontradas em uma espécie, para outras do mesmo gênero.

- A RT (rachadura de topo de tora) é uma boa variável para a condução do melhoramento genético para ambas as espécies.

- Nem sempre o melhoramento de uma característica de resistência mecânica ensaiada em laboratório, conduzirá ao melhoramento de outras características também ligadas a resistência da madeira. 


\section{REFERÊNCIAS BIBLIOGRÁFICAS}

ALBINO, J. C. Características de crescimento e variação da densidade básica da madeira em 12 espécies de Eucalyptus em três regiões do estado de Minas Gerais. Piracicaba, 1983. 90p. Dissertação (Mestrado) - Escola Superior de Agricultura "Luiz de Queiroz", Universidade de São Paulo.

ALBINO, J. C.; TOMAZELLO FILHO, M. Variação da densidade básica da madeira e produtividade de Eucalyptus spp. Boletim de Pesquisa EMBRAPA/CPAC, n. 26, p.1-43, dez, 1985.

ASSIS. T. F. Aspectos do Melhoramento de Eucalyptus para a obtenção de produtos sólidos da madeira. In: WORKSHOP: TÉCNICAS DE ABATE, PROCESSAMENTO E UTILIZAÇÃO DA MADEIRA DE EUCALIPTO, Viçosa, 1999. Anais. Viçosa: UFV, DEF, SIF, IEF, 1999. p.61-72.

BALLONI, E. A.; SIMÕES, J. W. O espaçamento de plantio e suas implicações silviculturais. Série Técnica IPEF, v. 1, n. 3, p.1-16, 1980.

BERENGUT, G.; PONCE, R. H.; FREITAS, A. R. Ensaio de desdobro de Eucalyptus saligna Smith. Silvicultura em São Paulo, v. 8, p.81-98, 1973. 
BARRET, R. T.; CARTER, D. T.; SEWARD, B. R. T. Eucalyptus grandis in Rhodesia. Research Bulletin Rhodesia Forestry Commission, v. 6, p.1-87, 1975.

BARRICHELO, L. E. G.; BRITO, J. O. Estudo da variação longitudinal da densidade básica de Eucalyptus spp. Silvicultura, v. 8, n. 28, p.726-731, 1982.

BARRICHELO, L. E. G.; NARIYOSHI, A. H.; BEIG, O.; DINIZ, A. S. Variação das características da madeira de eucalipto para diferentes espécies, idades e locais. In: CONGRESSO ANUAL DE CELULOSE E PAPEL, 17.; São Paulo. Anais. São Paulo: Associação Brasileira de Celulose e Papel. 1984. v. 1, p.385-399.

BORTOLETTO JUNIOR, G. Indicações para a utilização da madeira de 6 espécies/variedades de Pinus na construção civil. São Carlos, 1993. 119p. Dissertação (Mestrado) - Escola de Engenharia de São Carlos, Universidade de São Paulo.

BOYD, J. D. Tree growth stresses. I - Growth stresses evaluation. Australian Journal Science Research, v. 3, p.270-293, 1950a.

BOYD, J. D. Tree growth stresses. II - The development of shakes and other visual failures in timber. Australian Journal of Applied Science, v. 1, p.296-312, 1950b.

BOYD, J. D. Tree growth stresses. III - The origin of growth stresses. Australia Journal of Scientific Research, v. 3, p.294-309, 1950c. 
BOYD, J. D. Compression wood force generation and functional mechanics. New Zealand Journal of Forestry Science, v. 3, n. 2, p.240-258, July 1973.

BOYD, J. D. Basic cause of differentiation of tension wood and compression wood. Australian Forestry Research, n. 7, v. 3, p.121-143, July 1977.

BOYD, J. D. Relation between fibre morphology, growth strain and physical properties of wood. Australia Forest Research, v. 10, n. 4, p.337-360, Dec. 1980.

BRASIL, M. A. M. Variação da densidade básica da madeira de E. propinqua Deane Maiden em função do local e do espaçamento. Piracicaba, 1972. 75p. Dissertação (Mestrado) - Escola Superior de Agricultura "Luiz de Queiroz", Universidade de São Paulo.

BRASIL, M. A. M. Densidade básica e caracteristicas das fibras da madeira de Eucalyptus grandis Hill ex Maiden aos 3 anos de idade. Piracicaba, 1976. 126p. Tese (Doutorado) - Escola Superior de Agricultura "Luiz de Queiroz", Universidade de São Paulo.

BRASIL, M. A. M. Variação da densidade básica da madeira entre e dentro de procedências de Eucalyptus urophylla S. T. BLAKE. Botucatu, 1983. 89p. Tese (Livre Docência) - Universidade Estadual Paulista.

BRASIL, M. A. M.; FERREIRA, M. Variação da densidade básica da madeira de E. alba Reinw, E. saligna Smith e Eucalyptus grandis Hill ex Maiden, aos 5 anos de idade, em função do local e do espaçamento. IPEF, v. 2/3, p. $129-149,1971$. 
BRASIL, M. A. M.; VEIGA, R. A. A.; MELLO, H. A. Densidade básica de madeiras de Eucalyptus grandis Hill ex Maiden, aos 3 anos de idade. IPEF, v. 19, p.63-76, dez. 1979.

BREDENKAMP, B. V.; MALAN, F. S.; CONRADIE, W. E. Effects of pruning on growth and timber quality of Eucalyptus grandis in Zululand. African Forestry Journal, n. 114, p.29-34, Sept. 1980.

BROOKER, M. I. H.; KLEINIG, D. A. Field guide to Eucalyptus: Southeastern Australia. Melbourne: Inkata Press, 1983. 288p.

BROTERO, F. A. Métodos de ensaios adotados no I. P. T. para o estudo de madeiras nacionais. Boletim do Instituto de Pesquisas Tecnológicas, v. 31, p.7-28, jun. 1945.

BUSNARDO, C. A.; FOELKEL, C. E. B.; ZVINAKEVICIUS, C.; KAJIYA, S.; ALVES, E. E. Estudos comparativos da qualidade de algumas espécies de eucaliptos tropicais. Cenibra Pesquisa, v. 67, p.1-27, jul. 1978.

CALORI, J. V.; KIKUTI, P. Propriedades físicas e mecânicas da madeira de Eucalyptus dunnii aos 20 anos de idade. In: CONFERÊNCIA IUFRO SOBRE SILVICULTURA E MELHORAMENTO DE EUCALIPTOS, Salvador, 1997. Anais. Colombo: EMBRAPA, CNPF, 1997. v. 3, p.321-326.

CAMARGO, F. R. A.; BARRICHELO, L. E. G.; AMARAL, W. A. N. Caracterização tecnológica da madeira de povoamentos de Eucalyptus grandis Hill ex Maiden. In: CONGRESSO ANUAL DE CELULOSE E PAPEL, 20., São Paulo, Anais. São Paulo: Associação Brasileira de Celulose e Papel, 1987. p.1-15. 
CHAFE, S. C. Growth stress in trees. Australian Forest Research, v. 9 n. 3, p.203-223, 1977.

CHAFE, S. C. Variation in longitudinal growth stress, basic density and modulus of elasticity with height in tree. Australia Forest Research, v. 11, n. 1, p.79-82, 1981.

CHAFE, S. C. Variation in longitudinal growth stress with height in trees of Eucalyptus nitens Maiden. Australian Forestry, v. 15, n. 1, p.51-55, 1985.

CHAFE, S. C. Radial variation of collapse, volumetric shrinkage, moisture content and density in Eucalyptus regnans F. Muell. Wood Science and Technology, v. 20, n. 4, p.253-262, 1986.

CHAHUD, E. Contribuição para o estudo da metodologia para o ensaio de peças de madeira à tração paralela. In: ENCONTRO BRASILEIRO EM MADEIRAS E EM ESTRUTURAS DE MADEIRA, 2. São Carlos, 1986. Anais. São Carlos: LAMEM, 1986a. v. 2, p.91-113.

CHAHUD, E. Contribuição para o estudo do dimensionamento de peças de madeira à tração paralela. In: ENCONTRO BRASILEIRO EM MADEIRAS E EM ESTRUTURAS DE MADEIRA, 2. São Carlos, 1986. Anais. São Carlos: LAMEM, 1986b. v. 3, p.97-110.

CHAHUD, E.; LAHR, F. A. R. O módulo de elasticidade longitudinal da madeira. In: ENCONTRO BRASILEIRO EM MADEIRAS E EM ESTRUTURAS DE MADEIRA, 3. São Carlos, 1986. Anais. São Carlos: LAMEM, 1986. v. 4, p.103-129. 
COUTO, H. T. Z. Manejo de florestas e sua utilização em Serraria. In: SEMINÁRIO INTERNACIONAL DE UTILIZAÇÃO DA MADEIRA DE EUCALIPTO PARA SERRARIA, São Paulo, 1995. Anais. Piracicaba: IPEF, IPT, 1995. p.20-30.

COMBES, J. G.; BOUVET, J. M.; BAILLERES, H. Analyses of growth, morphological and wood properties traits in ortet populations of Eucalyptus in the Congo. In: CONFERÊNCIA IUFRO SOBRE SILVICULTURA E MELHORAMENTO DE EUCALIPTOS, Salvador, 1997. Anais. Colombo: EMBRAPA, CNPF, 1997. v. 3, p.37-42.

CRÊSPO, É. A. Tensão de crescimento e suas conseqüências, controláveis e não controláveis, no desdobro e secagem do Eucalyptus grandis e Eucalyptus saligna. Piracicaba, 2000. 119p. Dissertação (Mestrado) - Escola Superior de Agricultura "Luiz de Queiroz", Universidade de São Paulo.

DARROW, K.; ROEDER, K. R. Provenance trials of Eucalyptus urophylla and Eucalyptus alba in South Africa: seven-year results. South African Forestry Journal, v. 125, p.20-28, June. 1983.

DEL MENEZZI, C. H. S. Utilização de um método combinado de desdobro e secagem para a produção de madeira serrada de Eucalyptus grandis Hill ex Maiden e Eucalyptus cloeziana F. Muell. Piracicaba, 1999. 87p. Dissertação (Mestrado) - Escola Superior de Agricultura "Luiz de Queiroz", Universidade de São Paulo.

DINWOODIE, J. M. Growth stresses in timber. A review of literature. Forestry, v. 39, p. $162-170,1966$. 
DINWOODIE, J. M. Timber - a review of the structure-mechanical property relationship. Journal Microscopy, v. 104, n. 1, p. 3-32, 1975.

ELDRIDGE, K.; DAVIDSON, J.; HARWOOD, C.; VAN WYK, G. Eucalyptus grandis and Eucalyptus saligna. In: ELDRIDGE, K.; DAVIDSON, J.; HARWOOD, C.; VAN WYK G. Eucalypts domestication and breeding Oxford: Clarendon Press, 1994. cap.11, p.103-113.

ESBRISSE, E.; GOMES, F. S.; PIRES, I. E. Estabilidade e adaptabilidade genotípica de progênies de Eucalyptus urophylla S. T. Blake na região do Rio Jari - Pará. In: CONFERÊNCIA IUFRO SOBRE SILVICULTURA E MELHORAMENTO DE EUCALIPTOS, Salvador, 1997. Anais. Colombo: EMBRAPA, CNPF, 1997. v. 1, p.157-168.

FALCONER, D. S. Introdução à genética quantitativa. Viçosa: Imprensa Universitária da Universidade Federal de Viçosa, 1981. 279p.

FERNANDES, P. S. Variação da densidade básica da madeira e suas relações com as tensões de crescimento em progênies de Eucalyptus urophylla S. T. Blake. Piracicaba, 1982. 85p. Dissertação (Mestrado) - Escola Superior de Agricultura "Luiz de Queiroz", Universidade de São Paulo.

FERNANDES, P. S. Densidade da Madeira e suas Relações com as tensões de crescimento. Boletim Técnico do Instituto Florestal, v. 40A, n. 2, p.594-615, dez. 1986a.

FERNANDES, P. S. Tensões de crescimento em Progênies de E. urophylla S. T. Blake. Boletim Técnico do Instituto Florestal, v. 40A, n. 2, p.616-638, dez. 1986b. 
FERNANDES, P. S.; FERREIRA, M. C. Tensões de Crescimento em toras de E. urophylla Smith e suas relações com os diâmetros. Boletim técnico do Instituto Florestal, v. 40A, v. 2, p.639-649, dez. 1986.

FERREIRA, C. A.; FREITAS, M.; FERREIRA, M. Variação da densidade básica da madeira de Eucalyptus spp. em função da idade e qualidade do local. Boletim Informativo IPEF, v. 6, n. 20, p.1-19, 1978.

FERREIRA, M. Estudo da variação da densidade básica da madeira de Eucalyptus alba Reinw e Eucalyptus saligna Smith. Piracicaba, 1968. 71p. Tese (Doutorado) - Escola Superior de Agricultura "Luiz de Queiroz", Universidade de São Paulo.

FERREIRA, M. Tipos de florestas, base genética e populações base em Eucalyptus. In: REUNIÃO TÉCNICA SOBRE POPULAÇÕES BASE EM Eucalyptus, Piracicaba, 1990. Anais. Piracicaba: IPEF, 1990, p.9-16.

FERREIRA, M. Melhoramento e a silvicultura intensiva clonal. IPEF, n. 45, p.22-29, 1992.

FERREIRA, M.; KAGEYAMA, P. Y. Melhoramento genético da densidade da madeira de eucalipto. Silvicultura, v. 2, n. 14, p.148-152, 1978.

FERREIRA, M.; SANTOS P. E. T. Melhoramento genético florestal dos Eucalyptus no Brasil. Breve histórico e perspectiva. In: CONFERÊNCIA IUFRO SOBRE SILVICULTURA E MELHORAMENTO DE EUCALIPTOS, Salvador, 1997. Anais. Colombo: EMBRAPA, CNPF, 1997. v. 1, p.14-34. 
FERREIRINHA, M. P. Propriedade, físicas e mecânicas da madeira de eucaliptos. In: CONFERÊNCIA MUNDIAL DO EUCALIPTO, 2., São Paulo, 1961. Relatórios e Documentos. Säo Paulo: FAO, 1961. v. 2, p.1113-1122.

FOELKEL, C. E. B.; ZVINAKEVICIUS, C.; KATO, J.; BARLEM, N.; TOCHETTO, L. A.; FERREIRA, G. A. Variação acerca da influência do diâmetro das toras de eucalipto sobre alguns dos parâmetros de mensuração de madeira e sobre a qualidade da celulose Kraft. Cenibra Pesquisa, n. 65, p.1-21, maio. 1978.

FONSECA, A. G.; FLOR, H. M.; EUCLYDES, R. F.; BARROS, I. P. Estimativas de herdabilidade e de correlações entre caracteristicas de Eucalyptus grandis W. Hill ex. Maiden. Brasil Florestal, n. 67, p.35-40, 1989.

FREITAS, A. R.; BRITO NETO, O. Os avanços tecnológicos no processamento e uso de produtos florestais: produção de madeira serrada de eucalipto. In: CONGRESSO FLORESTAL PANAMERICANO, 1.; CONGRESSO FLORESTAL BRASILEIRO, 7., Curitiba, 1993. Anais. São Paulo: SBS, SBEF, 1993. v. 3, p.293-295.

GARCIA, J. N. Estados de tensão em árvores e de deformação em peças de madeira serrada. São Paulo, 1992. 243p. Tese (Doutorado) - Escola de Politécnica, Universidade de São Paulo.

GARCIA, J. N. Técnicas de desdobro de eucalipto. In: SEMINÁRIO INTERNACIONAL DE UTILIZAÇÃO DA MADEIRA DE EUCALIPTO PARA SERRARIA, São Paulo, 1995. Anais. Piracicaba: IPEF, IPT, 1995. p.59-67. 
GARCIA, J. N.; LIMA, I. L. Propriedades físicas e mecânicas como indicadores de seleção. In: CONGRESSO FLORESTAL BRASILEIRO, 6.; Campos do Jordão, 1990. Anais. São Paulo: SBS, SBEF, 1990. v. 3, p.685-689.

GOES, E. Os eucaliptos em Portugal: identificação e monografia de 90 espécies. Lisboa: DGSFA. 1960. 300p.

GOLFARI, L.; CASER, R. L. Zoneamento Ecológico da região Nordeste para experimentação florestal . Série Técnica PRODEPEF, n. 10, p.1-116, 1977.

GOLFARI, L.; CASER, R. L.; MOURA, V. P. G. Zoneamento Ecológico esquemático para reflorestamento no Brasil. Série Técnica PRODEPEF, n. 11, p.1-66, 1978.

GOUVÊA, C. F.; MORI, E. S.; BRASIL, M. A. M.; VALLE, C. F.; BONINE, C. A. V. Seleção fenotípica por padrão de proporção de casca rugosa persistente em árvores de Eucalyptus urophylla S. T. Blake, visando formação de população base de melhoramento genético: qualidade da madeira. In: CONFERÊNCIA IUFRO SOBRE SILVICULTURA E MELHORAMENTO DE EUCALIPTOS, Salvador, 1997. Anais. Colombo: EMBRAPA, CNPF, 1997. v. 1, p.355-360.

GROSSER, D. Defeitos da madeira. Série Técnica FUPEF, v. 2, p.1-62, mar. 1980.

GURGEL FILHO, O. A.; GURGEL, L. M. B. Manejo de Pinus elliottii Eng. var elliottii sob o "CCT Method". Silvicultura em São Paulo, v.7, p.87-94, 1970. 
HELLMEISTER, J. C. Sobre a determinação das características físicas da madeira. São Carlos, 1973. 161p. Tese (Doutorado) - Escola de Engenharia de São Carlos, Universidade de São Paulo.

HILLIS, W. E. Wood quality and utilization. In: HILLIS, W. E.; BROWN, A. G. Eucalypts for wood production. Melbourne: CSIRO, Division of Forest Research, 1984. cap.12, p.259-269.

HILLIS, W. E.; HARDIE, A. D. K; ILIC, Y. The occurrence of brittle heart in Eucalyptus grandis grown in Zambia. In: INTERNATIONAL UNION OF FORESTRY RESEARCH ORGANIZATIONS, 5., Pretoria, 1973. Proceedings, Pretoria: IUFRO, 1973. v. 3, p.486-493.

HOCHHEIM, N.; MARTIN, P. Influência da qualidade das toras no processo de fabricação. Rendimento, custo e rentabilidade da madeira serrada. In: CONGRESSO FLORESTAL PANAMERICANO, 1.; CONGRESSO FLORESTAL BRASILEIRO, 7., Curitiba, 1993. Anais. São Paulo: SBS, SBEF, 1993. v. 2, p.644-649.

JACOBS, M. R. The fibre tension of wood stems, with special reference to the genus Eucalyptus. Bulletin Commonwealthy Forestry Bureau, v. 22, p.7-37, 1938.

JARA, E. R. P.; MIRANDA, M. J.; HUMPHERYS, R. D. Influência do tratamento térmico na redução das tensões internas de crescimento em toras de Eucalyptus grandis. In: CONFERÊNCIA IUFRO SOBRE SILVICULTURA E MELHORAMENTO DE EUCALIPTOS, Salvador, 1997. Anais. Colombo: EMBRAPA, CNPF, 1997. v. 3, p.276-281. 
KALIL, E. B. Repetibilidade e hereditabilidade: Um exemplo de aplicação. Boletim de Zootecnia, n. 3 p.11-17, 1963.

KUBLER, H. Studies on growth stresses in trees - Part 1: The origin of growth stresses and the stresses in transverse direction. Melbourne: Commonwealth Scientific and Industrial Research Organization, 1959, 26p.

LAHR, F. A. R. Considerações a respeito da variabilidade de propriedades de resistência e de elasticidade da madeira. São Carlos, 1990. 161p. Tese (Livre Docência) - Escola de Engenharia de São Carlos, Universidade de São Paulo.

LAHR, F. A . R.; MASCIA, N. T. Metodologia do ensaio de madeira à flexão estática. In: ENCONTRO BRASILEIRO EM MADEIRAS E EM ESTRUTURAS DE MADEIRA, 2., São Carlos, 1986. Anais. São Carlos: LAMEM, 1986. v. 2, p.114-132.

LELLES, J. G.; SILVA, J. C. E. Problemas e soluções sobre rachaduras de topo de madeira de Eucalyptus spp. nas fases de desdobro e secagem. Informe Agropecuário, v.18, n. 186, p.62-69, 1997.

LHUELE, E. P.; WAUGH, G. Productivity of sawmills utilizing small diameter eucalypts. Melbourne: CSIRO/DBR, 1980. 17p.

LIMA, E. S. Novos rumos e desafios da indústria moveleira. In: SEMINÁRIO INTERNACIONAL DE PRODUTOS SÓLIDOS DE MADEIRA DE ALTA TECNOLOGIA, 1.; ENCONTRO SOBRE TECNOLOGIAS APROPRIADAS DE DESDOBRO, SECAGEM E UTILIZAÇÃO DA MADEIRA DE EUCALIPTO. Belo Horizonte, 1998. Anais. Belo Horizonte: SIF, UFV, p.65-68. 
LIMA, I. L. Variação de propriedades indicativas da tensão de crescimento em função da posição na árvore e da intensidade de desbaste. Piracicaba, 2000. 90p. Dissertação (Mestrado) - Escola Superior de Agricultura "Luiz de Queiroz", Universidade de São Paulo.

LIMA NETO, F. P. Efeito de uma geração adicional de recombinação sobre a resposta à seleção recorrente em milho (Zea mays L.). Piracicaba, 1998. 150p. Tese (Doutorado) - Escola Superior de Agricultura "Luiz de Queiroz", Universidade de São Paulo.

LOPES, G. A. Qualidade da madeira de E. saligna Smith, de Itatinga, associada aos padrões de casca apresentados pela população. Piracicaba, 2000. 74p. Dissertação (Mestrado) - Escola Superior de Agricultura "Luiz de Queiroz", Universidade de São Paulo.

LÓPEZ, C. B. Perspectiva de utilización de la madeira de eucalipto Eucalyptus globulus en carpintaría y mobiliário, técnicas de aserrado de la madera. In: SEMINÁRIO INTERNACIONAL DE PRODUTOS SÓLIDOS DE MADEIRA DE ALTA TECNOLOGIA, 1.; ENCONTRO SOBRE TECNOLOGIAS APROPRIADAS DE DESDOBRO, SECAGEM E UTILIZAÇÃO DA MADEIRA DE EUCALIPTO, Belo Horizonte, 1998. Anais. Belo Horizonte: SIF, UFV, 1998. p.186-190.

LÓPEZ, C. R.; FORNÉS, L. F. Estabilidade genética em progênies de Eucalyptus grandis (Hill) ex Maiden. In: CONFERÊNCIA IUFRO SOBRE SILVICULTURA E MELHORAMENTO DE EUCALIPTOS, Salvador, 1997. Anais. Colombo: EMBRAPA, CNPF, 1997. v. 1, p.163-167.

LÜCKHOFF, H. A. Pruning of Eucalyptus grandis. South African Forestry Journal, n. 8, p.15-23, Nov. 1967. 
LUZ, H. F.; MELZER, J. F.; COUTINHO, C. J.; FERREIRA, M. C. Manejo de florestas de eucalipto para usos múltiplos. In: CONGRESSO FLORESTAL PANAMERICANO, 1; CONGRESSO FLORESTAL BRASILEIRO, 7., Curitiba, 1993. Anais. São Paulo: SBS, SBEF, 1993. v. 3, p.283-290.

MALAN, F. S. The control of end splitting in saw logs: A short literature review. South African Forestry Journal, n. 109, p.14-18, June 1979.

MALAN, F. S. Studies on the phenotypic variation in growth stresses intensity and its association with tree and wood properties of South African grown Eucalyptus grandis. Stellenbosch, 1984. 272p. Thesis (Doctor) - University of Stellenbosch.

MALAN, F. S. Relatoinships between growth stress and some tree characteristics in South African grown Eucalypts hybrids. South African Forestry Journal, n. 144, p.43-46, Mar. 1988a.

MALAN, F. S. Genetic variation in some growth and wood properties among 18 full-sib families of South African grown Eucalyptus grandis: A preliminary investigation. South African Forestry Journal, n. 146, p.38-43, Sept. 1988b.

MALAN, F. S. Wood density variation in four trees of South African grown Eucalyptus grandis (Hill ex Maiden). South African Forestry Journal, n. 144, p.36-42, Mar. $1988 \mathrm{c}$.

MALAN, F. S. The wood properties of South African grown Eucalyptus grandis: some notes on their variation and association. Stellenbosch: DWS, 1990. $18 \mathrm{p}$. 
MALAN, F. S. The wood properties and qualities of three South African-grown eucalypts hybrids. South African Forestry Journal, n. 167, p.35-44, Dec. 1993.

MALAN, F. S. Eucalyptus improvement for lumber production. In: SEMINÁRIO INTERNACIONAL DE UTILIZAÇÃO DA MADEIRA DE EUCALIPTO PARA SERRARIA, São Paulo, 1995. Anais. Piracicaba: IPEF, IPT, 1995. p.1-19.

MALAN, F. S. Properties, processing and utilization of eucalypts. The South African experience. In: SEMINÁRIO INTERNACIONAL DE PRODUTOS SÓLIDOS DE MADEIRA DE ALTA TECNOLOGIA, 1; ENCONTRO SOBRE TECNOLOGIAS APROPRIADAS DE DESDOBRO, SECAGEM E UTILIZAÇÃO DA MADEIRA DE EUCALIPTO, Belo Horizonte, 1998. Anais. Belo Horizonte: SIF, UFV, 1998. p.134-143.

MALAN, F. S. The wood properties and sawn board quality of the Eucalyptus grandis x E. urophylla hybrid. South African Forestry Journal, n. 188, p.29-35, July 2000.

MALAN, F. S.; HOON, M. Effect of initial spacing and thinning on some wood properties of Eucalyptus grandis. South African Forestry Journal, n. 163, p.13-20, Dec. 1992.

MALAN, F. S.; VERRYN, S. D. Effect of genotype-by-environment interaction on the wood properties and qualities of four-year-old E. grandis hybrids. South African Forestry Journal, n. 176, p.47-53, July 1996.

MALAN, F. S.; RETIEF, R. J.; DYER, S. T. Improvement of South African timber resource: Concerns and proposed strategies. South African Forestry Journal, n. 176, p.61-64, July 1996. 
MARQUES, C. G. Aspectos tecnológicos para definição do projeto TECFLOR. In: SEMINÁRIO INTERNACIONAL DE PRODUTOS SÓLIDOS DE MADEIRA DE ALTA TECNOLOGIA, 1.; ENCONTRO SOBRE TECNOLOGIAS APROPRIADAS DE DESDOBRO, SECAGEM E UTILIZAÇÃO DA MADEIRA DE EUCALIPTO. Belo Horizonte, 1998. Anais. Belo Horizonte: SIF, UFV, p. 119-124.

MARSH, E. K.; BURGERS, T. F. The relation between silvicultural treatment and timber quality in Eucalyptus grandis (Hill) Maiden. Forestry in South Africa, n. 8, p.63-74, Nov. 1967.

MARTIN, B.; COSSATER, C. Les Eucalyptus des lles de la sonde. Bois et Forêts des Tropiques, v. 167, p. 3-24, mai/jun. 1976.

MASCIA, N. T. Contribuição para o estudo das relações entre parâmetros de ruptura e de elasticidade na flexão de peças de madeira. In: ENCONTRO BRASILEIRO EM MADEIRAS E EM ESTRUTURAS DE MADEIRA, 2., São Carlos, 1986. Anais. São Carlos: LAMEM, 1986b. v. 1, p.210-223.

MELLO, G. R. Processamento mecânico da madeira. Piracicaba: ESALQ/DS, 1978. 88p.

MENDES, A. P. Resistência da madeira ao cisalhamento. Sắo Carlos, 1984. 122p. Dissertação (Mestrado) - Escola de Engenharia de São Carlos, Universidade de São Paulo. 
MENDES, C. J.; SUITER FILHO, W.; REZENDE, G. C.; MORAES, T. S. A. Variação da densidade básica de madeira em diversas procedências de Eucalyptus grandis Hill ex Maiden. Silvicultura, v. 8, n. 32, p.832-837, set./out. 1983.

MENDES, L. M.; SILVA, J. R. M.; TRUGILHO, P. F.; LIMA, J. T. Técnicas corretas de secagem da madeira do eucalipto ao ar livre. In: CONFERÊNCIA IUFRO SOBRE SILVICULTURA E MELHORAMENTO DE EUCALIPTOS, Salvador, 1997. Anais. Colombo: EMBRAPA, CNPF, 1997. v. 3, p.373-380.

MIGLIORINI, A. J. Variação da densidade básica da madeira de Eucalyptus grandis Hill ex Maiden em função de diferentes níveis de produtividade da floresta. Piracicaba, 1986. 80p. Dissertação (Mestrado) - Escola Superior de Agricultura "Luiz de Queiroz", Universidade de São Paulo.

MIGLIORINI, A. J.; BARRICHELLO, L. E. G.; KAGEYAMA, P. Y.; CAMARGO, F. R. A. Variação da densidade básica da madeira de E. grandis Hill ex Maiden em função dos diferentes níveis da floresta. In: CONGRESSO ANUAL DE CELULOSE E PAPEL, 21., São Paulo, 1988. Anais. São Paulo: Associação Brasileira de Celulose e papel, 1988. p.25-36.

MIRANDA, M. J. A. C. Estudo da influência do espaçamento de plantio de Eucalyptus saligna Smith no rendimento em madeira serrada, nas condições verde e seca. Piracicaba, 1997. 177p. Dissertação (Mestrado) - Escola Superior de Agricultura "Luiz de Queiroz", Universidade de São Paulo. 
MIRANDA, M. J. A. C.; NAHUZ, M. A. R. Estudo da influência do espaçamento de plantio Eucalyptus saligna Smith no rendimento em madeira serrada verde. In: CONFERENCIA IUFRO SOBRE SILVICULTURA E MELHORAMENTO DE EUCALIPTOS, Salvador, 1997. Anais. Colombo: EMBRAPA, CNPF, 1997. v. 3, p.204-208.

MONTAGNA, R. G.; KRONKA, F. J. N.; MAINIERI, C.; DIAS, R. A.; KRONKA, S. A. Estudo do crescimento e a densidade da madeira de Pinus elliottii Englem var elliottii em função do espaçamento. Silvicultura em São Paulo, v. 8, p.33-52, 1973.

MORAES, M. L. T. Variação genética da densidade da madeira em progênies de Eucalyptus grandis e suas relações com as características de crescimento. Piracicaba, 1987. 129p. Dissertação (Mestrado) - Escola Superior de Agricultura "Luiz de Queiroz", Universidade de São Paulo.

MORI, E. S.; KAGEYAMA, P. Y.; FERREIRA, M. Variação genética e interação progênie $x$ locais em Eucalyptus urophylla. IPEF, n. 39, p.53-63, ago. 1988.

MOURA, V. P. G. Provenace variation of Eucalyptus camaldulensis Dehnh in Brasil. Oxford, 1986. 304p. Thesis (Doctor) - Green College Oxford University.

MUNERI, A.; LEGGATE, W.; PALMER, G. Relationship between surface growth strain and some tree, wood and sawn timber characteristics of Eucalyptus cloeziana. South African Forestry Journal, v. 186, p.41-49, Nov. 1999. 
NAHUZ, M. A. R.; FRANCO, N.; FIGUEROA, F. M. Z. Uso estrutural da madeira de eucalipto: a experiência do IPT. In: SEMINÁRIO INTERNACIONAL DE PRODUTOS SÓLIDOS DE MADEIRA DE ALTA TECNOLOGIA, 1.; ENCONTRO SOBRE TECNOLOGIAS APROPRIADAS DE DESDOBRO, SECAGEM E UTILIZAÇÃO DA MADEIRA DE EUCALIPTO. Belo Horizonte, 1998. Anais. Belo Horizonte: SIF, UFV, p.125-133.

NAHUZ, M. A. R.; MIRANDA, M. J. A. C.; FRANCO, N. Inovações na área de utilização da madeira de Eucalipto: A Fabricação de Móveis. In: WORKSHOP: TÉCNICAS DE ABATE, PROCESSAMENTO E UTILIZAÇÃO DA MADEIRA DE EUCALIPTO. Viçosa, 1999. Anais. Viçosa: UFV, DEF, SIF, IEF, 1999. p.28-33.

NASCIMENTO, C. C. Variabilidade da densidade básica e de propriedades mecânicas de madeiras da Amazônia. Piracicaba, 1993. 119p. Dissertação (Mestrado) - Escola Superior de Agricultura "Luiz de Queiroz", Universidade de São Paulo.

NICHOLSON, J. E. Growth stresses differences in Eucalyptus. Forest Science, v. 19, n. 3, p.169-174, Sept. 1973.

NICHOLSON, J. E.; CAMPBELL, G. S.; BLAND, D. L. Association between wood characteristics and growth stress level: a preliminary study. Wood Science, v. 5, n. 2, p.109-112, Oct. 1972.

NICHOLSON, J. E.; HILLIS, W. E.; DIRCHBURNE, N. Some tree growth - wood property relationships of eucalypts. Canadian Journal of Forest Research, v. 5, n. 3, p. $424-432,1975$. 
NIELSEN, I. R. Utilização da madeira comercial do hibrido de Eucalyptus urophylla S. T. Blake $x$ Eucalyptus grandis Hill ex. Maiden na confecção de vigas laminadas coladas. Curitiba, 1998. 109p. Dissertação (Mestrado) Universidade Federal do Paraná.

NOGUEIRA, M. C. J. A. Indicações para o emprego de dezesseis espécies de eucalipto na construção civil. São Carlos, 1991. 116p. Dissertação (Mestrado) - Escola de Engenharia de Sã́o Carlos, Universidade de São Paulo.

NOGUEIRA, M. C. J. A.; LAHR, F. A. R. Parâmetros relacionados com o emprego das madeiras de eucalipto na construção civil. In: CONGRESSO FLORESTAL PANAMERICANO, 1; CONGRESSO FLORESTAL BRASILEIRO, 7., Curitiba, 1993. Anais. São Paulo: SBS, SBEF, 1993. v. 2, p.650-653.

OBINO, C. R. Usos da madeira de eucalipto. In: SIMPÓSIO IPEF, 6., São Pedro, 1996. Anais. Piracicaba: IPEF, 1996. v. 4, p.27-29.

OBINO, C. R.; MENEZES, L. F. Manejo de florestas para serraria nas empresas nacionais: algumas experiências de manejo de eucalipto para serraria. In: SEMINÁRIO INTERNACIONAL DE UTILIZAÇÃO DA MADEIRA DE EUCALIPTO PARA SERRARIA, São Paulo, 1995. Anais. Piracicaba: IPEF, IPT, 1995. p.140-146.

ODA, S.; MENCK, A. L. M.; VENCOVSKY, R. Problemas no melhoramento genético clássico do eucalipto em função da alta intensidade de seleção. IPEF, n. 41/42, p.8-17, 1989. 
OKUYAMA, T. Assessment of growth stresses and peripheral strain in standing trees. In: CONFERENNCIA IUFRO SOBRE SILVICULTURA E MELHORAMENTO DE EUCALIPTOS, Salvador, 1997. Anais. Colombo: EMBRAPA, CNPF, 1997. v. 3, p.1-14.

OLIVEIRA, A. D.; TRUGILHO, P. F.; MENDES, L. M.; SILVA, J. R. M.; LIMA, J. T. Determinação da variação dimensional da madeira em clones de Eucalyptus grandis e Eucalyptus saligna aos 90 meses de idade. In: CONFERENNCIA IUFRO SOBRE SILVICULTURA E MELHORAMENTO DE EUCALIPTOS, Salvador, 1997. Anais. Colombo: EMBRAPA, CNPF, 1997. v. 3, p. $118-124$.

OLIVEIRA, J. T. S. Caracterização da madeira de eucalipto para a construção civil. São Paulo, 1998. 2 v., 429p. Tese (Doutorado) - Escola Politécnica de Engenharia, Universidade de São Paulo.

OLIVEIRA, J. T. S. Problemas e oportunidades com a utilização da madeira de Eucalipto. In: WORKSHOP: TÉCNICAS DE ABATE, PROCESSAMENTO E UTILIZAÇÃO DA MADEIRA DE EUCALIPTO, Viçosa, 1999. Anais. Viçosa: UFV, DEF, SIF, IEF, 1999. p.39-52.

OTTO, R. I. C. A velocidade de ensaio no estudo experimental da madeira. In: ENCONTRO BRASILEIRO EM MADEIRAS E EM ESTRUTURAS DE MADEIRA, 2., São Carlos, 1986. Anais. São Carlos: LAMEM, 1986. v. 2, p.30-74.

PEDERICK, L. A. Variation and inheritance of stem from and bark thickness in young loblolly pine. North Caroline State University, 1970. 44p. (Technology Report). 
PEREIRA, C. Método para contornar o problema de estimativas negativas em componentes de variância. Piracicaba, 1983. 59p. Dissertação (Mestrado) Escola Superior de Agricultura "Luiz de Queiroz", Universidade de São Paulo.

PIRES, L. E.; PAULA, R. C. Estado de arte do melhoramento genético para qualidade da madeira de eucalipto: uma revisão. In: CONFERENNCIA IUFRO SOBRE SILVICULTURA E MELHORAMENTO DE EUCALIPTOS, Salvador, 1997. Anais. Colombo: EMBRAPA, CNPF, 1997. v. 3, p.1286-191.

PONCE, R. H. Novas tecnologias de desdobro e beneficiamento de madeira: a busca da competitividade. In: CONGRESSO FLORESTAL PANAMERICANO, 1.; CONGRESSO FLORESTAL BRASILEIRO, 7., Curitiba, 1993. Anais. São Paulo: SBS, SBEF, 1993. v. 3, p.310-314.

PONCE, R. H. Madeira serrada de eucalipto: desafios e perspectivas. In: SEMINÁRIO INTERNACIONAL DE UTILIZAÇÃO DA MADEIRA DE EUCALIPTO PARA SERRARIA, São Paulo, 1995. Anais. Piracicaba: IPEF, IPT, 1995. p.50-58.

PURNELL, R. C. Variation in wood properties of Eucalyptus nitens in a provenance trial on the eastern Transvaal Highveld in South Africa. South African Forestry Journal, n. 144, p.10-22, Mar. 1988.

RESENDE, M. D. V.; VENCOVSKY, R. Condução e utilização de bancos de conservação genética de espécies de eucalipto. In: CONGRESSO FLORESTAL BRASILEIRO, 6., Campos do Jordão, 1990. Anais. São Paulo: SBS, SBEF, 1990. v. 3, p.434-439. 
REZENDE, M. A.; SAGLIETTI, J. R. C.; CHAVES, R. Variação da massa especifica da madeira de Eucalyptus grandis aos 8 anos de idade em função de diferentes niveis de produtividade. Scientia Forestalis, v. 53, p.71-78, jun. 1998.

ROCKWOOD, D. L.; DINUS, R. J.; KRAMER, J. M.; Mc DONOUGH, T. S. Genetic variation in wood, pulping and paper properties of Eucalyptus amplifolia and $E$. grandis in Florida. In: EUCALYPT PLANTATION: IMPROVING FIBRE AND YIELD AND QUALITY, Hobart, 1995. Proceedings. Sandy Bay: CRCTHF, IUFRO, 1995. v. 1, p.53-59.

SALES, A. Característica de resistência mecânica de espécies de eucalipto do Estado de São Paulo. São Carlos, 1991. 204p. Dissertação (Mestrado) Escola de Engenharia de São Carlos, Universidade de São Paulo.

SALES, A. Proposição de classes de resistência para madeira. São Paulo. 1996. 223p. Tese (Doutorado), Escola Politécnica de Engenharia, Universidade de São Paulo.

SANCHES ACOSTA, M. Experiência argentina en el uso de la madera de eucalipto. In: SEMINÁRIO INTERNACIONAL DE UTILIZAÇÃO DA MADEIRA DE EUCALIPTO PARA SERRARIA, São Paulo, 1995. Anais. Piracicaba: IPEF, IPT, 1995. p.74-91.

SANCHES ACOSTA, M. Estado de la tecnologia en usos no tradicionales de la madeira de eucalipto en el mercosur y otros paises. In: SEMINÁRIO INTERNACIONAL DE PRODUTOS SÓLIDOS DE MADEIRA DE ALTA TECNOLOGIA, 1.; ENCONTRO SOBRE TECNOLOGIAS APROPRIADAS DE DESDOBRO, SECAGEM E UTILIZAÇÃO DA MADEIRA DE EUCALIPTO. Belo Horizonte, 1998. Anais. Belo Horizonte: SIF, UFV, p.82-105. 
SANTOS, F. L. C. Perspectivas do mercado nacional de madeiras serradas oriundas de florestas plantadas. In: SIMPÓSIO IPEF, 6., São Pedro, 1996. Anais. Piracicaba: IPEF, 1996. v. 4, p.31-52.

SCHACHT, L. Variação de caracteres e suas implicações para o melhoramento genético da madeira serrada em Eucalyptus urophylla. Piracicaba, 1998. 61p. Dissertação (Mestrado) - Escola Superior de Agricultura "Luiz de Queiroz", Universidade de São Paulo.

SCHACHT, L; GARCIA, J. N. Variação genética de indicadores de tensões de crescimento em clones de Eucalyptus urophylla. In: CONFERÉNCIA IUFRO SOBRE SILVICULTURA E MELHORAMENTO DE EUCALIPTOS, Salvador, 1997. Anais. Colombo: EMBRAPA, CNPF, 1997. v. 3, p.405-410.

SCHACHT, L.; GARCIA, J. N.; VENCOVSKY, R. Variação genética de indicadores de tensão de crescimento em clones de Eucalyptus urophylla. Scientia Forestalis, n. 54, p.55-68, dez. 1998.

SCHÖNAU, A. P. G. The effect of planting espacement and pruning on growth, yield and timber density of Eucalyptus grandis. South African Forestry Journal, v. 88, p.16-23, Mar. 1974.

SENAI/CETEMO. A madeira do eucalipto na indústria moveleira. In: SEMINÁRIO INTERNACIONAL DE PRODUTOS SÓLIDOS DE MADEIRA DE ALTA TECNOLOGIA, 1.; ENCONTRO SOBRE TECNOLOGIAS APROPRIADAS DE DESDOBRO, SECAGEM E UTILIZAÇÃO DA MADEIRA DE EUCALIPTO. Belo Horizonte, 1998. Anais. Belo Horizonte: SIF, UFV, p.191-195. 
SHIELD, E. D. Plantation grown eucalypts : utilisation for lumber and rotary veneers - primary conversion. In: SEMINÁRIO INTERNACIONAL DE UTILIZAÇÃO DA MADEIRA DE EUCALIPTO PARA SERRARIA, São Paulo, 1995. Anais. Piracicaba: IPEF, IPT, 1995. p.133-139.

SHIMOYAMA, V. R. S. Variação da densidade básica e características anatômicas e químicas da madeira em Eucalyptus spp. Piracicaba, 1990. 93p. Dissertação (Mestrado) - Escola Superior de Agricultura "Luiz de Queiroz", Universidade de São Paulo.

SHIMOYAMA, V. R. S.; BARRICHELO, L. E. G. Densidade básica da madeira, melhoramento e manejo Florestal. Série Técnica IPEF, v. 6, n. 20, p.1-22, ago. 1989.

SILVA, J. R. M.; MENDES, L. M.; WENZEL, M. K; TRUGILHO, P. F. Secagem ao ar livre da madeira de Eucalyptus grandis para a produção de móveis. CERNE, v. 3, n. 1, p.170-186, 1997.

SIMÕES, J. W.; FERREIRA, M. Resultados do desbaste em 14 espécies de eucalipto para produção de madeira e sementes. In: CONFERÊNCIA IUFRO SOBRE SILVICULTURA E MELHORAMENTO DE EUCALIPTOS, Salvador, 1997. Anais. Colombo: EMBRAPA, CNPF, 1997. v. 3, p.343-348.

SIMULA, M. T.; TISSARI, J. T. Market prospects for eucalypts solid wood products in the european common market. In: SEMINÁRIO INTERNACIONAL DE PRODUTOS SÓlIDOS DE MADEIRA DE ALTA TECNOLOGIA, 1.; ENCONTRO SOBRE TECNOLOGIAS APROPRIADAS DE DESDOBRO, SECAGEM E UTILIZAÇÃO DA MADEIRA DE EUCALIPTO, Belo Horizonte, 1998. Anais. Belo Horizonte: SIF, UFV, 1998. p.29-48. 
SOUZA, A. P.; DELA LUCIA, R. M.; RESENDE, G. C. Estudo de densidade básica da madeira de Eucalyptus microcorys $F$. Muell, cultivado na região de Dionísio, MG. Revista Árvore, v. 3, n. 1, p.16-27, 1979.

SOUZA, V. R.; CARPIM, M. A. BARRICHELO, L. E. G. Densidade básica entre procedências e posições em árvores de E. grandis e E. saligna. IPEF, n. 33, p.65-72, ago. 1986.

STEELE, P. H. Factors determining lumber recovery in sawmilling. Washington: USDA, Forest Service, 1984. 8p. (FPL General Technical Report, 39).

TANAAMI, R. G. Influência da umidade e da densidade da resistência à flexão de peças de madeira. In: ENCONTRO BRASILEIRO EM MADEIRAS E EM ESTRUTURAS DE MADEIRA, 2., São Carlos, 1986. Anais. São Carlos: LAMEM, 1986. v. 1, p.126-152.

TANAAMI, R. G.; LAHR, F. A. R. Variação do módulo da resistência característica da madeira à flexão (MRFk) em função da umidade. In: ENCONTRO BRASILEIRO EM MADEIRAS E EM ESTRUTURAS DE MADEIRA, 3., São Carlos, 1989. Anais. São Carlos: LAMEM, 1989. v. 4, p.239-254.

TAYLOR, F. W. Anatomical wood properties of South African Grown Eucalyptus grandis. South African Forestry Journal, v. 84, p.20-24, Mar. 1973. 
TOMASELLI, I. A indústria de painéis no Brasil e no mundo: Tendências de mudanças do perfil de produção e usos. In: SEMINÁRIO INTERNACIONAL DE PRODUTOS SÓLIDOS DE MADEIRA DE ALTA TECNOLOGIA, 1; ENCONTRO SOBRE TECNOLOGIAS APROPRIADAS DE DESDOBRO, SECAGEM E UTILIZAÇÃO DA MADEIRA DE EUCALIPTO. Belo Horizonte, 1998. Anais. Belo Horizonte: SIF, UFV, p.55-64.

TRUGILHO, P. F.; VITAL, B. R.; Correlação entre algumas características físicas, químicas e anatômicas e a avaliação dimensional da madeira de eucalipto. Revista Árvore, v. 20, n. 4, p.515-533, out./dez. 1996.

TOME, M.; RIBEIRO, F.; SOARES, P.; PEREIRA, H.; MIRANDA, I.; PINA, J. P. Effect of spacing on Eucalyptus globulus fibre yield and quality. In: EUCALYPT PLANTATION: IMPROVING FIBRE AND YIELD AND QUALITY, Hobart, 1995. Proceedings. Sandy Bay: CRCTHF, IUFRO, 1995. v. 1, p.60-63.

TRUGILHO, P. F.; MENDES, L. M.; SILVA, J. R. M.; LIMA, J. T. Influência da idade nas características físicas, químicas e anatômicas da madeira de Eucalyptus grandis. In: CONFERENNCIA IUFRO SOBRE SILVICULTURA E MELHORAMENTO DE EUCALIPTOS, Salvador, 1997. Anais. Colombo: EMBRAPA, CNPF, 1997. v. 3, p.269-275.

TRUGILHO, P. F.; LIMA, J. T.; MENDES, L. M.; SILVA, J. R. M. Variação dimensional acima e abaixo da umidade de saturação das fibras da madeira de eucalipto. In: CONFERÊNCIA IUFRO SOBRE SILVICULTURA E MELHORAMENTO DE EUCALIPTOS, Salvador, 1997. Anais. Colombo: EMBRAPA, CNPF, 1997. v. 3, p.393-400. 
VALE, A. T.; MOURA, V. P. G.; MARTINS, I. S.; REZENDE, D. C. A. Densidade básica média em função da profundidade de penetração do pino "pilodyn" e da classe diamétrica e variação axial da densidade básica em Eucalyptus grandis Hill ex Maiden. Revista Árvore, v. 19, n. 1, p.80-91, jan./mar. 1995.

VAN LAAR, A. The growth of unthemed Pinus patula in relation to spacing South African Forestry Journal, n. 107, p.3-11, Dec. 1978.

VAN WYK, J. L. Hardwood sawmilling can have a bright future in South Africa. South African Forestry Journal, n. 107, p.41-53, Dec. 1978.

VENCOVSKY, R.; BARRIGA, P. Genética biométrica no fitomelhoramento. Ribeirão Preto: Sociedade Brasileira de Genética, 1992. 496 p.

VIANNA NETO, J. A. A. Considerações básicas sobre o desdobro de Pinus spp. Silvicultura, v. 9, n. 34, p.15-19, jan./fev. 1984.

VIEIRA, F. S.; BUCSAN, B. Ocorrências naturais do Eucalyptus urophylla na Indonésia. Silvicultura, n. 14, p. 359- 361, 1980.

VIGNOTE, S.; MOLINERO, I.; GERARD, J.; DIEZ, M. R. Estudio de las tensiones de crecimento del Eucalyptus globulus Labil en Galicia y su relacion com las caracteristicas de la estacion y morfologicas del proprio arbol. Investigacion Agracia Sistemas y Recursos Forestales, v. 5, n. 1, p.153-176, jun. 1996.

VILLELA FIILHO, A. Perspectivas do Mercado Internacional de produtos sólidos de madeira. In: SIMPÓSIO IPEF, 6., São Pedro, 1996. Anais. Piracicaba: IPEF, 1996. v. 4, p.1-26. 
VILLIERS, A. M. Utilization problems with some eucalypts in South Africa. In: IINTENATIONAL UNION OF FORESTRY RESEARCH ORGANIZATIONS, 5., Pretoria, 1973. Proceedings. Pretoria: IUFRO, 1973. v. 2, p.238-255.

VITAL, B. R.; DELLA LUCIA, R. M. Efeito do espaçamento na produção em peso e na qualidade da madeira de Eucalyptus grandis e Eucalyptus urophylla aos 52 meses de idade. Revista Árvore, v. 11, r. 2, p.132-145, 1987.

VITAL, B. R.; PEREIRA, A. R.; DELLA LUCIA, R. M.; ANDRADE, D. C. Efeito da idade da árvore na densidade da madeira de Eucalyptus grandis cultivado na região do cerrado de Minas Gerais. Boletim técnico IBDF, v. 8, p.49-52, ago. 1984.

WADE, M. W.; BULLARD, S. H.; STEELE, P. H.; ARAMAN, P. A. Estimating hardwood sawmill conversion efficiency based on sawing machine and log characteristics. Forestry Products Journal, v. 42, n. 11/12, p.21-26, nov./dez. 1992.

WAGNER, F. G.; TAYLOR, F. W. Impact of log sweep on warp in southern pine structural lumber. Forestry Products Journal, v. 45, n. 2, p.59-62, 1995.

WATAI, L. T. Substituição de espécies de madeiras nativas por madeiras de reflorestamento. In: CONGRESSO FLORESTAL BRASILEIRO, 6., Campos do Jordão, 1990. Anais. São Paulo: SBS, SBEF, 1990. v. 1, p.131-133.

WATANABE, N. A. Study of the origin of longitudinal growth in tree stems. In: IUFRO MEETING OF SECTION 41., Melbourne. 1965. Proceedings. Melbourne: IUFRO, 1965. v. 3, p.45-62. 
WILKINS, A. P. Nature and origin of growth stresses in trees. Australian Forestry, v. 49, n. 1, p.56-62, 1986.

ZANI FILHO, J.; STAPE, J. L.; RIBEIRO, F. A.; BALLONI, E. A.; Programa de melhoramento genético de $E$. urophylla $S$. T. Blake, através de seleção precoce. In: CONGRESSO FLORESTAL BRASILEIRO, 6., Campos do Jordão, 1990. Anais. São Paulo: SBS, SBEF, 1990. v. 3, p.464-471.

ZOBEL, B.; TALBERT, J. Applied forest tree improvement. New York: John Wiley, 1984. 505p.

ZOBEL, B. J.; JETT, J. B. Genetic of wood production. Berlin: Spring - Verlag, 1995. 337p. 